Journal of Agricultural Science in Finland

Maataloustieteellinen Aikakauskirja

Vol. 59: 251-354

\title{
THE RETURNS TO INVESTMENT IN AGRICULTURAL RESEARCH IN FINLAND 1950-1984
}

Selostus: Maataloustutkimuksen tuotto Suomessa 1950-1984

\section{JOHN SUMELIUS}

Agricultural Economics Research Institute,

Luutnantintie 13

SF-00410 HELSINKI, Finland

ACADEMIC DisSERTATION

TO BE PRESENTED, WITH THE PERMISSION OF THE

FACULTY OF AGriculture AND Forestry OF THE

UNIVERSITY OF HELSINKI, FOR PUBLIC CRITICISM

In Auditorium Porthania III, ON December 18, 1987 ,

AT 12 O'CLOCK NOON.

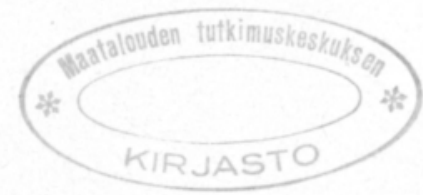





\section{Preface}

The returns to agricultural research have been analysed to a rather limited extent in the Nordic countries. The interest in the research on this subject is, however, increasing. On the initiative of The Scandinavian Association of Agricultural Scientists (NJF) a research symposium was held in the spring 1985 in Sweden where the topic was discussed. The participants from Finland and Sweden decided to start working on this field immediately. Some preliminary results were presented on the XVIII Congress of NJF in the summer 1987. The present study is an outcome of this concrete cooperation between the Nordic countries.

The study was carried out at the Agricultural Economics Research Institute. Without the encouragement, guidance and generous help of Professor LAURI KeTtUNEN, Head of the Marketing Research Department of the Institute, the study would not have reached its present extent. His daily readiness to listen, discuss and suggest methodological solutions to specific problems has been an invaluable help for me.

I also owe a debt of gratitude to my teacher in agricultural economics, Professor KarL Johan WeCKMAn, for his continuous interest and enthusiasm. His support has been important.

Without the facilities, assistance and equipment offered by the AERI, I would not have been able to carry out the investigation. I sincerely wish to thank Professor Matias Torvela, Head of the Institute, for this possibility.

Professor Ulf Renborg, Swedish University of Agricultural Sciences, has been a special source of inspiration. He has made many valuable suggestions on the manuscript.

Professor VILJo RYYNÄNEn has also provided me with useful comments.

Among all the persons offering me moments of fruitful discussion and constructive criticism PaAvo MăKınen, Bureau Chief, National Board of Agriculture, MıKKO RYÖKÄS, M.Sc., and JUKKA Kola, M.Sc., need to be mentioned. I also want to thank the personnel at the AERI, including Seppo Holmström, B.Sc., JAAna AHLSTEDT and ARJA JAUHIAINEN for their assistance.

Special thanks also to RiItTA Kunnas, M.Sc., and MarJatta Lahtinen, Bureau Chief, National Board of Vocational Education, for help with collecting data.

Sevastiana Ruusamo, M.A., has revised the English text for which I am most grateful.

The study was supported by grants from the Finnish Cultural Foundation and the Svenska Vetenskapliga Centralrädet. In addition to these, I want to thank the Scientific Agricultural Society of Finland for including this study in their journal.

Finally, I want to express my thanks to Heidi for her patience during my work.

Helsinki, October 1987 



\section{Contents}

Abstract

2. Methods of Estimating the Economic Returns to Research ............ 263

2.1. Early Attempts to Measure the Returns to Research ................... 263

2.1.1. The Value of Inputs Saved Calculated by Schultz and the Follow-up Study

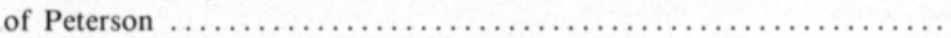

2.1.2. The Estimate of Tweeten and Hines: Contributions of Agricultural Productivity to National Economic Growth .................... 265

2.2. External and Internal Rates of Return, Average and Marginal Rates of Return 265

2.3. Production Function Analysis ............................... 267

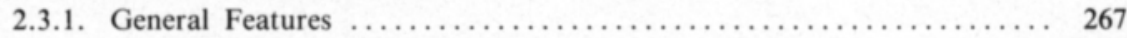

2.3.2. The Aggregated Production Function Study of Griliches .......... 267

2.3.3. The Poultry Study of Peterson ......................... 268

2.3.4. Production Function Studies of Evenson .................... 268

2.3.5. The Studies of Evenson and Kislev ......................... 279

2.3.6. Some Other Production Function Studies ................... 271

2.4. The Welfare Economics Approach ........................... 272

2.4.1. General Features ................................... 272

2.4.2. The Study on Hybrid Maize by Griliches ....................... 273

2.4.3. The Welfare Economics Approach According to Hertford and Schmitz 274

2.4.4. Comments on the Welfare Economics Approach ............... 275

2.4.5. Returns from Rice Breeding in Japan Estimated by Akino and Hayami 277

2.4.6 The Study on Returns to Pasture Improvement Research by Duncan .. 277

2.4.7. Canadian and Spanish Studies of Crop Development Research ....... 277

2.4.8. The Distribution of Economic Benefits from Agricultural Research .... 278

2.5. Criticism of the Examined Studies ............................ 279

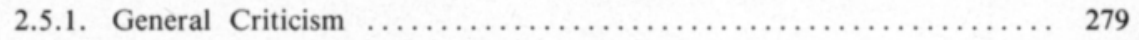

2.5.2. Criticism of the Production Function Approach $\ldots \ldots \ldots \ldots \ldots \ldots .280$

2.5.3. Criticism of the Welfare Economics Approach ................ 281

3. The Returns to Investment in Agricultural Research 1950-1984

- An Aggregated Production Function Study ..........................

3.1. Productivity Increase, Technological Change and Economies of Scale - the Con-

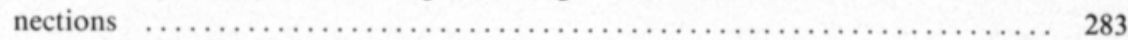

3.1.1. The Concept of Productivity . . . . . . . . . . . . . . . . . . . . 283

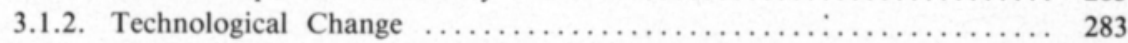

3.1.3. Economies of Scale and Changes in the Prices of Production Factors .. 285

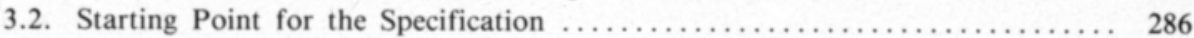

3.3. Specification of the Model ................................ 288

3.3.1. The Form of the Production Function and the Variables ......... 288

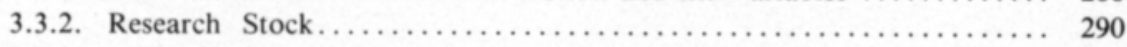

3.3.3. A Productivity Index Specification ....................... 291

3.3.4. Distributed Lags ..................................... 291

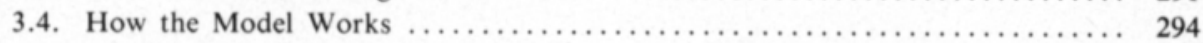

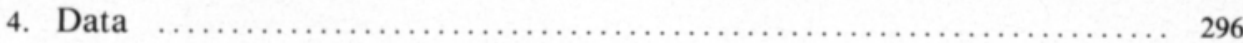

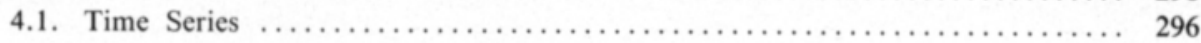




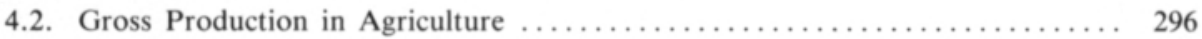

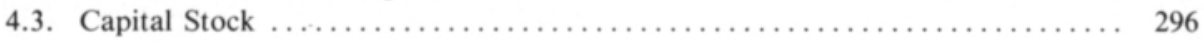

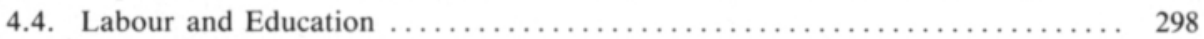

4.5. External Inputs Used in Production ........................... 299

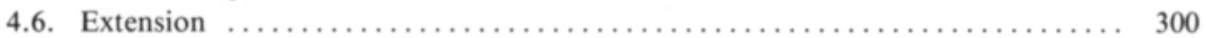

4.7. The Research Input in the Public Sector in 1950-1984 .............. 301

4.7.1. Research at Institutions under the Ministry of Agriculture and Forestry 301

4.7.2. The University of Helsinki and the College of Veterinary Medicine .... 302

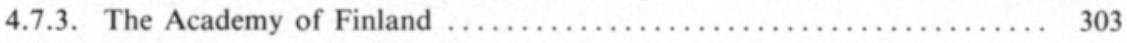

4.7.4. Finnish National Fund for Research and Development and Public Founda-

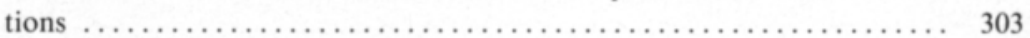

4.7.5. Work Efficiency Association ........................ 304

4.7.6. Agricultural Research Outside the Research Definition ............. 304

4.7.7. The Development of Public Research Input in 1950-1984 ......... 305

4.8. The Research Input in the Private Sector in $1950-1984 \ldots \ldots \ldots \ldots \ldots \ldots . \ldots . \ldots 5$

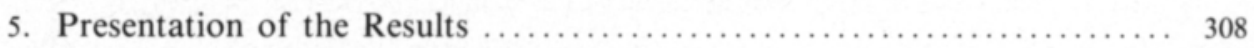

5.1. The Research Input Measured as a Flow ...................... 308

5.1.1. Linear Models without Lags .......................... 309

5.1.2. Cobb-Douglas Models without Lags .................... 313

5.1.3. Multicollinearity and Ridge Analysis .................... 315

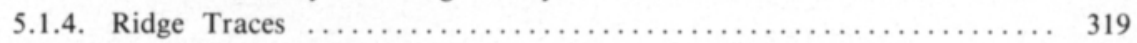

5.1.5. Autocorrelated Errors and Autoregressive Models ................ 319

5.1.6. Cobb-Douglas Models for Shorter Periods ..................... 322

5.2. Cobb-Douglas Flow Models with Lags ........................ 323

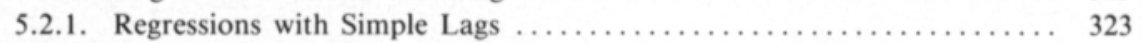

5.2.2. Regressions with Almon Lags ........................ 324

5.3. The Research Input Measured as a Stock ....................... 326

5.3.1. Undepreciated Research Stock ........................... 326

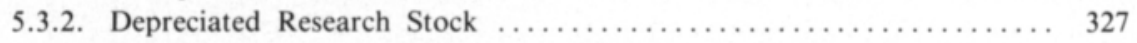

5.3.3. Productivity Index Model ........................... 329

6. The Returns to Agricultural Research and University Education ....... 330

6.1. The Selection of an Elasticity .............................. 330

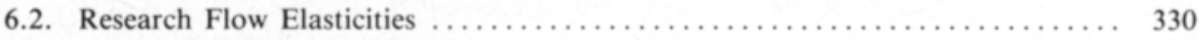

6.3. Research Capital Elasticities ............................... 331

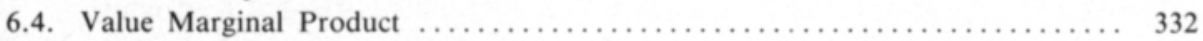

6.5. Marginal Internal Rate of Return ........................... 334

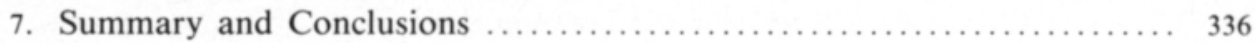

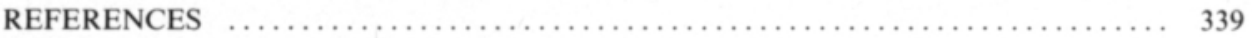

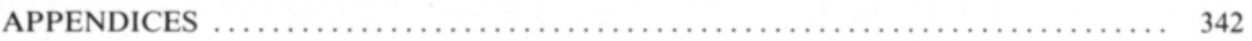




\title{
The Returns to Investment in Agricultural Research in Finland 1950-1984
}

\begin{abstract}
This study attempts to estimate the value marginal product and the marginal internal rate of return for agricultural research in Finland. Based on production function analysis, different Cobb-Douglas and linear models are specified and estimated. A variable for the research input is measured through the flow of public expenditures for research and university-level education in 1950-1984. In addition, a stock of research capital consisting of funds accumulated since 1920 is constructed and included in the models. The estimates of elasticity with respect to public research are used to compute rates of return. State expenditures for extension agencies are also taken into account on the cost side.

It is concluded that the stock of research capital estimates are more believable than the flow estimates, because of difficulties in identifying an appropriate lag. Based on the stock estimates, the value marginal product for public research during the period studied seems to have been 1.83-1.91. The conclusion implies that additional public investment in agricultural research would have annually returned by $183-191 \%$ over the inflation rate. The marginal internal rate of return for public research is calculated to have been $20-62 \%$ depending on the length of the lag (4-10 years).
\end{abstract}




\section{Introduction}

The most important variable explaining differences from one country to another as to agricultural productivity is the ability to create a technology adapted to the particular country's physical, environmental and cultural endowments. Despite the importance of this ability, however, the processes by which this capacity creates and diffuses technical innovations have received relatively little attention until recently. The role of agricultural research was pointed out explicitly only in the $1950 \mathrm{~s}$ and 1960s. Since then, considerable effort has focused on measuring the impact of research on growth in productivity (ARNDT and RUTTAN, 1977).

Estimation of the value of research is a difficult task complicated by great uncertainties. In spite of these difficulties the task seems to be important. Many studies carried out in the USA, Canada, Japan, India, Mexico, Australia, and Brazil have found that the returns to investment in agricultural research and extension in many cases have been very high. The estimated annual rate of return in these countries has varied from approximately 20 to $80 \%$. Both consumers and producers benefit from this social rate of return through lower costs of food and reduced production costs (PINSTRUP-ANDERSEN, 1982).

In the 1950s T.W. Shultz $(1956,1958)$ pointed out how important it would be to calculate the costs and benefits of technical improvements. He contended that technical improvements in agriculture are not manna from heaven, but represent inputs that should be taken into account when explaining an increase in agricultural production or in agricultural productivity. The majority of studies carried out thereafter have had a similar con- clusion: society as a whole, both producers and consumers, benefit from agricultural research.

It is not known whether agricultural research has created a positive economic surplus in the Nordic countries, particularly in Finland. The table in Appendix 1, presenting the estimated annual rate of return from 50 different research programmes, shows a high rate of return in other countries. On average, the annual rate of return was somewhat below $50 \%$ and only four programmes showed an annual rate of return below $20 \%$ (PINSTRUPANDERSEN, 1982). A similar compilation of data from 32 studies on research profitability, put together by EvENSON et al. (1979) in the magazine Science, illustrates approximately the same rates of return. The agricultural research input in Finland needs to be investigated in order to determine whether the high rates of return are also true for a northern environment.

More specifically, empirical estimations of the economic returns to agricultural research (or of its benefits) can be justified as follows:

1. Research is an economic activity, competing for the scarce resources of society, which creates something of value by producing knowledge that can be further refined into an input in the production process. To be able to allocate funds between research and other activities of society decision-makers need some measure for determining optimal allocation (Schultz 1971). If the future value of research to society could be estimated, the extent of public spending on agricultural research could be determined on the basis of its relative benefits (PInSTRUP-ANDERSEN 1982).

2. Research leads to a more effective use 
of resources by providing knowledge to be used instead of more expensive and scarcer resources, e.g. land, water and labour. The constraints on production imposed by the most expensive or least available resource are alleviated through research; the same production volume is achieved with less inputs than previously (HAYAMI and RUTTAN 1971). Quantification of this marginal product of research enables valuation of the gain in efficiency.

3. It is possible to demonstrate that, in the long run increases in productivity are transferred to consumers through lower food prices. Welfare economics also makes it possible to estimate the consumers' surplus and the producers' surplus thereby making it possible to determine which group benefits more. The total economic surplus is principally often sufficient to compensate probable losers, i.e. late adopters of new methods and means of production (HERTFOrd and Schmitz 1977).

4. According to one assertion, landowners obtain a large part of the utility from increased productivity, the input industry another part. Thus Rosine and Helmberger (1975) claim that land rents dramatically increased in USA in 1948-1972 as a result of improved productivity. Technological change led to a drop in the prices of agricultural products, whereas the prices of inputs rose and labour did not benefit from increases in productivity. An important question thus is whether landowners and the input industry share in the benefits from investment in agricultural research and extension, and how big is their share ? This study makes no attempt to answer this question since circumstances differ in Finland from those in the USA.

5. It is difficult to set an exchange value on real or expected research results, yet it must be possible, as such values are set all the time, in the form of decisions concerning the allocation of resources to research. Current price setting is insufficient because it is based on imperfect information. The authorities granting funds for agricultural research need objective evaluation of research (PAULSEN 1971).

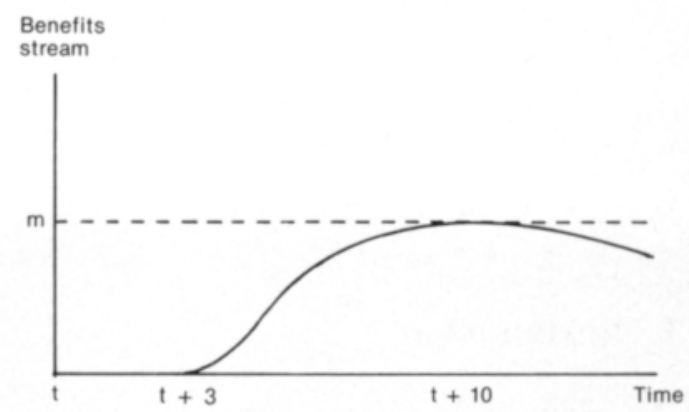

Fig 1. The timing of research benefits (EvENSON 1977).

6. There appears to be a lag between the point in time when research funding takes place and actual results in the form of higher productivity. This lag can be expressed as a function of time, as is illustrated in Figure 1.

Investment in research in the period t starts producing a stream of benefits at $t+3$; this stream increases to $\mathrm{m}$ at $\mathrm{t}+10$, and thereafter decreases. Attempts have been made to estimate such a lag, with various success. Can a lag be found for aggregate agricultural research in Finland?

Whether or not the growth of knowledge is cumulative, a topic that has been discussed in the philosophy of science, becomes relevant in this connection. Those who, like Karl Popper, are apt to look upon science as a steady process of approaching truth in infinity probably contend that research results have an eternal component of value. From this point of view, research results accumulate rather than replace each other. Those who, like Thomas Kuhn, advocate a view that science should be seen as a sequence of paradigms replacing each other probably consider all knowledge to be perishable even with respect to its practical utilization. Even though Kuhn thought of rather long periods, later philosophers of science e.g. Lakatos have used his concept in the context of shorter intervals. In principle this distinction is important, since the decision whether the benefits of research are cumulative (lasting forever) or concern only a few decades might affect the estimated rate of return. Varying opinions about how the benefits of research should be depreciated 
are associated with a more general philosophical discussion.

7. In recent years administrators have become engaged in the evaluation of research. The returns of agricultural research can be understod as one of many criteria by which the quality of research is assessed. Research certainly can be justified on grounds other than purely economic ones (environmental, sociopolitical, or quality aspects). This does not, however, decrease the importance of the social rate of return.

These are some resons for evaluating the returns to investment in agricultural research. It is, however, important to keep some central circumstances in mind.

First: The end results are essentially affected by what is included in the research costs, and what is not. According to Zentner and PETERSON (1984), this question is difficult to answer. Most studies have included costs for extension too; thus investment in research is also covering the public expenditure for extension. In this study, all funds for universitylevel agricultural education have also been included. The estimation is thus a calculation of the profitability of research, where the costs of extension and university education are credited on the cost side, a procedure which may overestimate the cost component.

Second: An important part of all research takes place in the private sector. Farmers, however, pay for this research as its costs are included in the prices of agricultural inputs. For this reason it may be unnecessary to include research done in the private sector; inclusion or exclusion of such research depends on the study methods used for a particular investigation.

Third: It should be kept in mind that research spreads across national borders; the benefits of research are not confined to the country of origin. This is often characterized as a "spillover effect"'. Changing technology is seldom completely specific to the country where the research has been carried out. A central part of research findings is also imported from other countries. It is, however, very difficult to distinguish between the effects of imported research findings and the effects of domestic research on agricultural production. One can only assume that borrowed knowledge plays a greater role in small countries than in large countries. An interesting topic for investigation would be to distinguish imported research from domestic research.

Fourth: How should improved productivity be accounted for when it leads to a national surplus of agricultural products, with little prospects for sales? Is it realistic to assume that all resources find alternative employment at zero cost?

Fifth: Schultz (1956) and Peterson (1971) point out that research contains a stochastic element and can be compared to drilling oil, when most holes turn out to be dry. Perhaps one out of ten holes strikes oil. The value of this tenth hole, however, makes up for the nine earlier trials that were fruitless.

There is a major gap in knowledge about the yield of Finnish agricultural research in relation to its costs. The purpose of this study is to fill that gap by seeking an answer to the following question:

- What has been the value marginal product (marginal rate of return) as well as the marginal internal rate of return for public expenditure on agricultural research and for total public and private expenditures on agricultural research 1950-1984?

The study concentrates mainly on public research, which includes university education, but also takes into account the private research even though farmers pay for the research done in the private sector.

The empirical study is based on production functions where a specific research variable forms the core of analysis. The estimates of regression coefficients are derived through regression analysis. Two different measures are used to approximate the research input. The first is the conventional measure of research flow, comprising the flow of annual funds to research. The second is a stock measure of the accumulated research capital. The stock of research capital has not been widely 
used in earlier empirical analyses of returns to agricultural research.

Theoretical discussion of the methods that can be used to estimate economic benefits, earlier studies and the criticism of these are reviewed in chapter 2 . Furthermore, productivity can increase because of factors other than research. These issues as well as the speci- fication of a model for estimating the returns to research are presented in chapter 3 . The data is explained in chapter 4 , and the results of the estimations are reported in chapter 5 . In chapter 6 a value marginal product and a marginal internal rate of return for the period studied are calculated, whereas conclusions are summarized in chapter 7 . 


\section{Methods of Estimating the Economic Returns to Research}

The methods used for evaluating the returns to research can be divided roughly into two groups. The first approach consists of estimating a production function, in which a variable for research and extension is included. In the next stage the contribution of the research variable to production or to growth in productivity is determined on the basis of the coefficients. Normally the marginal rate of return serves as a measure of profitability. This group of methods is classified here as production function analysis. Sometimes these methods are referred to as the regression analysis approach or sources of growth methods.

The second basic approach makes use of either welfare analysis or cost and benefit analysis. An average rate of return is usually calculated and generally refered to as the internal or social rate of return. These methods are said here to use the welfare economics approach. Sometimes this group is referred to as an index number or consumers' surplus method. Many scholars in the field have used both approaches. Griliches $(1958,1964)$ is mostly cited for his pioneering cost-benefit work on hybrid maize research, but has also made a profound contribution to the production function analysis. Both major approaches are reviewed in sections 2.3. and 2.4.

Before we proceed to scrutinize these methods, a couple of early attempts belonging to neither major approach will be examined. We shall also define some of the central measures used in these types of studies.

\subsection{Early Attempts to Measure the Returns to Research}

\subsubsection{The Value of Inputs Saved Calculated by Schultz and the Follow-up Study of Peterson}

Schultz (1953) uses the value of inputs saved method in the first study to measure quantitatively the returns to investment in agricultural research. Schultz includes all public expenditures for research and extension in his analysis. He examines research at the level of total agricultural production.

Schultz estimates the growth in productivity in American agriculture in the period 19101950. Thereafter he proceeds to calculate the value of inputs saved by the increase in productivity. Growth in productivity is attributed to improved production technology and agricultural research. This value is related to total expenditures for research and extension activities.

Schultz makes a rough calculation of the resources needed to produce the agricultural output of 1950 with the technology of 1910 . The difference in resource inputs is equal to the value of inputs saved.

An upper and a lower limit for this value is set. The upper limit is established by determining a $14 \%$ growth in resources needed using the prices of $1946-1948$ as weights. In 1950 total agricultural production was $75 \%$ higher than in 1910. The output-input ratio had thus grown by $54 \%$. In other words, $54 \%$ more resources would be needed to pro- 
duce the output of 1950 with the technology of 1910 , this $54 \%$ being worth USD 16.2 billion. Correspondingly, a lower limit is set using the prices of $1910-1914$ as weights for the resources needed. With these weights, inputs had grown by $33 \%$ whereas the value of the resources saved to produce the output of 1950 were USD 9.6 billion (the output-input ratio was thus improved by $32 \%$ ). This figure, USD 9.6 billion is consequently the lower limit for resources saved during one single year, 1950.

After these calculations Schultz assumes that the expenditures for research and extension per year during 1910-1950 were as great as in 1950, which in fact is a gross overestimation of the actual research costs. Using Shultz's assumption, total expenditures in 1910 - 1950 would have been USD 7 billion. The total expenditures for a period of 40 years thus were less than the value of inputs saved during one single year, i.e. USD 9.6 billion in 1950. This figure indicates tremendous returns from research.

Schultz however presents a double warning in his argument. First he points out that extension costs may be overestimated since not all of these resources are used to advance agricultural techniques. Second, he points out that the research of the private sector have not been taken into account, and that productivity may rise because of reasons not associated with research (economies of scale, education etc.). On the other hand, the research costs are heavily overestimated and some of the research is necessary to maintain the same level of production as before.

Peterson (1971) used the method of Schultz to follow up the development 19501967. The value of inputs saved in 1950 alone, measured in the price level of 1957-1959, was USD 10.11 billion (USD 9.6 billion in the price level of 1950). Using the same price level the value of inputs saved was USD 26 billion in 1967. Even if one assumes that the research expenditures of the private sector are equal those of the public sector, the sum of total research costs for the period 1910-1967 (USD 18.914 billion dollar) is less than the value of inputs saved only in 1967.

The values calculated by Peterson are shown in Table 1. In the table the expenditures of the public sector have been doubled to take into account the expenditures of the private sector. The figure of $\mathrm{O} / \mathrm{I}$ shows the output-input ratio; the table thus reveals growth of the productivity ratio.

An interesting feature is that the value of inputs saved has risen faster than the expenditures for research and extension. (In 1930, changes in the $\mathrm{O} / \mathrm{I}$ ratio and the value of inputs saved were negative, and therefore were omitted by Peterson). Peterson also calculated a rate of return for the investments in agricultural research; it is described in section 2.2.

Table 1. Value of inputs employed in agriculture, proportionate change in productivity $(\mathrm{O} / \mathrm{I})$ since 1900 , values of inputs saved, and expenditure for agricultural research and extension, in millions of 1957-1959 dollars for selected years (Peterson 1971).

\begin{tabular}{|c|c|c|c|c|c|}
\hline Year & & $\begin{array}{l}\text { Value of } \\
\text { Inputs }\end{array}$ & $\begin{array}{l}\text { Proportionate } \\
\text { Increase in } \\
\text { O/I from } 1900\end{array}$ & $\begin{array}{c}\text { Value of } \\
\text { Inputs Saved }\end{array}$ & $\begin{array}{c}\text { Research and } \\
\text { Extension }\end{array}$ \\
\hline 1930 & USD & 22,380 & -1 & -1 & USD \\
\hline 1940 & & 22,349 & 0.091 & 2,034 & 335 \\
\hline 1950 & & 35,103 & 0.288 & 10,110 & 390 \\
\hline 1960 & & 34,895 & 0.591 & 20,623 & 727 \\
\hline 1967 & & 40,729 & 0.636 & 25,904 & 882 \\
\hline
\end{tabular}

I Changes in the $\mathrm{O} / \mathrm{I}$ ratio and value of inputs saved were negative for 1930 and, thus omitted. 
2.1.2. The Estimate of Tweeten and Hines: Contributions of Agricultural

Productivity to National

Economic Growth

In the mid 1960s, Tweeten and Hines (1965) launched a method for roughly estimating the effects of investment in agricultural research and education. Their method of estimation is based on following reasoning.

The national income in the USA in 1963 was USD 476 billion. Of this $3.7 \%$ originated in the agricultural sector. In 1963, the national income per capita was USD 1,310 in the agricultural sector and USD 2,617 in the rest of the economy. Due to research, extension and vocational training, the need for labour in agricultural production had decreased, and human labour had thus been released from American farms in 1910-1963. This released labour now works in the nonagricultural sector. According to this reasoning the contribution to national income can be calculated on the basis of per capita income differences in the agricultural and the nonagricultural sectors. In $191035 \%$ of the American population lived on farms, after which the figure declined. Tweeten and Hines concluded that had the distribution of agricultural people/ nonagricultural people of 1910 prevailed in 1963 , the national income would have been USD 68 billion, or $14 \%$ lower than the actual national income of USD 476 billion.

The earnings from growth in productivity were USD $1-1.5$ billion a year in the beginning of the $1960 \mathrm{~s}$. Discounted with a $5 \%$ discount rate, this makes for about USD 20 billion. Public investments in agricultural research, education and vocational training, farm programme expenses and various miscellaneous items accounts for a total expenditure of USD 10 billions. This sum thus includes much more than research expenditures. On the basis of these sums, one can easily see that a benefit/cost quota of 2 is obtained. PETERSON (1971) points out that since costs are estimated only for a current year (1963), it is not possible to compute an internal rate of return. A $10 \%$ external rate of return is obtained with a $5 \%$ discount rate.

Peterson (1971) also points out a bias in this technique. The estimated contribution to national income depends on the extent of disequilibrium between per capita income in the agricultural and nonagricultural sectors. The larger this difference is, the greater the contribution to national income will be. But through extension the per capita income will increase in the agricultural sector, thereby decreasing the gap in per capita income, making the contribution lower. There is obviously a paradox in the argument. In addition, the increases in productivity of American agriculture during 1910-1930 were not worth mentioning whereas big increases occured in the late 1950 s and early 1960s. The method of using per capita income as a determinant, however, gives the same contribution to national income for both periods. The method is evidently incomplete.

The method of Tweeten and Hines has not been applied to a large extent, and is mentioned here as a curiosity.

\subsection{External and Internal Rates of Return, Average and Marginal Rates of Return}

By comparing the costs of research with the value of inputs saved, like Shultz did, one can form a rough idea of the relation between inputs and returns. More exact measures are needed to create a more detailed picture of the returns from research. Two such general measures are the external and the internal rate of return, commonly refered to as the social rate of return.

The external rate of return according to GriLiches (1958) is measured as follows: One assumes the development to end at a point in time, cumulating all past expenditures at a reasonable interest, which reflects for instance the opportunity cost in the economy. The cumulated research costs are expressed as a capital sum. The past returns are cumulated to the same point in time, and are also expressed a capital sum. At the same discount rate as 
earlier used, the rate of return on these cumulated returns is projected into the future. The estimated flows of future returns are added to past returns, to arrive at a perpetual flow of returns. This flow, divided by the cumulated research expenditures gives us the external rate of return.

Akino and Hayami (1975) define the external rate of return by the formula (2.1.)

(2.1) $r_{e}=\frac{100(\mathrm{iP}+\mathrm{F})}{\mathrm{C}}$

$r_{e}=$ external rate of return

$\mathrm{P}=$ the value of past returns

$\mathrm{F}=$ the value of future returns

$\mathrm{C}=$ research expenditures

$\mathrm{i}=$ discount rate

The external rate of return is a subjective measure because it depends on the discount rate chosen. The formula (2.1) can be applied to Petersons figures in Table 1; the result is Table 2. The returns extend from 1937 to perpetuity, the calculating point in time being 1967. All research and extension costs for 1910-1967 are accumulated to 1967.

Table 2. Calculation by Peterson (1971) of the external rate of return, USD billions.

1. Cumulated past returns

2. Past returns as an annual flow

1,238

3. Annual future returns

124

4. Total annual return $(2+3)$

5. Cumulated past research expenditures

6. External rate of return $(100 \times 4 / 5)$

An external rate of return of $75 \%$ is obtained. This should be interpreted to mean that the invested research expenditures have returned to society at an annual rate of $10 \%$ until 1967. From now on, each dollar invested in 1910-1967 will yield $75 \%$ annually by saved inputs (PETERSON 1971).

Hayami and RutTan (1971, p. 41) present a formula for converting the external rate of return to a benefit/cost ratio.

Benefit $/$ cost ratio $=\frac{\text { Annual rate of return }}{100 \text { interest rate }}$
The external rate of return can thus be interpreted closely to a benefit/cost ratio (GRILICHES 1958). The external rate of return above of $75 \%$ and a discount rate of $10 \%$ equal a benefit/cost ratio of 0.75 . Critical questions are whether the value of inputs saved are due only to research, and if they can be thought of as extending to perpetuity?

According to Peterson (1971), the internal rate of return can be defined as the rate of interest that makes the accumulated present value of the flow of costs equal to the discounted present value of the flow of returns, at a given point in time. Another formulation of the internal rate of return is the rate of return for which the $\mathrm{B} / \mathrm{C}$ ratio $=1$. The internal rate of return can be calculated from the formula (AKINO and HaYAMI 1975):

(2.2) $\sum_{t=0}^{T} \frac{\left(R_{t}-C_{t}\right)}{\left(1+r_{i}\right)^{t}}=0$

$R_{t}=$ the social benefit (return) in year $t$

$\mathrm{C}_{t}=$ the research cost in year $\mathrm{t}$

$\mathrm{T}=$ the year the research ceases to produce returns

$\mathrm{r}_{\mathrm{i}}=$ the internal rate of return

If we know $R_{t}$ and $C_{1}$, then we are also able to calculate $r_{i}$. For a given interest rate, the discounted flow of returns is equal to the discounted flow of costs. This interest rate $r_{i}$ is to be interpreted to mean that every unit of investment has, on average, returned by $r_{i}$ per cent annually above the rate of inflation from the moment the investment was made (Zentner and Peterson 1984).

It is important to note that the internal rate of return is sensitive to the length of the studied period.

Peterson observed that if the figures in Table 1 are applied to the formula of the internal rate of return, the returns were negative for 1910-1937 and positive for 1937-1967. The average internal rate of return for this period was $19 \%$, clearly less than the $75 \%$ external rate of return. This discrepancy is due to the sensitivity of the rate of return to the length of the period. During 1910-37 costs were also included but no returns were ob- 
tained, obviously because of a long lag between investment and visible results in productivity ratios.

Evenson $(1977$, p.239, 245) calls it a serious matter that some of the estimates of the returns from research have been derived through the use of systematic econometric formulations. He argues that rates of returns must be seen in a systematic context and that overvalued estimates of the returns have often been reported. He claims it is necessary to supplement the calculations of rates of return with other information. Yet the average rate of return, which preceding formulas (2.1) and (2.2) both measure, is meaningful only in a historical sense. The relevant measure to research policy is, in his opinon, not the average but the more conventional marginal prod$u c t$ of research. The marginal product tells us the additional productivity or production gain for one more unit invested in agricultural research. The marginal product is easily converted into a marginal rate of return in production function analysis. The partial regression coefficients give us information about the elasticity of research. According to EvENSON (1977), production function analysis should be less subject to error than the welfare economics approach.

In order to assess the returns from research, a lag structure should be involved in the context of a production function analysis. Research does not yield returns immediately but only after a number of years, when the results are applied to the production process. The length of this lag varies, depending on the type of research. The lag structure has been the object of many estimation procedures (cf. Evenson 1967, and Ravenscraft and SCHERER 1982).

Though it would be interesting to know the average rate of return, Evenson seems to look upon the marginal rate of return as the more appropriate measure for decision-makers. PETERSON and HAYAMI (1977) found in a comparison of studies that the marginal rate of return was higher than the average rate of return. Peterson (1971) found the marginal returns to be $42 \%$ in the previously mentioned study whereas the internal rate of return was $19 \%$.

\subsection{Production Function Analysis}

\subsubsection{General Features}

One of the major approaches in assessing the profitability of research starts from the estimation of a production function. The estimation may focus upon a special product, a group of products or the whole of agriculture. The production function includes variables for research and/or education. The coefficients of the production function can be estimated by regression analysis, normally with ordinary least squares method (OLS). The coefficients for research can be converted to a marginal product and a marginal rate of return for the research input. A marginal internal rate of return can be derived for the coefficients.

\subsubsection{The Aggregated Production Function Study of Griliches}

Zwi Griliches (1964) was one of the first to include a research variable in the production function. In his estimation of an aggregate Cobb-Douglas function for American agriculture, he used one variable for education per worker and one variable for research and extension. In addition to these variables five "traditional" variables were included. The data consisted of three different crosssections of data $(1949,1954,1959)$ from 39 different states in the USA.

In order to allow for some lags in effects, the research variable was defined as an average of the flow of expenditures in the previous year and the level six years before. Thus the average of 1953 and 1958 was used in the cross-section for 1959.

The estimated research elasticity 0.059 may seem small. Keeping in mind, however, that the expenditures for research and extension for the whole period $1949-54-59$ were only 
USD 32 per farm and per year (the variable was defined as research expenditure per farm) while gross output per farm and year was USD 7,205 , the absolute effect becomes considerable. The estimated marginal product for research and extension is then $0.059 \times 7,205 / 32$ or, approximately USD 13 of output for every additional dollar invested in research and extension (equal to a rate of return of about $1300 \%$ per cent per year).

Even accounting for a large share of research in the private sector and for the fact that the marginal product stated above is an overestimation, the result from Griliches' study indicates a very high return from investment in agricultural research. Griliches himself adjusted the calculations so that both research in the private sector and the support to agriculture were considered. The adjusted marginal product then was found to be USD 3 (a rate of return equal to $300 \%$ ).

Peterson (1971) converted Griliches' marginal product of USD 6.50 (assuming that research in the private sector was roughly equal to that in the public sector) to an internal rate of return of $53 \%$. This $53 \%$ was based on the assumption that the returns continue to perpetuity. If all benefits are assumed to return once and for all, the internal rate of return becomes $36 \%$.

GriLiches (1963 a) also made a study in which he tried to break down the technical change into different sources of growth in productivity during 1940-1960. Education accounts for some of the growth in agricultural productivity. Griliches first computed a statistically significant variable for education, concluding that education affects productivity. However, it was found to be easier to adjust the series for labour by an index of education rather than to include a separate variable for education. Later in the same study he constructed such an index of education per man-year in agriculture. This index was computed by weighting years of school, high school and college completed by the rural population by the average income of all American males in respective schoolyear class.
He thereby obtained a rising index, which was multiplied with the labour input series. In this way Griliches was able to reduce the number of variables by one while still taking notice of the effects of education.

\subsubsection{The Poultry Study of Peterson}

In his attempt to estimate the benefits of poultry research carried on by state agricultural experiment stations, the U.S. Department of Agriculture, and suppliers of poultry inputs, Peterson (1967) applied both a production function approach and a welfare economics approach ("index number approach"). With a method similar to the one used by Griliches, Peterson calculated the adjusted marginal product of poultry research to be USD 6 which is equivalent to a $33 \%$ internal rate of return if the time lag is ten years. This internal rate of return was actually a marginal return. Calculated with the welfare economics approach, the average internal rate of return was found to be $18 \%$.

In a later comment PETERSOn (1971) states that a ten year lag is probably too long. If a lag of six years is assumed, the marginal internal rate of return is about $50 \%$, not $33 \%$.

\subsubsection{Production Function Studies of Evenson}

Evenson $(1967,1971,1977)$ has carried out a number of studies using the production function approach. An investigation done together with Kislev summarizes several studies (see section 2.3.5.).

EVENSON (1967) estimated the marginal rate of return to aggregate investment in research on the experiment stations and in the United States Department of Agriculture. The analysis applied cross-sectional data on research expenditures for the different states and timeseries data for total research. The average lag between research expenditures and effect on production was also estimated.

In the most simple econometric models technological change is treated exogenously as 
a shift in the production function. Evenson presumes that the contributions of agricultural research cannot be explained by a small number of important research findings. Instead he thinks of the contributions as small changes in the quality of inputs. In the production function

$$
\begin{aligned}
Y= & f\left(X_{11}, X_{12}, \ldots X_{1 m}, X_{21},\right. \\
& \left.X_{22}, \ldots X_{2 m}, \ldots, X_{n 1}, X_{n 2}, \ldots X_{n m}\right)
\end{aligned}
$$

the subscript $\mathrm{n}$ indicates the type of input and the subscripts $m$ denote various qualities. The variables are usually aggregated using relative price weights. The quality differences are not reflected in this typical aggregation. Evenson therefore found that conventional input measures fail to reflect changes in the quality of inputs. Thus it became important to put forward the hypothesis that a specific "research production function" exists in the form:

$$
\text { (2.4.) } Q=f\left(Z_{i k}, u\right)
$$

where $Z_{i k}$ denotes the research input in the form of scientific skill, supporting staff, and buildings and supplements, whereas $u$ is an error term. The research input can be measured by public expenditures for research.

The quality improvements in year $t$ are defined as $R_{t}$, in the year $t-1$ as $R_{t-1}$, etc. If a lag operator is included, the research production function becomes:

$$
\mathrm{R}_{\mathrm{t}}=\mathrm{W}(\mathrm{L}) \mathrm{Z}_{1}+\mathrm{C}(\mathrm{L}) \mathrm{u}_{1}
$$

where $\mathrm{W}(\mathrm{L})$ indicates a distributed lag function with weights $w_{i}\left(w_{1} Z_{1}+w_{2} Z_{t-1}\right.$, etc. $)$ of research expenditures. $\mathrm{C}(\mathrm{L}) \mathrm{U}_{\mathrm{t}}$ is a distributed lag function of error terms.

With the research production function $R_{t}$, a stock of knowledge $\mathrm{K}$ is defined. The stock of knowledge is filled in with the help of $R_{t}$ at the same time as some of the knowledge depreciates (becomes obsolete).

Evenson attempted, in particular to estimate the mean time lag. In doing so he explores both an exponentially declining and a symmetric or inverted V distribution. The length of lag is estimated by ordinary least squares and the alternative with the highest coefficient of determination $\mathrm{R}^{2}$ is chosen. The data used is from American agriculture. Two different functions are used. The first is an aggregate Cobb- Douglas function including a research variable, and the second is a "residual" function with the ratio of output to input as the dependent variable $\left(\mathrm{Y} / \mathrm{J}=\mathrm{AR}^{\mathrm{d}}\right)$.

His conclusions are:

1. The highest $R^{2}$ is found at six to seven and a half years. The average lag between investment in research and results in production thus seems to be six to seven and a half years. With a $95 \%$ confidence interval, the mean time lag would be three and a half to eleven years.

2. Griliches calculated the marginal product of research and extension to be USD 13 of output produced for each dollar invested in research and extension. Using the same cross- sectional data, Evenson reports to have calculated a similar marginal product of USD 10. Using time-series data, he reports estimates of a marginal product of about USD 40.

3. Cross-sectional data tend to underestimate the research results, as the "spillover" effect (cf. chapter 1) between states is not included in the cross-section. The state of research origin cannot capture all the benefits of research, since some of it passes over to other states. The research carried out in one state thus affects the production function of other states.

A study carried out later (EvEnSON 1971) concerning the organization of agricultural research uses the same theoretical framework. The conclusions of this study support the assumption that economies of scale also applies to research at the experiment stations. It is also commented that a stochastic term could well be included in the research production function $\mathrm{R}_{1}$.

EvENSON (1977) later points out that attempts should be made to distinguish between different types of skills - inventive, technical and engineering, technical-scientific, conceptual-scientific etc. - because their relevance applies to the production function in 
different ways. Correspondingly an attempt could be made to distinguish between different types of research so that several categories could be utilized.

\subsubsection{The Studies Carried out by Evenson and Kislev}

EVENSON and KISLev (1975) summarized their studies on the economics of agricultural research in the book Agricultural Research and Productivity. The perspective is international, and focuses on the diffusion of agricultural innovations to developing countries. Only a few parts of the book will be touched upon here.

A special " knowledge production function" is defined on the basis of scientific publications in agricultural sciences, scientific man-years in agricultural research, expenditures on agricultural research, GNP per capita and the number of newspapers per 10,000 people. Cross-sectional data is used to estimate a Cobb-Douglas knowledge production function. The data is collected from 44 different countries.

Determinants of research investment are estimated in a similar way. The explaining vari- ables used are the value of the product in question out of total output, its share of exports, the proportion of farm labour out of the total labour force, etc.

One chapter deals with research programmes for wheat and maize. The period analyzed is 1948-1968, and the data was collected from 68 different countries. The yields are defined as a function of soil, climate and technology. Technology is determined by the stock of knowledge, which is partly indigenous, partly imported from other countries. Functions for estimating both the regional and the borrowed stocks of knowledge are specified. Figure 2 illustrates the internal relation between the stocks of knowledge.

Two different sets of estimates are calculated, one on the basis of cross-sections and one on the basis of cross-sections and timeseries.

The growth of yields in maize and wheat production are expressed as a function of a knowledge function. The knowledge function is expressed through the sum of counts of articles in "Plant Breeding Abstracs", from 1948 to 1968 . Regressions were used to calculate the marginal rate of return for one publication. Other explaining factors of the yield increa-

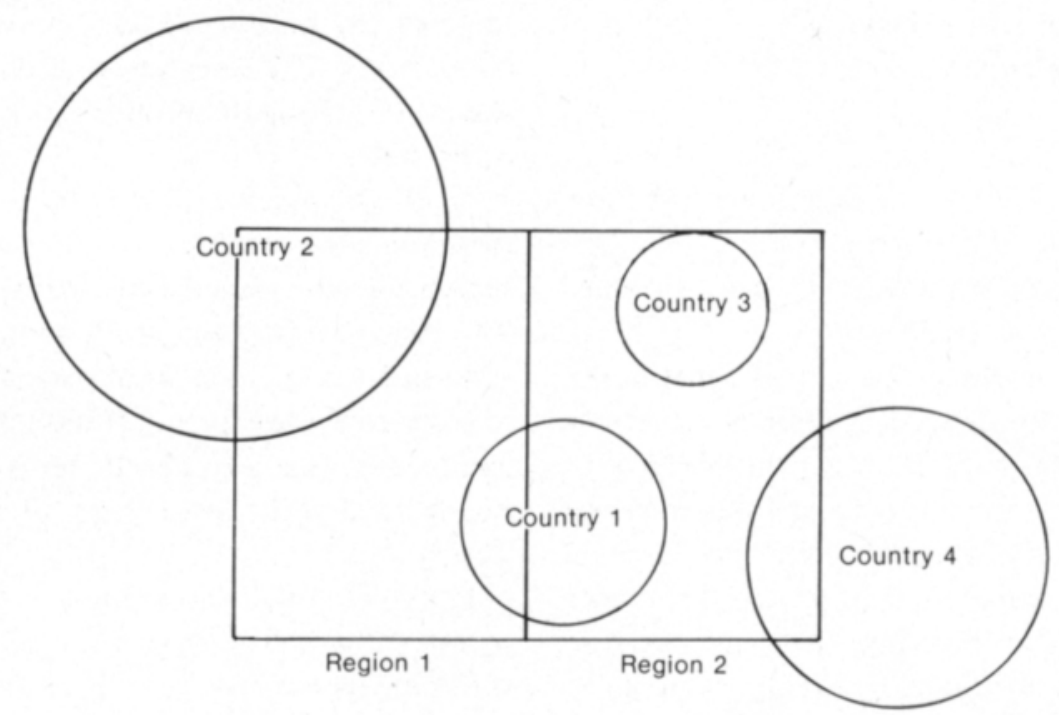

Fig. 2. Stocks of knowledge in regions and countries. Region 2's stock of knowledge is the total stock of country 3 plus parts of the stocks of countries 1 and 4 . Country 1's borrowable knowledge is the total knowledge of country 3 and parts of 2 and 4 (EvENSON and KISLEV 1975). 
ses in 1948-1968 are the rate of change of yield in 1920 - 1939 and a time factor. The marginal rate of return ten years later is USD 30,822 for maize and USD 20,287 for wheat. In the first year the marginal rate of return is USD 2,330 for maize respectively USD 1,581 for wheat.

Besides this direct contribution to productivity by indigenous research, the publication has another indirect value. It consists of accelerating effects of the country's own work on knowledge borrowed from abroad. Still another value is the spillover effect, spreading over the borders of the original country of research.

One chapter examines the aggregate production function for 36 different countries. The production function is specified in order to consider the differences in productivity, partly between countries ("'level”' coefficient) and partly over time (time trend coefficient) as illustrated by Figure 3 .

Four different regressions are calculated, one with both level and time trend differences, two with one difference considered each, and one without either difference. In each case the research variable is positive.

On the basis of these estimations a marginal benefit/cost quota of 2 is obtained. This quota, however, does not take into account that the knowledge becomes obsolete. According to this study, the marginal productivity of research would be considerable.

\subsubsection{Some Other Production Function Studies}

KAHLON et al. (1977) used two different methods in a study of Indian agricultural research. The first method was similar to the one described in section 2.3.1. The second method consisted of estimating the output for two different periods with fixed levels of inputs. The difference in production between these periods was attributed to additional investment in agricultural research.

The returns from research were estimated partly on the state-level, partly on the all-India level. In the analysis the relative share of each factor in the growth of output for the two

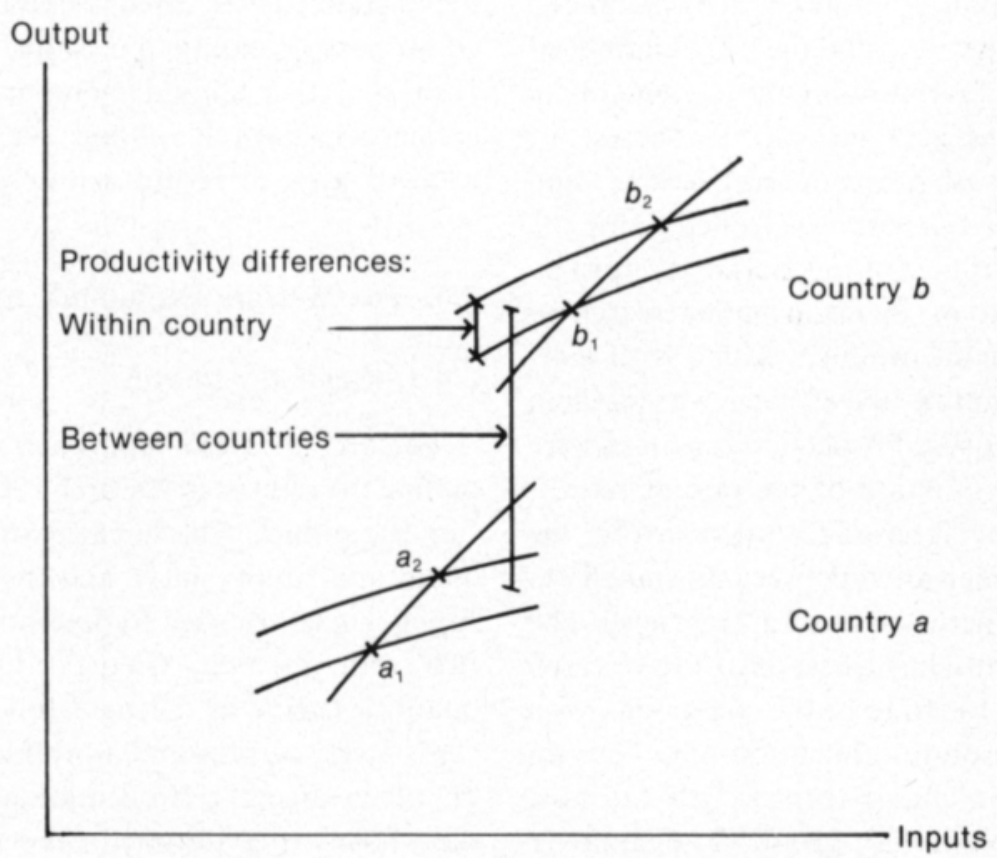

Fig. 3. Country-specific "level" differences and country-specific trend differences (EvEnSON and KISLEV 1975). 
Table 3. Returns to investment in agricultural research in India.

\begin{tabular}{lccc}
\hline Output and Investment & $\begin{array}{c}\text { First Period } \\
(1)\end{array}$ & $\begin{array}{c}\text { Second Period } \\
(2)\end{array}$ & $\begin{array}{c}\text { Difference } \\
(2)-(1)\end{array}$ \\
\hline $\begin{array}{l}\text { Estimated output (million rupees) } \\
\begin{array}{l}\text { Average investment in agricultural } \\
\text { research (thousand rupees) }\end{array}\end{array}$ & $6,592.00$ & $6,945.00$ & 353.00 \\
$\begin{array}{l}\text { Return to 1 rupee invested }=\frac{353.00 \text { million rupees }}{3,040.23 \text { thousand rupees }} \\
\text { R }\end{array}$ & 11.61 rupees. & $6,412.28$ & 3040.23 \\
\hline
\end{tabular}

periods, $1960 / 61-1964 / 65$ and $1967 / 68-$ $1972 / 73$, are calculated. Using dummies, the shares of net sown area, human labour, fertilizers and irrigation in the output growth rate are presented. The production function is of the Cobb-Douglas type.

The returns from research estimated through the different periods are presented in Table 3.

From the table it is possible to see that 1 rupee invested in agricultural research yields 11.61 rupees, with a lag of five years. This is equal to an annual internal rate of return of $63.3 \%$. This estimate is comparable to the estimated internal rate of return to Indian research of $50 \%$ calculated by Evenson and Jha when the lag was assumed to be eight years.

Bredahl and Peterson (1976) estimated the marginal product and the internal rates of return for the four most important commodity groups in American agriculture. These four groups were cash grains, poultry, dairy, and livestock. The purpose was to determine the internal importance of the marginal return by commodity group. By reallocating research inputs in favour of products with a high marginal rate of return, the efficiency of research could be improved. Production functions were used in the estimation of the rate of return.

The marginal internal rate of return for the USA as a whole varied between 36 and $46 \%$. The returns fluctuated more at state level. The commodity with the highest payoff to research was generally found to be the commodity with the largest absolute value of output. Thus on state-level the highest returns were in the most important commodity group. The spillover effect between states, however, was not con- sidered. A final comment is made that the figures should not be read literally. They are inteded to complement rather than to serve as a substitute for common sense and good judgement.

The purpose of a study by KNUTSON and TwEETEN (1979) was to determine an optimal rate of future investment in agricultural research. In doing this, marginal rates of return for earlier decades were calculated first. These were then projected from 1976 to 2015 under various scenarios defining the rate of increase in research expenditures, demand for farm output, and inflation. The results showed that the optimal rate of future investment in agricultural research depends on the growth of demand. For instance, slow growth of demand coupled with rapid increases in research could pose economic hardships for farmers. If on the other hand demand grows fast, incremental research outlays are required to keep the rate of return as low as $10 \%$.

\subsection{The Welfare Economics Approach}

\subsubsection{General Features}

The second major approach used in estimating the returns to research is based on welfare economics. The intersections of the demand and supply curve and the shift of the supply curve are used to determine the benefits from research. Changes in prices and quantities serve as the base for estimating a consumers' surplus and a producers' surplus or, taken together, an economic surplus for the whole society. Sometimes separate benefits and costs have been estimated instead of 
the economic surplus. Normally not the marginal but the average returns to research are estimated. The pioneering study in this field was the study on the returns from hybrid maize research carried out by Zvi Griliches.

\subsubsection{The Study on Hybrid Maize by Griliches}

GrILICHES (1958) estimates the realized social rate of return of private and public funds invested in hybrid corn research. He calculates the loss in surplus to society that would take place if hybrid corn were to disappear. Griliches computes an external rate of return exceeding $700 \%$. The internal rate of return, however, was $35-40 \%$.

Griliches starts from the assumption that the annual gross social returns of research approximately equal the value of an increase in maize production as a result of this research. The additional costs for producing this maize are subtracted from these gross returns, giving an annual flow of net social returns. These are then compared to the costs of research, expressed as a capital sum.

The value of hybrid maize research is illustrated by Figure 4 .

In case a) in the figure the supply of maize is assumed to be infinitely elastic, in case b) as completely inelastic. Both cases represent extremes. Griliches now calculates the loss of benefits, had no hybrid maize been developed, i.e. the shift of both curves from $\mathrm{S}$ to $\mathrm{S}^{\prime}$.

In case a) the benefits of research are equal to the value of lower production costs for the production volume $\mathrm{Q}_{2}$ and the growth of consumers' surplus as a consequence of lower prices. This value is equal to the area of the rectangle $\mathrm{P}_{1} \mathrm{P}_{2} \mathrm{P}_{2}{ }^{\prime} \mathrm{P}_{1}{ }^{\prime}$ and the triangle $\mathrm{P}_{1}{ }^{\prime} \mathrm{P}_{2}{ }^{\prime} \mathrm{P}_{1}{ }^{\prime \prime}$. In this case the total loss to society would be equal to the area $\mathrm{P}_{1} \mathrm{P}_{2} \mathrm{P}_{2}{ }^{\prime} \mathrm{P}_{1}{ }^{\prime \prime}$. This area can be approximated by the formula:

(2.6) $\operatorname{LOSS} 1=\mathrm{kP}_{1} \mathrm{Q}_{1}(1-1 / 2 \mathrm{kn})$

$\mathrm{k}=$ Percentage change in yield

$\mathrm{n}=$ Absolute value of the price-elasticity of demand

$\mathrm{P}_{1}=$ Price

$\mathrm{Q}_{1}=$ Quantity

In case b) the loss to society consists of the loss of the production $\left(\mathrm{P}_{1}{ }^{\prime} \mathrm{P}_{1}{ }^{\prime \prime} \mathrm{Q}_{1} \mathrm{Q}_{2}\right)$ to the old price $\mathrm{P}_{1}$ and the additional loss in consumers' surplus $\left(\mathrm{P}_{1}{ }^{\prime} \mathrm{P}_{2}{ }^{\prime} \mathrm{P}_{1}{ }^{\prime \prime}\right)$ or:

$$
\text { LOSS } 2=k P_{1} Q_{1}(1+1 / 2 k n)
$$

On the basis of (2.6) which gives a lower estimate, Griliches calculates the returns to hybrid maize research using the following figures. Yields have increased by $15 \%$, the price elasticity is $0.5,90 \%$ of all future maize cropping areas are planted with hybrid seed and the value of the average production volume for 1937-1948 was USD 3 billion (in the prices of 1955). According to (2.7) the loss to society had no hybrid seed research taken place would be:

$0.9 \times 15 / 115 \times$ USD 3 billion $(1-1 / 2 \times 0.9$ $\times 15 / 115 \times 0.5)=$ USD 341 million.
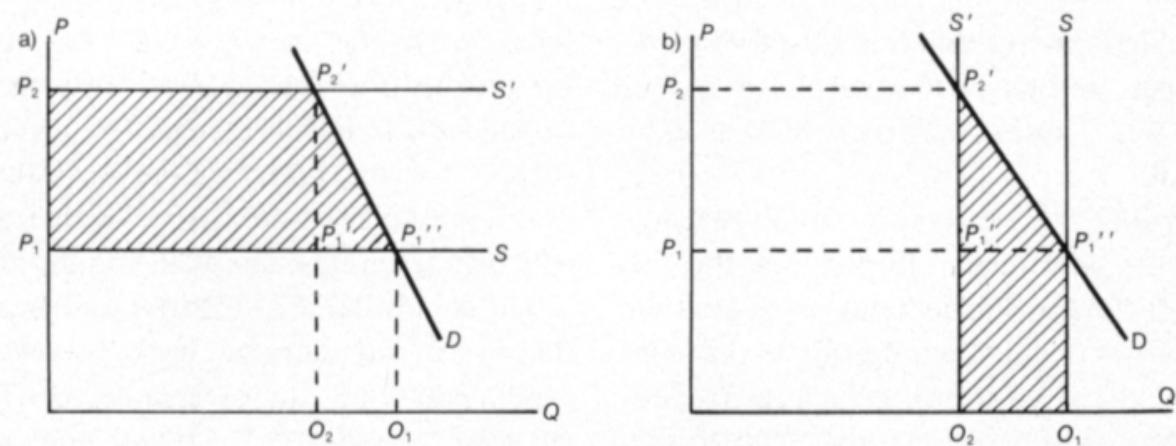

Fig. 4. The effects of a shift in supply caused by increasing productivity (GriLiches 1958). 
Subtracting the annual cost of hybrid seed, production and research, USD 93 million, the net social return becomes USD 248 million.

The study gives an external rate of return of $743 \%$ and an internal rate of return of $35-40 \%$ for hybrid maize research. This is the average (historical) rate of return, not the marginal rate of return.

This study of Griliches has since been criticized on some points. It only takes into account research applying directly to hybrid maize, neglecting all resources devoted to basic research on hybridization. There can be no doubt, however, that genetic research has strongly affected the development of hybrid maize (Peterson and Hayami 1977). As such, research expenditures seem to have been underestimated.

EvEnSON (1977) critcizes Griliches among others, for having estimated extraordinarily high rates of return on the basis of erroneous econometric formulations. He finds this a serious matter. According to EvENSON and KISLEV (1975) Griliches is guilty of a systematic mistake in neglecting quality improvements in labour.

\subsubsection{The Welfare Economics Approach According to Hertford and Schmitz}

Many different variations of the welfare economics approach have been used since the study of Griliches. A general theoretical framework has been outlined by HERTFORD and Sснмітz (1977). The central Marshallian concept of economic surplus is important in this analysis.

The economic surplus consists of consumers' surplus and producers' surplus as earlier pointed out. These concepts are illustrated by Figure 5.

According to HertFord and Schmitz (1977), the consumers' surplus has the following meaning: The demand curve $\mathrm{D}$ in the figure shows the maximum price a consumer would be prepared to pay for successive, additional units of a commodity. Thus to buy one more unit, the consumer is only willing

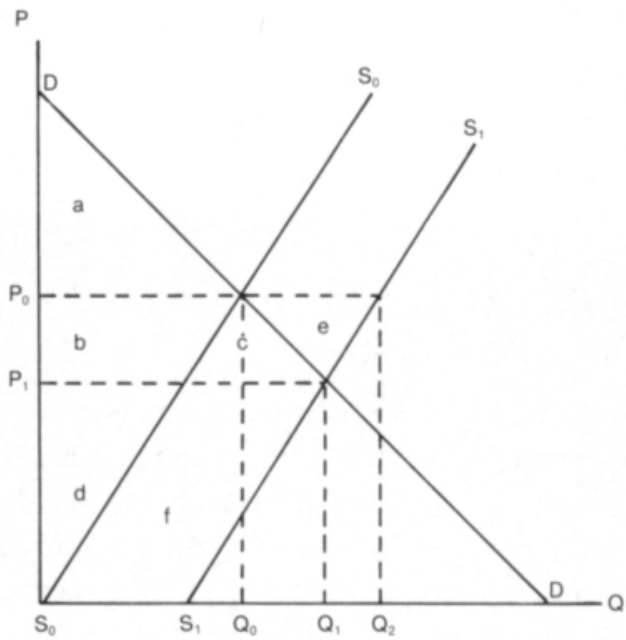

Fig. 5. Combined consumers' and producers' surplus (Hertford and Schmitz 1977).

to pay a lower price. If we assume the falling demand curve to intersect the supply curve at $Q_{1}$, the consumer is only ready to pay $P_{1}$ per unit purchased. Had he bought the units successively, the total costs would be equal to the area left of the demand curve. When buying all units directly on the market instead, he only has to pay $\mathrm{P}_{1}$ for each of the units. His savings are thus equal to $\mathrm{a}+\mathrm{b}+\mathrm{c}$. This area is the consumers' surplus. It can be regarded as a collective surplus for all consumers on the market.

The producers' surplus analogically refers to the difference of what a producer receives for the sale of a good and the smallest price at which he would be prepared to sell the good. In Figure 5 the supply curve $\mathrm{S}_{\mathrm{o}}$ reflects the lowest price the producer is willing to sell for, thus being 0 in origo and $\mathrm{P}_{\mathrm{o}}$ at market balance. On the market he can sell all units for a higher price than successive sales of additional units would bring in. The producers' surplus for the supply curve $\mathrm{S}_{\mathrm{o}}$ is thus the area equal to $b+d$, i.e. the collective surplus of return resulting from selling on the market.

The supply curve of the industry represents the sum of the marginal costs curves of the producers, while the area under the supply curve of the industry is equal to the variable costs of production. If productivity increases 
the supply curve shifts from $S_{0}$ to $S_{1}$, and costs will decrease. If the price stays at the preceeding level $\mathrm{P}_{\mathrm{o}}$, the producer will receive an increase in his surplus equal to $\mathrm{e}+\mathrm{c}+\mathrm{f}$, the total producers' surplus now being $b+d+$ $\mathrm{e}+\mathrm{c}+\mathrm{f}$.

When productivity in agriculture increases due to new research results, the supply curve shifts in Figure 5 from the initial position of $\mathrm{S}_{\mathrm{o}}$ to the new position of $\mathrm{S}_{1}$, and the price falls from $P_{0}$ to $P_{1}$. The increase in consumers' surplus that results from the price fall is then equal to the area $b+c$ in the figure. The increase in producers' surplus due to the sale of a larger quantity is $\mathrm{c}+\mathrm{f}$, and the decrease in producers' surplus due to the price fall is equal to $b+c$, or the net change in producers' surplus will be $\mathrm{c}+\mathrm{f}-\mathrm{b}-\mathrm{c}=\mathrm{f}-\mathrm{b}$. When both surpluses are combined the total economic surplus is $b+c+f-b=c+f$. The latter area can be calculated from the formula (2.8).

$$
k P_{1} Q_{1}\left(1 \frac{1 / 2}{n+e}\right)
$$

where

$\mathrm{k}=$ percentage increase in production due to research

$\mathrm{n}=$ price elasticity of demand

$\mathrm{e}=$ price elasticity of supply

The percentage increase $\mathrm{k}$ can be calculated by dividing the distance between the supply curves with the value of final production $Q_{1}$. In practice the critical determinant of the economic returns from research is the factor $\mathrm{k}$.

Hertford and Schmitz point out that when research leads to the development of new production methods for a certain product, the finding can affect the use of other resources. For instance, producers who lack the possibility to utilize the new production methods may be forced out of business, and other production resources may not find any alternative use. The benefits may be overestimated if this is not taken into account.

An advantage of the welfare economics approach is that it enables classification of who benefits from research, producers or consumers, and how the returns are divided between these groups.
Comments on the welfare economics approach have led to the consideration of more complex issues. Some of these are reviewed in the next section.

\subsubsection{Comments on the Welfare Economics Approach}

Normally the demand and supply curves are not linear as in Figure 5. A more realistic illustration is shown in Figure 6.

The increase in the combined consumers' and producers' surpluses in the figure above is indicated by the area OBA. This area corresponds to the area $\mathrm{c}+\mathrm{f}$ in Figure 6 .

LiNDNER and JARRETT (1978) note the essential difference between the assumption of a parallel, a divergent and a convergent shift in the supply curve. This is shown in Figure 7 , where the demand curve is conveniently assumed to be completely inelastic.

According to Lindner and Jarrett, earlier studies did not distinguish between the types of supply shift. Important comments on the shift of the supply curve have also been made by JARRETT and LindNER (1977), Rose (1980), WISE and FELl (1980) and LiNDNER and JARRETT (1980).

WISE $(1981,1984$ a) outlined a welfare economics analysis of the benefits from research which is not based on the consumers' and producers' surplus concepts, but on costs and

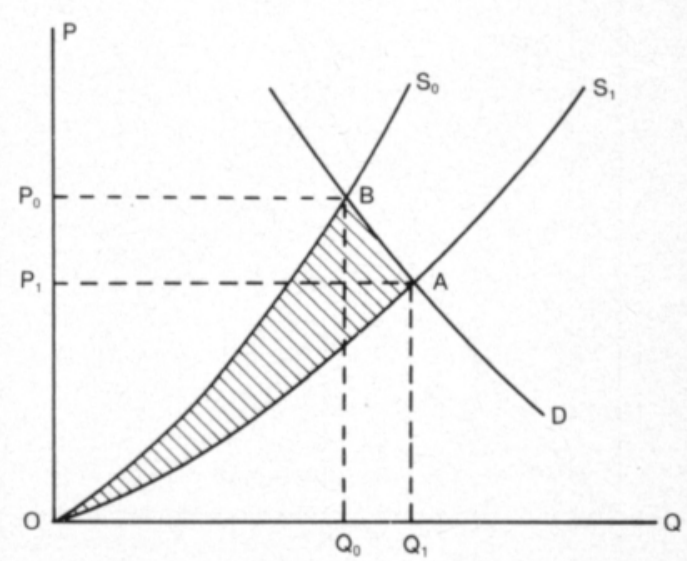

Fig. 6. Effect of a new technology in shifting supply curves (DALRYMPLE 1977). 
(a)

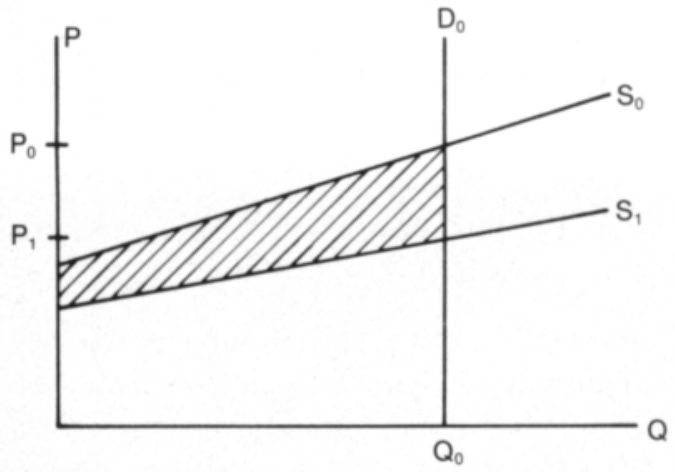

(b)

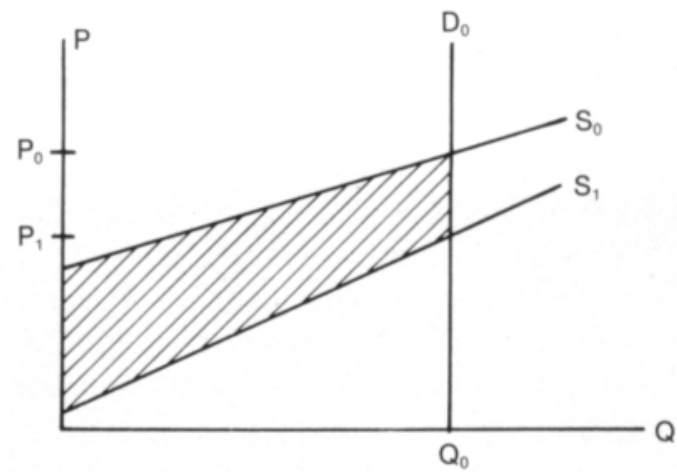

Fig. 7. Divergent (a) and convergent (b) shifts of the supply curves,

benefits. Wise argues that the essential curve to consider in benefit analysis is the cost curve and not the supply curve. In elementary models the two coincide, but Wise draws upon Capstick for many cases when factors other than costs affect the supply. Wises analysis is shown in Figure 8.

Figure 8 a) corresponds to Figure 6, and is based on the assumption of identical cost and supply curves. In Figure b) AM is the original cost curve showing the national output $\mathrm{X}$.

According to Wise, it is not necessary to estimate the new curve resulting from tech- nological change. It is enough to note that the original level of production $\mathrm{X}$ changes to a new level $\mathrm{X}^{*}$.

The economic benefits in case b) consist of three components $B_{1}, B_{2}$ and $B_{3}$. $B_{1}$ is equal to the value of increased production. $\mathrm{B}_{2}$ corresponds to the value of fewer producers being able to produce the previous output, enabling some of the producers to move into other sectors. Essential for this part of the benefits is that alternative possibilities for employment are found. All costs of creating places for work for displaced people must otherwise be (a)

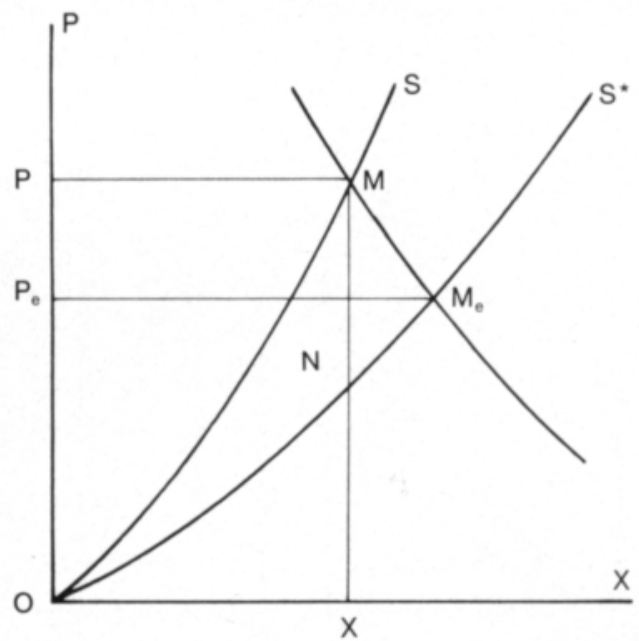

(b)

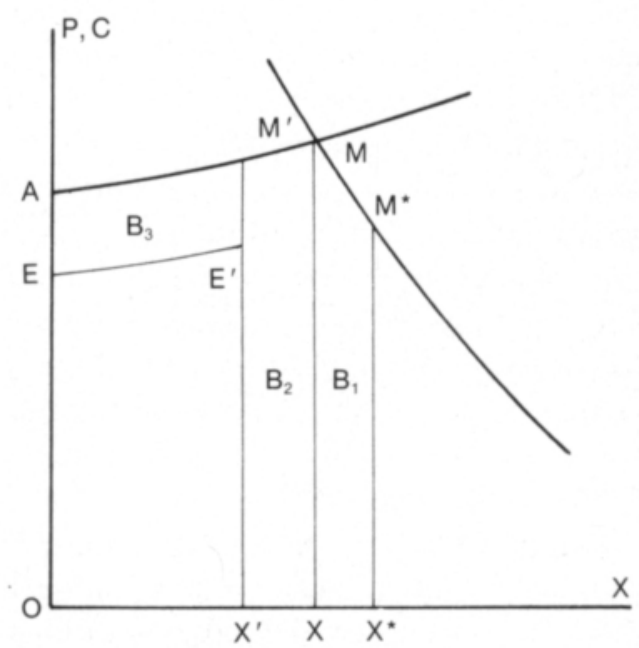

Fig. 8. Conventional construction in terms of surpluses (a) and alternative approach in terms of benefits (b) (WISE 1981). 
subtracted from $B_{2} . B_{3}$ is, finally, the value of specific input savings needed to produce $\mathrm{X}$. The input savings are a consequence of better production methods.

Freebairn et al. (1982) analyzed the importance of research at different levels of production; research on nonfarm input, farming and marketing. In a model based on pure competition the benefits of research will, however, be equally divided between the various levels.

Discussion of the welfare economics approach has shown that the conclusions and the size of the rate of return are largely dependent on the assumptions made about the form and shift of the supply curve. Practical application of the welfare economics approach thus must be done with care.

\subsubsection{Returns from Rice Breeding in Japan Estimated by Akino and Hayami}

With the help of a model of demand and supply curves like the one in Figure 6, AкINO and НАYAMI (1975) estimated an internal rate of return for rice breeding in Japan for two different periods, 1915-1953 and 19321961. Two different cases, an autarky case and an open economy case, and two alternative assumptions as to the streams of returns were used. One assumption was that net returns in 1935 and in 1951 would have continued forever, the other assumption was that net returns would become zero after 1953 and after 1961. The difference between the autarky case and the open economy case was minimal. For the first period the internal rate of return was $26-27 \%$ in the autarky case and $25 \%$ in the open economy case. These figures concern both assumptions on the stream of returns. The internal rate of return was $73-75 \%$ for both cases and both asumptions in the second period.

\subsubsection{The Study on Returns to Pasture Improvement Research by Duncan}

DunCAN (1972) attempted a) to identify important pasture research findings and b) to estimate the internal rate of return to research

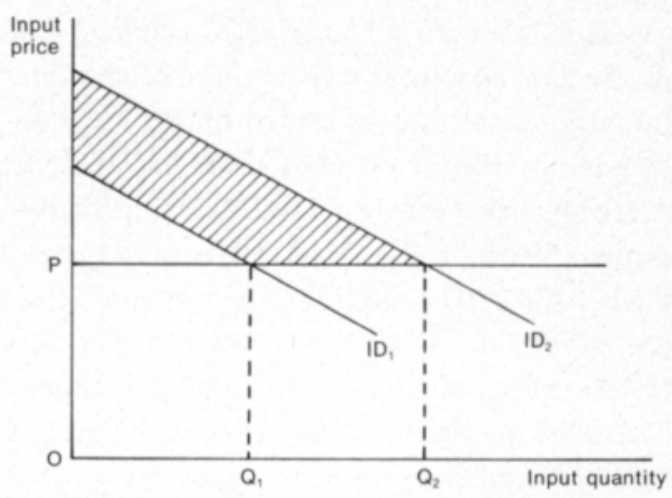

Fig. 9. The gains from an increase in the productivity of an input (DunCan 1972).

on pasture improvement. The study focused on an input resource, pasture. What was the effect of this research on demand for pastures? The benefits were assumed to correspond to the area between the new and the old demand curve for pastures above the price. Three different regions were separated in the study.

Figure 9 shows that supply is assumed to be perfectly elastic. A regression model was formulated to estimate the own price elasticity of demand. The demand for pastures was assumed to be a function of the real price and the state of pasture technology. Polynomial distributed lags of degree three and four (Almon lags) were fitted to each of these independent variables.

Briefly, the results were as follows:

1) The most important research contribution has been in the field of plant nutrition

2) The internal rate of return was very high, $20-80 \%$ depending on region and elasticity.

3) Both adoption lags and lags in adjustment of the stock of improved pastures to changes in prices were very short

No firm conclusion could be made concerning the effects of research on the demand for pastures.

\subsubsection{Canadian and Spanish Studies of Crop Development Research}

NAGY and FurTan (1978) studied the returns from public and private investment in 
rapeseed breeding in Canada. Consumers' and producers' surpluses were estimated. A computed internal rate of return of $101 \%$ indicated that the investment level in rapeseed breeding has been too low. Consumers obtained $53 \%$ of the total net benefits, producers $47 \%$. The method used was similar on the whole, to that of AKINO and HAYAMI (1975) in their study of rice breeding in Japan. The relevant figure is the same as illustrated by Figure 6 .

The recent Canadian studies include the one carried out by Zentner and Peterson (1984). The internal rates of return for research on new varieties and for all research dealing with wheat production ranged between 30 and $39 \%$. Only direct resource expenditures and extension activities were considered as costs.

Herruzo (1985) has estimated the returns to rice breeding in Spain. Following the work of Schmitz and SeCKLER (1970), the study assessed two types of social benefits from rice breeding: gross social benefits and net social benefits their difference being wage losses resulting from the adoption of new technology. The internal rate of return as computed from gross social benefits was $18 \%$. If labour displacement is considered, with $50 \%$ of the displaced population receiving compensation, the value of the internal rate of return drops to $17 \%$. The study further showed the consumers to be the sole beneficiaries of research, whereas producers suffered losses due to the low price elasticity of demand.

\subsubsection{The Distribution of Economic Benefits from Agricultural Research}

The introduction of new production methods created by research affects the prices of the products. An increase of the supply decreases the price. Conventionally measured, some of the benefits will accrue to consumers and some to producers through the drop in prices. The distribution of these mutual benefits has been explained in Figure 5. Are there any losers in agricultural research?
Producers unable to apply the new methods, whether because of the small size of their firm or for other reasons are the losers. The total social benefits from modern technology have generally been sufficient to compensate the losers, though compensation has not usually been made even in cases were it would have been possible (PINSTRUP-ANDERSEN 1982).

In a well-known, controversial study of the tomato harvester in California, SсHмIтz and SeCKLer (1970) concluded that the gross social rate of return from aggregate research and development expenditures on the tomato harvester was nearly $1,000 \%$. If displaced tomato workers are compensated the net social rate of return ranges -8 to $929 \%$, depending on the amount of compensation (from 0 to $100 \%$ ). If $50 \%$ of the displaced workers do not find alternative working opportunities and receive compensation, the net social return is $460 \%$, thus still an extremely high rate.

Hertford and Schmitz (1977) emphasize that aggregative models tend not to consider distributional effects. For a given commodity there are many types of producers: small-scale farmers, large-scale farmers, landowners, sharecroppers, and farmers with unmechanized and mechanized farms. The estimated returns often tend to neglect this subdivision between producers and the respective distribution of benefits.

Schultz (1977) argues that, in the long run, the major share of benefits from research is transferred to consumers. The distribution between various consumer groups can also be different, since the price elasticity of demand may vary between different consumer groups.

On the whole, however, lower food prices tend to decrease income disparities (PInStrupANDERSEN 1979).

Many studies have focused on the distribution of benefits between producers and consumers. It was pointed out in section 2.4.7. that NAGY and FurTAN (1978) estimated consumers' gains from rapeseed breeding in Canada to be $53 \%$ and producers' gains to be 
$47 \%$. Akino and Hayami (1975) examined two cases in their study of the returns from rice breeding in Japan. In the first case made under the autarky assumption all benefits went to consumers, while in the second case, based upon an open economy assumption, both producers and consumers became better off. SCOBIE and PosAda (1978) found that the major share of the benefits of technological change in rice production in Colombia went to consumers, wheras small producers suffered losses. The benefits exceeded total costs in spite of this. Herruzo (1985) concluded that consumers were the main beneficiaries of rice breeding in Spain while producers, or at least some of them, became worse off because of the low price elasticity of demand.

ScoBIE (1976) argues that analysis of the distribution of the economic surplus should include two additional simple questions: 1) Under what conditions will consumers gain more than producers as a result of technological change?, and 2) Under what conditions will the producers' surplus be positive?

Scobie presents a clear example in order to show the difficulties in calculating how benefits are distributed. A Minister for Allocation of Agricultural Research Funds is confronted with a proposal to grant USD 10 million for research on the "bongoyam"'. His office informs him that the demand and supply elasticities for bongoyams respectively are -0.7 and 0.4 . After receiving this information he poses both the above mentioned questions to his economists. The answers they give him depend on the formula used, and are illustrated in Table 4.

Table 4. Relative magnitudes of consumer and producer benefits for bongoyams (SCOBIE 1976).

\begin{tabular}{lcc}
\hline Formula used & $\begin{array}{c}\text { Will con- } \\
\text { sumers gain } \\
\text { more than } \\
\text { producers? }\end{array}$ & $\begin{array}{c}\text { Will produc- } \\
\text { ers' benefits } \\
\text { be positive? }\end{array}$ \\
\hline $\begin{array}{l}\text { Akino and Hayami } \\
\begin{array}{l}\text { Hertford and Schmitz } \\
\text { Ramalho de Castro } \\
\text { and Schuh }\end{array}\end{array}$ & YES & NOS \\
\hline
\end{tabular}

The conclusion is that the Minister must be confused by these contradictory answers. This fable also illustrates some of the difficulties connected with the welfare economics approach.

\subsection{Criticism of the Examined Studies}

\subsubsection{General Criticism}

The research field of estimating the economic returns to research has been a controversial subject since the first study made by Schultz in 1953. The credibility of estimated returns has been questioned, in particular the reliability of the earlier studies. Both of the reviewed methods for estimating the returns to research have been criticized on many points. The criticism has resulted in more detailed models where a more accurate approximation of research costs and a bigger cautiousness in estimations have been considered. According to RutTan (1982), this tendency has led to more recent credible studies which tend rather to underestimate the returns to research. Anyhow it is clear that many of the earlier studies, particularly those with a welfare economics approach, have been subject to methodical errors and insufficient data on research costs. The next sections review these aspects.

Rosenberg (1982, p. 25, 141-159) maintains that the rate of growth of an industry's output depends on factors of demand at least as much as it does depend on factors of supply. This can even be expressed in another way, i.e. technological change should not be seen as a predetermined exogenous factor automatically evolving according to a given pattern. Rather, it should be regarded as an endogenous force. Economists have tended to be interested more in the consequences of technological change than in the determining factors. Omission of these decisive, exogenous factors and the assumption that technological change develops according to a past pattern mean that science and technology are treated as though independent from economic and social circumstances. 
Rosenberg further stresses the importance of inter-industry relationships when considering the contribution of technical progress to productivity growth. The growth of productivity, for instance in American agriculture during the 19th century, was dependent on a stronger regional product specialization. This, in turn, was connected with the development of transport facilities (roads, railways, the steam engine and refrigeration) which made regional specialization possible. Technological improvements in one sector clearly depend on developments in other sectors. This fact has not been considered clearly enough in the early studies of returns to research.

Rosenberg also notes that the estimation of returns to industrial research overlooks the improvement in the quality of final products bought by the consumers, which may prove to be as important as growth in productivity. Agricultural research is easier to evaluate in this respect, since the final products are more homogeneous because the food industry is not included in most of the studies.

In connection with Rosenberg's inter-industry relationships it is worth mentioning the considerable importance of the spillover effect particularly in small countries. A large proportion of the research results are imported from other countries, modified only to a certain degree. It could thus be argued that the wisest thing for small countries to do would be to let bigger nations carry out all research and only to import ready results. There are, however, two functions of a domestic research capacity that cannot be compensated, as pointed out by EDWARDS and FreEbaIRN (1981). One function is to facilitate the utilisation of imported research results, both basic and applied. The other function is to investigate those promising areas and specific problems which are not covered by foreign research. Feeding methods based on silage as the main source of protein is perhaps one such from Finland. Nevertheless the problem of how to measure the spillover contribution from abroad still seems to be an unsolved problem in the field.
VUORI (1984) argues that estimates may be too high if one or more variables indirectly affecting productivity not have been taken into account. One such variable could be the growth of human capital. Usually this factor is attributed to increased education and increased experience through learning by doing. Human behaviour, however, consists of many factors that are difficult to estimate.

Pasour and Johnson (1982) also question whether the calculated rates of return are appropriate measures for comparing agricultural research and other public activities. WISE (1984 b) emphasizes that an economic criterion of welfare is only one of several possible criteria for political decision-making. Thus our values will decide whether or not this economic criterion is a sufficient criterion. A modest analysis of the economic benefits will be better suited to detect not only the many logical pitfalls but also the influence of value assumptions, and it should take care not to extend the economic quantification beyond normative and technical limits.

\subsubsection{Criticism of the Production Function Approach}

One of the most difficult methodical problems in the production function analysis is the collinearity between the research variable and other variables. According to LUND et al. (1980), this fact in connection with the incapacity to analyze separate production branches has led to the conclusion that the production function approach has only limited applicability.

WISE (1984 b) reports that re-interpretation of several earlier studies reveals the estimated rates of return to have been considerably lower in reality. According to him, both production function analysis and the welfare economics approach have used relatively simple models which are insufficient. They are inadequate in explaining how research affects the system it is part of.

Wise points out that the marginal product was calculated as b Q/R in Peterson's (1967) 
production function study of poultry research in the USA. Here b represents the index for the research variable in the production function and $\mathrm{R} / \mathrm{Q}$ the value of the research input in relation to the output. A ten-year lag was incorporated. According to Wise, the model is faulty. He argues that the marginal product should be calculated as b Q/RN, where $\mathrm{N}$ is the number of years over which the original research continues to affect output. If $\mathrm{N}$ is infinite, the marginal product approaches zero.

Should Wise's criticism be justifiable at this point, the estimated value of the marginal product is highly overestimated. But it seems hard to understand the criticism, since b represents the elasticity of production in the CobbDouglas function. According to the definition of elasticity, it shows the percentage change in production when research input is changed by $1 \%$. It is difficult to understand why this change should be divided by the number of years the research affects output.

Peterson (1985) calls attention to the conventional inputs in the production function. If they have not been corrected for a change in quality, the research variable will pick up these quality improvements. As the quality of fertilizer, buildings and other external inputs has risen faster than their prices, these changes will influence output. If the research variable only measures public research, the effects of private research will be included incorrectly. These changes in the quality of inputs are hard to measure if only the publicly funded research is taken into account. This argument is a call to pay explicit attention, in one way or another, to private research in the models.

On the other hand, expenditures for private research are included in the prices of products. Farmers thus actually pay for private research. Thus the problem of taking private research expenditures into account is not self-evident if a variable for external inputs is included in the production function. Depending on which view is accepted, private research is either included or omitted.

VUORI (1984) calls attention to the treat- ment and content of the research variable which, she thinks, considerably influences estimated returns. It is especially difficult to value how the effects of research are distributed among individual years. In her own study on the rates of return from industrial research in Finland and Sweden in 1964-1980 Vuori used geometrically distributed lags and an Almon lag of second degree. Still one more difficulty, Vuori states, is the aggregation of research expenditures. Different types of research have different lengths of lags; in other words the time lags are assymetric. The difficulties in estimating the profitability of industrial research are further aggravated by the disparity between different industries, a cicumstance which does not concern agricultural research to the same degree.

\subsubsection{Criticism of the Welfare Economics Approach}

Pinstrup-Andersen (1979) states that a considerable portion of the studies on how the returns from research have been distributed between consumers and producers are based on incomplete analysis. Various supply curves of production costs should be considered in order to observe the division of producers' surplus between separate groups of farmers. However, he contends that distributional issues are more easily dealt with through political measures than through research. There is a significant difference between an open and a closed economy. In countries where technological change has contributed to production growth but where export possibilities are limited because of unprofitable price relations, the situation is near that of a closed economy.

WISE (1981, $1984 \mathrm{a}, 1984$ b) has stated that methods based on consumers' and producers' surpluses have been too simple. He considers the internal rate of return to be an inappropriate measure for the economic utility of research. It is a suitable indicator of profitability only when the returns can be reinvested, while its analogous use in the con- 
text of a national economy has not a comparable content. PASOUR and JoHnSON (1982) and later, Peterson (1985) have also suggested that a "social internal rate of return" not is comparable to the internal rates of return in the private sector.

WISE (1984 b) further points out that the treatment of costs of implementing new innovations has been ambiguous in the earlier studies. Implementation costs can be treated as negative benefits and subtracted from the sum of benefits whereafter the difference becomes a benefit/cost quota. But implementation costs can also be treated directly as costs. The alternative chosen will considerably influence the result, as can be seen from the expressions $\mathrm{B} /(\mathrm{P}+\mathrm{Q})$ and $(\mathrm{B}-\mathrm{P}) / \mathrm{Q}$. In the former case the implementation costs represent pure costs, whereas they represent negative benefits in the latter. As Wise puts it:

"No great mathematical skill is required to see that the negative benefit approach can lead to very high benefit-cost ratios if, say, $\mathrm{P}$ is large but $\mathrm{Q}$ is small and $\mathrm{P}$ is treated as a negative benefit"' (WISE 1984 b).

In Griliches' (1958) hybrid maize study and in Peterson's (1967) poultry study, implementation costs were treated as negative benefits; this may have lead to overestimated rates of return.

WISE $(1981,1984$ a) has presented his alternative to the economic surplus method on the basis of cost and benefit analysis (see section 2.4.4.). He still stresses that the magnitude of error probably has not been great in the earlier formulation. Wise establishes four criteria that should be met in order to calculate reliable estimates of the benefits:

(i) The appropriate market mechanism must be identified.

(ii) The original cost curve must be adequately defined.

(iii) The technical parameters relating to willingness to adopt new technology, to the implementation costs of so doing and to the yield increases obtained must be satisfactorily established; any variations among producers in these respects must also be duly incorporated in the calculations.

(iv) There must be no covert, and possibly unjustifiable, assumptions such as that displaced resources, at zero cost, immediately find equivalent employment elsewhere in the economy, that demand curves adequately evaluate agricultural surpluses, or that there is a large pool of efficient producers waiting on the sidelines, etc. (WISE 1984 a).

WISE (1984 b) further questions whether the studies carried out have considered possible defects or adverse effects appropriately. Mechanical use of formulas without criticism can lead to distorted views of the long-term benefits of research. Thus he calls attention to the fact that the internal rate of return in the welfare economics approach avoids the problem of dealing with certain drawbacks. If, for instace, some built-in defect in the hybrid maize in the study of GRILICHES (1958) had led to all maize production being wiped out forever after 1955, the internal rate of return would have sunk only from $35 \%$ to $34 \%$.

Helander (1985) states that the fundamental goals of society for agricultural policy should be the starting point for evaluating the relevance of research. If the economic benefits represent one aspect of this overall relevance to society, the social benefits of research represent the other aspect. This study makes no attempt to evaluate social benefits. Certain examples of what such social benefits could consist of need to be mentioned, however. Improved working and social conditions for the agricultural population, a decreased use of energy, environmental aspects and new complementary sources of livelihood for the rural population could represent social benefits which should be evaluated on basis other than the strict econometric analysis used in this study. 


\section{The Returns to Investment in Agricultural Research - An Aggregated Production Function Study 1950-1984}

\subsection{Productivity Increase, Technological Change and Economies of Scale - the Connections}

\subsubsection{The Concept of Productivity}

In two previous chapters we reviewed the reasons for estimating the returns to agricultural research as well as methods that have been applied to do so. Research raises the quality of inputs in such a way that it is possible to produce a greater output with a given quantity of resources. This is analogous to growth in productivity. Because other factors can influence increases in productivity as well, a distinction between these sources needs to be made.

The internal relations between technological change, productivity and economies of size are illustrated by UhLIN (1985) in Figure 10:

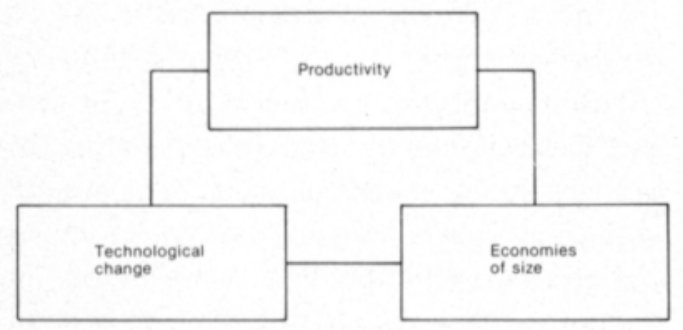

Fig. 10. The connections between sources of growth in productivity.

Productivity is defined as the empirical relation between production and unit of input:

$$
\mathrm{P}=\frac{\mathrm{Q}}{\mathrm{A}}
$$

$\mathrm{P}=$ productivity

$\mathrm{Q}=$ production

$\mathrm{A}=$ input
Growth in productivity implies that less resources are used for the production of one unit of a good, alternatively a higher production for a given quantity of resources. Growth in productivity accounts for that portion of a production increase that cannot be explained by an increase in the amounts of inputs.

Economies of scale is defined by PETERSON and Hayami (1977) as a more efficient organization of traditional inputs stemming from an increase in the size of the firm. Technological change refers to an increase in productivity stemming from new inputs or quality improvements of traditional inputs.

Economies of scale refers to the effect of increased output on average costs when all inputs are increased in the same proportions. The similar concept economies of size, however, refers to the effect of an increased output on average cost when inputs are increased not in proportional but in least cost combinations (Doll and Orazem 1978).

Difficulties in distinguishing between the concepts arise from the fact that technological innovations are often developed with certain requirements for the minimal size of the firm. By definition technological change is conceptually different from scale economies.

\subsubsection{Technological Change}

Adaption of a technology not previously used in the production process implies technological change. There are numerous definitions of technological or technical change. According to HaYAMI and RUTTAN (1971), it is the substitution of cheaper and more abundant factors of production for more expen- 
sive and scarcer ones at a certain volume of production. The constraints on production caused by inelastic supplies of resources can be released through technological change. The quality of inputs will be improved or totally new inputs will be developed. The quality improvements of inputs, both physical and labour, are due to research, education and learning by experience.

PinSTRup-Andersen (1982) refers to the technological state of any given production process as the composition and combination of inputs and technologies that exist at a given time. Thus, technological change describes a movement from one technological state to another. According to VUORI (1984), although difficulties are encountered in the estimation of technological change, it is usually measured with growth in productivity.

In the context of production function analysis, technological change manifests itself in several ways. We examine the Cobb-Douglas function

$$
\mathrm{Q}_{\mathrm{t}}=\mathrm{aK}_{\mathrm{t}}{ }^{\alpha} \mathrm{L}_{\mathrm{t}}{ }^{\beta}
$$

where $Q_{t}$ represents production, $K$ capital, $L$ labour, $\mathrm{a}$ is a constant and $\alpha$ and $\beta$ corresponding elasticities of production. According to HeErTJE (1977, p. 126, 147), technological change can be mirrored, firstly, as an increase in coefficient a, which means that the maximum of $\mathrm{Q}$ is higher though the combination of production factors remains the same. At the same time, it can be viewed as a shift in the production function. In the case of a microeconomic production function, technological change, secondly, can alter the elasticity of scale $(\alpha+\beta)$, but a difficulty here is that such alteration can also be caused by growth of the firm. Thirdly, technological changę can alter the elasticity of production so that growth in either $\alpha$ or $\beta$ occurs separately, resulting in more capital-intensive or labourintensive production methods.

HeERTJE (1977) reviews two forms of technological change: the case when technological change is embodied in capital goods used by the firm and the case of disembodied tech- nological change not related to capital goods. The division is made in order to create an operationally suitable distinction between quality improvements in capital goods and other quality improvements (cf. also HEMILÄ 1982).

The embodied form of technological change implies that the farm is supplied with innovations in the form of capital assets and equipment of a certain vintage (machines, buildings, seed etc.). One central force behind this type of technological change is agricultural research, which increases productivity in many ways. It lowers production costs, increases production, improves the quality of the product, creates totally new products or lessens the vulnerability to uncontrolled factors.

The disembodied form of technological change is not dependent on capital. It consists mainly of factors that increase farmers professional skills, e.g. education and learning by doing. Increased opportunities for education raise the farmer's own productivity and increase the marginal product for a given volume of inputs. Better education also increases the ability to acquire information, to interpret statements about costs and prices, and the adaption of new production methods.

There are, however, also a number of factors affecting changes in productivity which are more difficult to grasp. According to ROSENBERG (1982), the role of inter-industry relations, improved roadnetworks and transport facilities are important in considering the contribution of technical progress to growth in productivity. Changing patterns in values and attitudes probably have a substantial influence in the very long run. They may be of crucial importance when technical change is viewed with a historical perspective. The importance of knowledge borrowed from abroad has also been discussed rather little. All these factors are examples of disembodied technological change.

It is important to distinguish between the two types when attempts are made to quantify the technological change. HeErTJE (1977, p. $174-178$ ) shows that the production func- 
tion can be expressed in the following way. When technological change is embodied in capital goods produced in the year v (vintage) production in the year $t$ will depend on the state of technology in the year $v$. The production function becomes:

$$
\text { (3.2.) } \mathrm{Q}(\mathrm{v}, \mathrm{t})=\mathrm{A}(\mathrm{v}) \mathrm{F}(\mathrm{K}(\mathrm{v}, \mathrm{t}), \mathrm{L}(\mathrm{v}, \mathrm{t}))
$$

If technical change is not embodied in capital goods the level of production (as far as technological change is concerned) depends only on the general trend factor in period $\mathrm{t}$ :

$$
\text { (3.3.) } \mathrm{Q}(\mathrm{v}, \mathrm{t})=\mathrm{A}(\mathrm{t}) \mathrm{F}(\mathrm{K}(\mathrm{v}, \mathrm{t}), \mathrm{L}(\mathrm{v}, \mathrm{t}))
$$

In the former case one should construct a model which shows that the productivity of capital goods depends on the year $\mathrm{v}$ in which they were made. With a Cobb-Douglas function, the technological change embodied in capital goods can be expressed as:

$$
\mathrm{Q}(\mathrm{v}, \mathrm{t})=\mathrm{Be}^{\mathrm{tv}} \mathrm{L}(\mathrm{v}, \mathrm{t})^{\alpha} \mathrm{K}(\mathrm{v}, \mathrm{t})^{1-\alpha}
$$

where $\mathrm{e}^{\mathrm{tv}}$ is the embodied technological change. The disembodied technological change is easy to introduce through the trend factor $\mathrm{e}^{\mathrm{tv}+\pi}$ where $\mathrm{r}$ is a measure of the rate of disembodied technological change.

Another important divider between different forms of technological change is that between exogenous and endogenous technologi cal change. When technological change is treated as an externally predetermined factor without explaining the sources behind it, it is exogenous. Technological change is then attributed the passing of time. The previous expressions (3.2), (3.3) and (3.4) can all be considered exogenous treatments. Technological change embodied in capital goods is always exogenous, while the increase in the productivity of capital goods is attributed time (the vintage) (HEERTJE 1977).

According to SATO (1981) endogenous technical progress is regarded as the result of the rational behaviour of human beings. Models that treat technological change endogenously can explain it with one or more factors, e.g. (HeERTJe 1977): a) changes in the long run in price relations between factors of production,

b) a process of learning by experience,

c) an investment in education and research.

Technological change is not then treated as a predetermined quantitative factor in the production function, but as a result of how scarce resources with alternative use are allocated.

Technological change has an endogenous character. Heertje (1977) therefore advocates an endogenous treatment when using production function analysis. It is, however, important at the same time to observe that an exogenous treatment does not necessarily imply that technological change is independent of economic factors, such as education, extension and research.

This study attempts to explain technological change endogenously. The endogenous explaining factors consist of investment in agricultural research and extension.

\subsubsection{Economies of Scale and Changes in the Prices of Production Factors}

In the context of a production function, technological change can be seen as a shift in the function, whereas economies of scale can be thought of as moving along the function in the direction of increased production. Naturally, it is possible that the firm is situated on a point below the production function, being efficient neither technically nor in the sense of scale (Uhuin 1985). In a Cobb-Douglas function economies or disceconomies of scale are reflected in the sum of elasticities (the sum $\alpha+\beta$ in (3.1)) (Hemilä 1982).

Price reductions shift the supply curve to the right. They are connected with technological change and research, but can also stem from reductions of monopoly power or easing of import restrictions. An important example of price reductions at a given quality of input is the reduction in the real price of fertilizer (Peterson \& Hayami 1977).

Agricultural research can result in new knowledge and new materials. These may be 
used directly for technology, or can serve as new inputs in the research process. Research which serves only as a base for further research is sometimes called basic research, whereas research with a direct application is called applied research. Yet this division is largely arbitrary and sometimes misleading. Through improving technical efficiency and lowering production risks, agricultural research exerts an influence on farm and consumer real income, on exchange earnings and on human nutrition. These effects have consequences for the three major goals of society, shown in Figure 11: growth, equity and security against crises (PInSTRUP-ANDERSEN 1982).

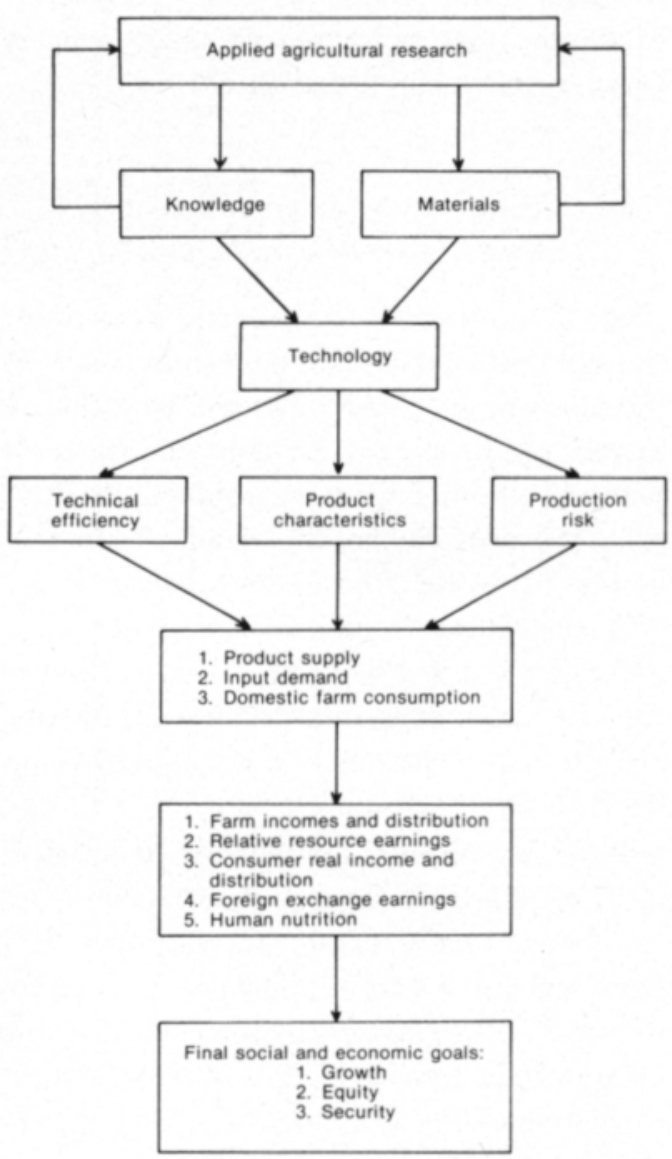

Fig. 11. Illustration of the potential outcome and implications of agricultural research (PINSTRUP-AN. DERSEN 1982).

\subsection{Starting Point for the Specification}

Let us repeat that the purpose of this study is to estimate the value marginal product of agricultural research in Finland. The second chapter reviewed studies carried out in the field, and issues related to technological change were accounted for in section 3.1.

In the study an aggregated production function for agriculture is estimated. A separate research variable is included in the production function. On the basis of the regression coefficient with respect to research a value marginal product, i.e. a marginal rate of return and a marginal internal rate of return for investment in agricultural research and university education will be calculated. The method used is therefore reminiscent of the studies presented under the heading " 2.3 . Production Function Analysis',

The study focuses on the whole agricultural sector and the aggregated research input. The welfare economics approach would offer another method for estimating the rate of return. This method has been criticized on the basis of the arguments reviewed in section 2.5. The main reasons for not using this approach in the current study are, however, twofold.

Firstly, the supply curve in a heavily regulated market like the Finnish one is affected by a multitude of market interventions. Since the economic surplus is calculated as the area between the old and the new supply curve, the supply management linked with several measures dictated by agricultural policy make it even more difficult to decide upon the nature of the supply shift depending on research.

In addition, the assumption of an open or a closed economy is crucial.

Secondly, the object of study is aggregate agricultural research. Application of the welfare economics approach requires an estimation of the real supply and demand curve. Since elasticities are estimated by product and aggregated supply and demand curves seem impossible to estimate, supply curves for the different products need to be estimated. The question of how to split up the research input 
for different products then arises; how should, for instance, research on agricultural machines be divided among plant, dairy, and meat production? This argument is the major reason for abandoning the welfare economics approach. In addition, the elasticities of the various products change over time, a fact further complicating the estimation.

The method chosen is the production function approach. Technological change is treated as an investment in research, extension and university education. This method makes it possible to attribute relative shares of the various independent variables in production growth. Unfortunately it is not possible to calculate the distribution of the returns between consumers and producers with this method. At the same time, the returns to agricultural research are seen from the viewpoint of the whole national economy.

The inclusion of university education as well as agricultural research needs to be explained. In data collection, it was impossible to separate university education from university research. In fact, it seemed like such a division would have been rather arbitrary. If there was no university education, there would probably be a drastic decrease in the number of agricultural researchers. Thus the university education was included in the research costs. University research and education during $1950-1984$ has been $24-52 \%$ of total research input. Most persons educated at the university have, however, not been working with research after graduating. The research costs would thus be overvalued for that component of education which actually does not belong to the research input.

In the study the imported research results, based on studies originally carried out in other countries, were not taken into account. The spillover effect, in other words, is assumed to be zero, i.e. the benefits exported from indigeneous research are assumed to be as great as the imported benefits. This assumption is not correct, since the major share of agricultural machines and plant protectants are imported, while exports are small. The spillover effect is clearly a problematic issue, and needs to be treated more exhaustively than has been possible within this study. The same simplifying assumption of no spillover effects from abroad, however, has been made e.g. in the work by WYATT (1983) on the rates of return from industrial research in Finland and Sweden in 1960 to 1980.

The possibility to include the effects of education in the form of a variable measured with a knowledge and skill index, as in the study by Ihamuotila (1972), was considered. In that study the knowledge and skill index was constructed on the basis of the number of farmers with professional training as listed in the agricultural censuses of 1950, 1959 and 1969. The proportion of farmers with professional training was further adjusted by the farmer's share of total labour input.

Because of high intercorrelation problems with the explanatory variables, which make the tests on individual regressors weak, education was not included in the specification. The possibilities to adjust labour for quality improvements according to the number of years in vocational schools were also investigated. The data on school years proved to be quite rough, thus being dubious; in addition, the effects of adjusting the labour series would not have been great. The idea of adjusting the labour series for training was therefore dropped.

The relationship specified between the inputs in the Cobb-Douglas function is complementary. According to the Wicksell-Johnson theorem the sum of the two elasticities $\alpha$ and $\beta$ in the Cobb-Douglas function is equal to the elasticity of scale (HEERTJE 1977). This is true if one is prepared to assume no relevant factors have been excluded. Increasing, constant or decreasing returns to scale prevail depending on whether a small proportional increase in all inputs leads to a more than proportionate, proportionate or less than proportionate increase in output (HEADY and DILLON 1961) (cf. also Hemilä 1982). The enlargement of average farm size and exploited economies of scale are therefore reflected by a 
change in the elasticity of scale $(\alpha+\beta)$ in expression (3.1). The sum of these elasticities should be about 1.0 or slightly more since economies of scale have not been exploited to a very big extent in Finland. Substitution of capital for labour is reflected in the changes in both $\alpha$ and $\beta$ (cf. also GrILICHES 1963 a).

Changes in the relative prices due to research are reflected in the research variable. The development of productivity during the 1960 s and 1970 s was most likely affected by production and import restrictions on farm products and production inputs. The effects of these measures were contradictory at least to certain degree; On the one hand, the whole production capacity has not been in use, a situation which has resulted in a smaller output than the potential; on the other hand, the protection of agriculture from imports has guaranteed a higher price for outputs. Here the assumption is made that the combined effect of these interventions on the market equals zero.

Owing to the relatively homogeneous conditions in Finnish agriculture, a time series study appears to be the most natural. The study should not be seen as a prognosis of research contribution in the future, but as a historical study of past returns to agricultural research. In other words, the study is of the ex post and not of the ex ante type.

\subsection{Specification of the Model}

\subsubsection{The Form of the Production Function and the Variables}

The basic model in the study is an aggregated production function that explains the gross production of agriculture.

A production function can be expressed as:

$$
\text { (3.5) } Y=f\left(X_{1}, X_{2}, \ldots, X_{n}\right)
$$

where $Y$ denotes gross production and $X_{i}$ the different inputs and the form of the function. The simplest form of the production function is the linear function:

$$
\mathrm{Y}=\mathrm{b}_{1} \mathrm{X}_{1}+\mathrm{b}_{1} \mathrm{X}_{2}+\ldots+\mathrm{b}_{\mathrm{n}} \mathrm{X}_{\mathrm{n}}+\varepsilon
$$

The linear production function expresses a constant marginal ratio between output and the various inputs. The random disturbance term $\varepsilon$ is an expression for the unsystematic component of the variation which cannot be explained by the systematic component $\mathrm{X}_{1}+$ $\mathrm{X}_{2}+\ldots+\mathrm{X}_{\mathrm{n}}$ (Heady and Dillon 1961).

At declining marginal products the CobbDouglas function

$$
\mathrm{Y}=\mathrm{aX}_{1}^{\mathrm{b}_{1}} \times \mathrm{X}_{2}^{\mathrm{b}_{2}} \times \ldots \times \mathrm{X}_{\mathrm{n}}^{\mathrm{b}_{\mathrm{n}}}
$$

has been used frequently because of its statistical simplicity and convenience. In expression (3.7), $a$ is a constant and $b_{i}$ are exponents equal to the elasticity of the various inputs i.e.

$$
E=\frac{d y}{y}: \frac{d x}{x}=\frac{x}{y} \times \frac{d y}{d x}=\frac{x}{y} \times b_{i}
$$

When $b_{i}<1$, the marginal products will decline as $\mathrm{X}$ increases because $\mathrm{X}^{\mathrm{b}}<\mathrm{X}$. Graphically illustrated the curve of the production function flattens out.

The Cobb-Douglas function is easily changed into logarithmic form:

$$
\begin{aligned}
& \log (Y)=\log (a)+b_{1} \log \left(X_{1}\right)+ \\
& b_{2} \log \left(X_{2}\right)+\ldots \ldots+b_{n} \log \left(X_{n}\right)+\varepsilon
\end{aligned}
$$

In Finnish studies of aggregate agriculture or aggregate crop and livestock production functions the Cobb-Douglas function has been used by Rouhiainen (1972), Kettunen and Rouniainen (1972) and Ihamuotila (1972). Ihamuotila also used linear production functions.

The Cobb-Douglas function has been commonly used to estimate the returns from agricultural research. Two pioneering examples are the studies by GriLICHES (1964) and EVENSON (1967) (see sections 2.3.2. and 2.3.4).

Other possible forms of the production function could be offered by the transcendental function, the quadratic function, the Spillman function (cf. HEAdy and Dillon 1961) and the CES function (cf. HEMILA 1982). This study is, however, based on the conventional Cobb-Douglas function. A linear production function is also estimated, 
though mainly in order to compare results with the Cobb-Douglas form.

In the formulation of the production function the specifications of GrILICHES (1964), Evenson (1967) and Norton and Davis (1981) have been followed. The choice of variables has, to a large extent, been done analogically with the production function study of Ihamuotila (1972).

The agricultural gross production is produced by labour, external purchased inputs and by capital (including cultivated area, soil and water constructions, machinery, buildings and animals). The vocational skills acquired through education, experience and extension also influence the production results.

The dependent and independent variables can be seen from the model formulated below:

(3.9) $Q=A L^{b_{1}} K^{b_{k}} I^{b_{i}} R^{\alpha} N^{o}$

$\mathrm{Q}=$ the volume of production

$\mathrm{A}=\mathrm{a}$ constant

$\mathbf{L}=$ labour input

$\mathrm{K}=$ capital input

$I=$ external purchased inputs

$\mathrm{R}=$ research input

$\mathrm{N}=$ extension factor

$b_{j}=$ elasticities of the different inputs

$\alpha=$ elasticity of research

$\sigma=$ elasticity of extension

This production function differs from the one formulated by Ihamuotila in including a research variable and an extension variable. Ihamuotila, on the other hand, included a special variable for human knowledge and skill, measured by an index of farmers' share of total labour input adjusted in proportion to an index of trained farmers. Furthermore, Ihamuotila also had a certain technological factor constructed on the basis of an index where the real capital stock was divided by the corresponding labour input (assuming that technological change is reflected by the amount of human labour saved). In this respect, the present study differs by measuring technological change as a result of investment in research. Labour input is not quality adjusted (for discussion, see section 4.4.). No weather variable is included.

In comparison with the model by TER-
LECKYJ (1980), there are two additional variables in this specification: purchased inputs and extension.

The effect of an increase in average farm size and its contribution to growth in productivity is reflected by the change in relation between the elasticities of different inputs $b_{i}$. Increasing returns to scale are indicated by growth in the sum of elasticities, which becomes larger than 1 (Heady and Dillon 1961, p. 589).

The variables of capital, labour and external inputs in (3.9) may be specified on two different levels, the aggregate level and the farm level. Farm level variables can be derived by dividing the aggregate variables by the number of farms. Research and extension are measured only at aggregate level. This is due to the way research affects agriculture. On a single farm, it is difficult to single out a special research input in the way it is possible to point at purchased inputs, fields, machines or labour.

In most studies the expenditures for research and extension have been added up and expressed as one single variable. The reason for this is that research results spread to farmers primarily through information activities. According to earlier studies this is, strictly taken, the correct procedure. The practice has probably been used, since in many cases the data for research and extension are not separated but presented together. There are, however, two immediate reasons why this course of action not has been applied here. Firstly, the data available for extension activities is based on State support for extension which actually was bigger than research expenditures in the first half of the 1950s. Since the purpose of this study is to estimate the returns primarily to research, not extension, the use of a single variable cannot be considered appropriate here. Secondly, the data on extension is deficient, since linear extrapolation was used to derive the figures between 1951-55, 1955-60, 1960-1965 and 1965-1970. The figures on research expenditures, however, can be characterized as fairly reliable. 
Since State support for extension will be taken into account as costs in the final calculation of the value marginal product (section 6.4.), the returns will not be biased in a positive direction. In fact, one could argue that the omission of extension expenditures when calculating the elasticity of research probably leads to a more realistic elasticity. Extension merely represents a complementary input for spreading research results, not a measure of research input. It should certainly be credited on the cost side in the final calculation. But the effect of extension on increasing the stock of knowledge or improving the quality of inputs is minor. One can ask whether studies not distinguishing between research and extension in elasticity calculation really are as valid as if a distinction had been made? A separate parameter for extension to use for sensitivity analysis is still incorporated in the models.

After consideration, a trend factor was not included in the model. The trend is assumed to pick up some of the potentially omitted variables. The trend could be assumed to include a number of factors rather difficult to measure. These could comprise changes in the pattern of values and attitudes which, in the long run, may considerably affect agriculture; the effects of agricultural policy; development in other sectors; infrastructural improvements; and other factors with effects on a higher hierarchical level. The problem is that it uncertain what a trend factor (a linearly growing series) actually measures. Preliminary results showed that a trend component did not improve the model in any way. There is good reason to believe that the trend factor does not add any significant explanatory power to the model. In the alternative formulation in section 3.3.3. a factor representing the disembodied technological change, i.e. a trend, is incorporated.

The form of the theoretically somewhat illogical linear production function is

$$
\begin{aligned}
& \mathrm{Q}=\mathrm{A}+\mathrm{b}_{1} \mathrm{~L}+\mathrm{b}_{\mathrm{k}} \mathrm{K}+\mathrm{b}_{\mathrm{i}} \mathrm{I}+ \\
& \mathrm{b}_{\mathrm{r}} \mathrm{R}+\mathrm{b}_{\mathrm{n}} \mathrm{N}
\end{aligned}
$$

where

bj $=$ the marginal product of the input
In the estimation of the Cobb-Douglas function, the ordinary least squares criterion is used. In addition, ridge regressions and autoregressive models are applied. The estimates of the different parameters are derived from index series of the different variables.

When we take the logarithms of (3.9), we obtain:

$$
\begin{aligned}
& \ln (\mathrm{Q})=\ln (\mathrm{A})+\mathrm{b}_{1} \ln (\mathrm{L})+\mathrm{b}_{\mathrm{k}} \ln (\mathrm{K})+ \\
& \mathrm{b}_{\mathrm{i}} \ln (\mathrm{I})+\mathrm{b}_{\mathrm{r}} \ln (\mathrm{R})+\mathrm{b}_{\mathrm{n}} \ln (\mathrm{N})
\end{aligned}
$$

Here the elasticities $b_{r}$ and $b_{n}$ indicate the share of growth in production due to research and extension respectively.

\subsubsection{Research Stock}

There are two different possibilities for measuring the research input; as either a flow or a stock. The flow concept has been used in the absolute majority of studies on the economic returns to research. A different possibility is, however, offered by formulating a stock of research capital.

In the following, a research capital $R_{k}$ is formulated, on the basis of a specification of Peterson (1985) for three different cases:

a) The research capital is assumed to be equal to the sum of of all previous funds for agricultural research since 1920 , i.e. is accumulating to $100 \%\left(\mathrm{~d}_{\mathrm{t}}=0\right)$. Funds allocated to research before 1920 are assumed not to have had any effect on production.

$$
\begin{aligned}
& \text { (3.12) } \quad R_{K}=\Sigma\left(K_{t}-d_{t} K_{t}\right) \text {, where } d_{t}=0 \\
& R_{k}=\text { research capital } \\
& K_{t}=\text { accumulated funds } \\
& d_{t}=\text { rate of depreciation }
\end{aligned}
$$

b) Half of the research capital is assumed to become obsolescent 20 years after the funding took place, and is thus depreciated by $50 \%$. The other half is added to the research stock. Research carried out before 1920 does not have any effect.

$$
R_{K}=\Sigma\left(K_{t}-d_{t} K_{t-20}\right)
$$

where

$\mathrm{d}_{\mathrm{t}}=0.5$

c) As in b), except that all of the research capital is assumed to become obsolescent 20 
years after funding, and is depreciated by $100 \%$.

(3.14) $\mathrm{R}_{\mathrm{K}}=\Sigma\left(\mathrm{K}_{\mathrm{t}}-\mathrm{d}_{\mathrm{t}} \mathrm{K}_{t-20}\right)$,

where

$\mathrm{d}_{\mathrm{t}}=1.0$

The initial figure for the research capital is derived by simple trend analysis back to 1920 , omitting the years 1940-1944, since normal research activities were seriously disturbed during the war years. In (3.12) $-(3.14) \mathrm{K}=$ $54.3+16.6 \mathrm{t}$ for public research, $23.0+$ $22.5 \mathrm{t}$ for total research. Accumulating the flows up to 1950 gives an initial stock. On the basis of the index series of real flows of funds for research, this initial value is further accumulated up to 1984. A series of accumulating research capital is thereby obtained.

The research capital has the convenient advantage of not demanding any lag operator. In this respect the research stock measure seems rasier to handle than the research flow measure. In the estimations both the flow and the stock concept of the research input will be used to estimate (3.9).

\subsubsection{A Productivity Index Specification}

The research stock will also be needed in the specification of an alternative model. In the empirical part of the study, the internal collinearity of the variables was found to be a serious problem. One purpose of this alternative specification is, therefore, to reduce the number of independent variables and thus to reduce the multicollinearity.

The following presentation of an alternative model is largely based upon the works of Terleckyj (1980), Griliches (1980) and VuoRI (1984). The difference in relation to the presentation in section 3.3.1. lies mainly in the use of a productivity index instead of gross production as the dependent variable. NoRTON and DAVIS (1981) state that an alternative specification similar to (3.15) has been popular because of intercorrelation problems with time series in models like (3.9). The advantage with this specification is that the traditional variables can be omitted, and thus the prob- lem of internal collinearity disappears, or at least becomes smaller.

A general lack of data for conventional variables has also contributed to the use of this model. The purpose of specifying a productivity index model is to obtain another estimate of the returns to research in order to see whether the estimates lie in the same range.

The productivity at a point in time $t$ can on the basis of (3.9) be explained as the relation between gross production $\mathrm{Q}$ and the "conventional" inputs labour, capital and external inputs, i.e. $\mathrm{L}, \mathrm{K}$ and $\mathrm{I}$ :

$$
\begin{aligned}
& \text { (3.15.) } P_{t}=\frac{Q_{t}}{L_{t}^{b_{l}} K_{t}^{b_{k}} I_{t}^{b_{i}}}=e A^{t t} R^{a} N^{\sigma} \\
& t=\text { time factor } \\
& \tau=\text { coefficient of time factor }
\end{aligned}
$$

This relation consists of three parts: one component representing the cumulative effects of autonomous technological change (e raised to the power of $\tau t$ ), i.e. a trend factor (this autonomous technological change factor has been added to (3.9)); one component representing the stock of research capital $\mathrm{R}$ raised to the power of an exponent representing the elasticity of research with respect to this research capital; and one extension component. In order to simplify the presentation the extension component $N_{t}$ raised to the power of $\sigma$ is omitted. Thus we obtain

$$
\text { (3.16.) } \mathrm{P}_{\mathrm{t}}=\mathrm{Ae}^{\pi t} \mathrm{R}^{a}
$$

The function can then be written as

$$
\text { (3.17) } \ln \mathrm{P}_{\mathrm{t}}=\ln \left(\mathrm{Ae}^{\pi t} \mathrm{R}^{a}\right)
$$

By estimating a research capital $\mathrm{R}$ as specified in section 3.3.2., it is possible to avoid a long and difficult deduction such as those in the specifications of GriLiches (1980), TerLECKYJ (1980) and VUORI (1984). $\tau$ denotes the autonomous technological change (trend). The dependent variable is thus an production/input index.

\subsubsection{Distributed lags}

The contribution of research to growth in productivity is not immediately observable in 
the same year that research was funded. There is one lag in the "availability" of technology, i.e. between research funding and ready production inputs, and another lag in the "acceptance" of technology. The incorporation of lags is thus an important and critical issue in estimating the returns to research (see, for instance, PASOUR and JoHnSON 1982). Nevertheless, satisfactory treatments of the lag structure are rare in the field.

The formulation of a lag function seems to be a difficult part of evaluating the returns to research. VUORI (1984) points at the difficulties in specifying a general lag for aggregated research. The length of the lag may vary for different categories of research, and the problem consequently consists of finding an average lag.

GriLiches (1964) basic way of treating the lags was to define research costs as the average of the research costs of the previous year and six years prior to the observed output year. This arbitrary treatment cannot be considered sufficient. Since simple lags do not provide a satisfactory explanation; a specific lag function needs to be specified.

One possibility is to estimate different lags directly by applying the ordinary least squares criterion. According to PINDYCK and RUBINFELD (1981) this leads to problems through losses of degrees of freedom and because of the heavy multicollinearity resulting from the large number of variables. Moreover, the picture of the form of the lag may remain unclear.

RAVENSCRAFT and Scherer (1982) note that it takes three years, on average, to complete industrial research and development projects. They also state that in measuring the returns from research and development, the time-lag factor in most econometric studies has been assumed to have a constant rate of decline, because of the convenience of the Koyck transformation. They argue that, for instance a bell-shaped curve describing the lag structure may be more correct. Such a curve could be provided by Almon lags. Preliminary experiments with Almon lags, however, uncov- ered serious drawbacks, according to them, Whether this is the case for agricultural research is not known.

Pindyck and Rubinfeld (1981) present the general form for a distributed lag model as:

$$
\begin{aligned}
& Y_{t}=\alpha+\beta_{0} X_{t}+\beta_{1} X_{t-1}+ \\
& \beta_{2} X_{t-2}+\ldots \cdots= \\
& \alpha+\sum_{t=0}^{\infty} \beta_{z} X_{t-2}+e_{t}
\end{aligned}
$$

VUORI (1984) used a geometric (Koyck) time lag and an Almon lag. Duncan (1972) also used Almon lags of degrees three and four in estimating the returns from Australian pasture research (see section 2.4.6.). The geometric lag depends on only two parameters. The parameters $\beta$ are assumed to decrease exponentially with time (WONNACOTT and WON. NACOTT 1970). If the general form of the model is:

$$
\begin{aligned}
& Y_{t}=\beta_{0} X_{t}+\beta_{1} X_{t-1}+\beta_{2} X_{t-2}+ \\
& \ldots+\beta_{n} X_{t-n}+e_{t}
\end{aligned}
$$

the geometric lag will be expressed by:

$$
\beta_{j}=\beta_{0} \tau^{j} \text { where } 0<\tau<1
$$

Since the weights of the lagged explanatory variables decline with time, the geometric lag cannot be considered the best possible. Instead a polynomially distributed lag, or Almon lag, theoretically could fit the research variable.

The Almon lag is based on the assumption that the lag structure is a polynomial of some degree $n$, with $n+1$ parameters. The original lag specification with $\mathrm{S}$ number of lags is:

$$
\begin{aligned}
& Y_{t}=\beta_{1}+\beta_{2} X_{t}+\beta_{3} X_{t-1}+\ldots \\
& +\beta_{s+2} X_{t-s}+e_{t}
\end{aligned}
$$

Instead of estimating the coefficients $\beta_{i}$ directly (as could be done in the geometric lag), we think of the lag as a polynomial. The polynomial of degree three is:

$$
\beta_{j}=Y_{o}+Y_{1 j}+Y_{2 j}{ }^{2}+Y_{3 j}{ }^{3}
$$

In a more general formulation $\beta_{\mathrm{j}}$ is a function $f(j)$. The polynomial (3.22) can be approximated by more simple functions. Through the Almon procedure these simpler 
(a)

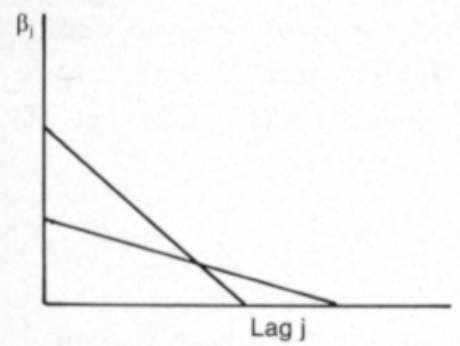

(b)

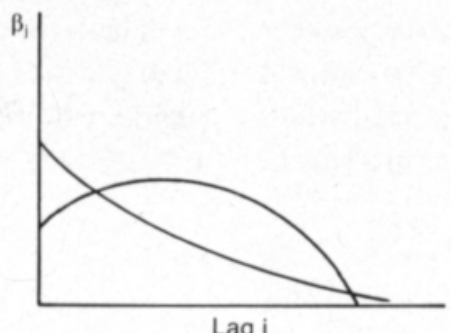

Lag j (c)

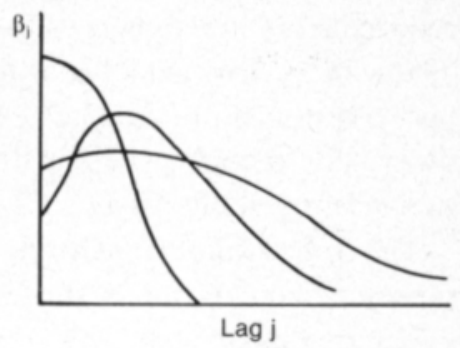

Fig. 12. Some polynomials of various degrees: (a) Degree 1, (b) Degree 2, and (c) Degree 3 (Wonnacotr and WONNACOTT 1970).

transformations are estimated in order to receive estimates $\hat{\beta}_{\mathrm{j}}$. The procedure reduces the number of parameters to be estimated, and probably also problems with losses of degrees of freedom and multicollinearity.

Figure 12 shows possible shapes of the Almon lag for polynomials of various degrees.

The Almon lags of degrees higher than one seem to provide a suitable possibility to take the adjustment process into account. The main effect of the explanatory variables can be assumed to lie many periods of time in the past. In order to estimate the transformed variables, certain assumptions on the distribution and length of the lag structure need to be made. The polynomial of degrees two and three seem to be logical in estimating the lags for research.

The Almon procedure was used by NevaLA (1976) in a model estimating the lagged responses of firms to changes in the variations in prices of fertilizer. The model below is, to a great extent, based on the formulation of Nevala. The dependent variable here is, however, gross production, and the explanatory variable is the lagged research input. A basic model including distributed lags, where the effects of research are distributed over m number of years, can be presented as:

$$
Y_{t}=\sum_{j=0}^{m} \beta_{j} X_{t-j}
$$

$\mathrm{Y}_{\mathrm{t}}=$ gross output in year $\mathrm{t}$

$\mathrm{X}_{\mathrm{t}-\mathrm{j}}=$ research input in year $\mathrm{t}-\mathrm{j}$

If the coefficients of regression $\beta_{j}$ $(j=2, \ldots m-2)$ can be assumed to be on the numerator of a polynomial of degree three, which is equal to zero when $\mathrm{i}=\mathrm{m}$ the vector $\beta_{j}$ can be compensated by

$$
\beta_{j}=\sum_{f=0}^{3} b_{f} \frac{(m-j)^{f}}{S f}
$$

$$
\text { where } \begin{aligned}
S_{f} & =\sum_{j=0}^{m}(m-j), \\
(f & =0,1,2,3)
\end{aligned}
$$

When this transformation is substituted for $b_{j}$ in (3.23) we have:

$$
\begin{aligned}
& Y_{t}=b_{o} \sum_{j=0}^{m} \frac{(m-j)^{0}}{s_{o}} X_{t-j}+ \\
& b_{1} \sum_{j=0}^{m} \frac{(m-j)^{1}}{s_{1}} X_{t-j}+ \\
& b_{2} \sum_{j=0}^{m} \frac{(m-j)^{2}}{s_{2}} X_{t-j}+ \\
& b_{3} \sum_{j=0}^{m} \frac{(m-j)^{3}}{s_{3}} X_{t-j}
\end{aligned}
$$

$$
\text { where } \begin{aligned}
S_{1} & =\sum_{j=0}^{m}(m-j)^{1} \\
S_{2} & =\sum_{j=0}^{m}(m-j)^{2} \\
S_{3} & =\sum_{j=0}^{m}(m-j)^{3}
\end{aligned}
$$

$(j=$ the first year of influence, $m=$ the last year of influence)

This model will be used to estimate the parameters $b_{0}, b_{1}, b_{2}$ and $b_{3}$. In relation to the 
basic model the number of variables has been reduced from m numbers to four (cf. Nevala 1976). In a polynomial lag of degree two, the last component $b_{3}$ in (3.26) naturally falls away. For the rest, the lag structure can be derived in a similar way.

The four Almon transformations in (3.26) presume that a notion of the length of the lag is acquired in advance. EvENSON (1967) found the length of the lag to be three and a half to eleven year, with a confidence of $95 \%$. He estimated the average lag to be six to seven and a half year. When the transformations

$$
\begin{aligned}
& Z_{0 t}=\sum_{j=0}^{m} \frac{(m-j)^{0}}{s_{0}} X_{t-j} \\
& Z_{1 t}=\sum_{j=0}^{m} \frac{(m-j)^{1}}{s_{1}} X_{t-j} \\
& Z_{2 t}=\sum_{j=0}^{m} \frac{(m-j)^{2}}{s_{2}} X_{t-j} \\
& Z_{3 t}=\sum_{j=0}^{m} \frac{(m-j)^{3}}{s_{3}} X_{t-j}
\end{aligned}
$$

have been calculated, the coefficients $b_{0}, b_{1}$, $b_{2}$, and $b_{3}$ can, in turn, be calculated for different lengths of adjustment with ordinary least squares. With these coefficients the model for the lagged research input can be presented as:

$$
\begin{aligned}
& \hat{\beta}=\hat{b}_{0} \frac{(m-j)^{0}}{S_{0}}+\hat{b}_{1} \frac{(m-j)^{1}}{S_{1}}+ \\
& \hat{b}_{2} \frac{(m-j)^{2}}{S_{2}}+\hat{b}_{3} \frac{(m-j)^{3}}{S_{3}} \\
& (j=0, \ldots m)
\end{aligned}
$$

With the help of these coefficients the model can be expressed in the basic form (3.23)

$$
Y_{t}=\sum_{j=0}^{m} \hat{\beta} X_{t-1}
$$

The coefficients estimated for different lengths of the lag are thus dependent on the lagged research variables $b_{0}, b_{1}, b_{2}$ and $b_{3}$. The form of the $\beta$-vector can be presented graphically.
The elasticities for the research variable can be calculated in the ordinary way. A cumulated elasticity for research over the entire period can be calculated (see $\mathrm{CHEN}$ et al. 1972, p. 81).

$$
e=\sum_{j=0}^{m} \hat{\beta}_{1} \frac{\bar{X}}{\bar{Y}}
$$

$\overline{\mathrm{X}}$ and $\overline{\mathrm{Y}}$ are the averages for both variables. When the Almon lag is put into the CobbDouglas function (3.9) in section 3.3.1. the function becomes:

$$
Q=A L^{b_{i}} K^{b_{k}} I^{b_{i}} R^{\sum_{j=0}^{m}\left(\hat{\beta}_{1-j}\right)} N^{\sigma}
$$

where $\hat{\beta}_{t-j}$ denotes a certain research elasticity for each lagged year $\mathrm{t}-\mathrm{j}$. The cumulative research elasticity for all years was expressed by (3.36).

\subsection{How the Model Works}

Two production functions have been specified parallelly: one Cobb-Douglas function (3.9) and one linear production function (3.10). An alternative specification (3.17) based on a productivity index instead of gross production have also been formulated. In addition, polynomial lags of degrees two and three have been specified for the Cobb-Douglas function. All models are based on the following assumptions:

i. There are no linear relations between the explanatory variables $\mathrm{L}, \mathrm{K}, \mathrm{I}, \mathrm{R}$ and $\mathrm{N}$ (does not apply to the productivity index model (3.17)).

ii. The expected value for the residual $\varepsilon=0$ and the variance $\sigma^{2}$ is constant.

iii. The residuals $\varepsilon_{\mathrm{j}}$ for the different observations do not correlate.

iv. The residuals are normally distributed.

The first condition i. can be controlled by studying the intercorrelation between the explanatory variables. The second condition ii. concerning the expected value and variance of $\varepsilon$ can be examined by investigating the distribution of residuals. An uneven distribution of the residuals, the so-called heteroscedasti- 
city, is thus incosistent with hypothesis ii. of this model.

The third condition iii., that of the residuals not being autocorrelated, can be verified by the Durbin-Watson test. The fourth and last condition iv., which can also be seen from the distribution of residuals, is needed to enable testing the significance of the coefficients. When the residuals are normally distributed they can be studied by the t-test.

The partial coefficients of regression for the explanatory variables explain the increase in the dependent variable when the variable in question is changed by one unit, on the condition that the other explanatory variables stay constant. The assumption of the other variables remaining unchanged is of crucial importance. Thus the coefficient of research input explains the increase in gross production (or the production/input relation in the productivity index model) that follows from a one unit change in research input, provided that capital and labour and external inputs remain unchanged. In the linear models the coefficients explain this increase as a marginal product. Because the coefficients are derived from index series, the absolute level of the marginal product cannot be seen directly, but first need to be transformed into an elasticity. In the Cobb-Douglas model (3.9) the coefficients represent the elasticity directly.

When the Almon lag is applied to the research variable, different research elasticities are obtained for each lagged year $\mathrm{t}-\mathrm{i}$. The influence of the research input has a maximum value between the first year $\mathrm{t}-\mathrm{i}$ and the last year $\mathrm{t}$, and it declines in both directions according to Figure 12. On the basis of (3.36), the elasticity for the whole period is calculated. The Cobb-Douglas function is the logic form of the production function when measuring the gross production on farm level at a certain point in time. A linear production function is hardly justifiable in this case because the marginal product is constant. The law of diminishing returns is valid also on the aggregate level in case we use cross-section data. But in time series studies the situation is somehow different, since the production function shifts upwards each year. Thus we have a series of shifting production functions. The Cobb- Douglas function is, however, less controversial and should thus be regarded as the major model. The linear model should be seen as an additional source of information, one which complements the Cobb-Douglas function.

The model measures research input as a flow of funds for agricultural research as well as a stock of research capital. The flow measure implies that if no funds are available for one year, the model values the effects of research on gross production as zero for this year. A stock of the research capital has, however, been formulated in section 3.3.2. Interpretation of this research capital is different. The quantity of this research capital $\mathrm{K}$, which exists at any point in time, is equal to the sum of all previous funds of research subtracted by the proportion that has depreciated over time according to formulas (3.12)-(3.14). The elasticity of this research capital, therefore, is different from the elasticity of the research flow. The lag structure need not be incorporated with the research stock. 


\section{Data}

\subsection{Time Series}

The sum of the squares of errors will be minimized in order to estimate the CobbDouglas production function. As the absolute level of time series need not be known in this procedure, the estimates can be derived from index series. Since the conventional variables in the study have been chosen on the basis of the production function study for 1950-1969 by Iнамuотіla (1972), the same series are followed up until 1984.

The capital variable is defined here as the gross capital stock, whereas Ihamuotila rather used a net capital stock (see section 4.3.).

The data for research and extension have been collected separately. Since agricultural research is the focus of this study, a detailed description of the contents of the research variable will be given in this chapter. The time series are presented in Appendix 2.

\subsection{Gross Production in Agriculture}

The source used for measuring agricultural gross production was the "total accounts of agriculture'" calculated at the Agricultural Economics Research Institute (AERI). Another possibility would have been to employ the national income account drawn up by the Central Statistical Office. The two series differ, since the total accounts of agriculture calculated by AERI include only basic agriculture (crop production, animal husbandry and outdoor garden production), whereas in addition to basic agriculture, the national income account also includes reindeer, bee and fur animal husbandry and incomes from services, including the hiring of machines. Outdoor garden production was not included in the total accounts before 1975. The total accounts series was chosen because the study primarily concerns basic agriculture.

The data from the total accounts of AERI have been converted to the price level of 1970 . The sources of total accounts are the following: Ihamuotila (1972) for 1950-1960; SiltANEN (1977) for 1961-1975; and the corresponding figures released by AERI for 1976-1984. The figures for 1950-1969 have been adjusted to correspond to calendar years, not crop years. State support (subsidies and compensations) as well as changes in the value of animal stock have not been included in the time series. The subperiods have simply been linked at 1961, 1964 and 1975.

\subsection{Capital Stock}

According to Vihavainen et al. (1980), the capacity of production of the capital stock is best approximated by the gross capital stock. This concept does not allow machines or buildings to depreciate before being taken out of production once and for all. The gross capital stock thus expresses the value of the real capital stock. In the net capital stock, on the contrary, the annual depreciations are subtracted from the capital stock.

In this study the gross capital stock has been used to measure the productive capacity of the capital stock. The main portion of the capital stock has been taken from the national income account at the price level of 1980. It includes agricultural buildings, soil and water constructions and machines, inventories and means of transport. The capital stock as defined in the national income accounts is presented in Appendix 5. 
The capital stock measured by the preceding items has been corrected by adding cultivated land and livestock. Stores, any other land improvements, capital invested in growing crops and receivables, however, have not been included even though both IHAMUOTILA and Stanton (1970) and Ihamuotila (1983) took them into account. Moreover, their share in the whole capital stock is minor.

The information on cultivated area is based on the Monthly Review of Agricultural Statistics (Board of Agriculture) 1955-1984 and on the Official Statistics of Finland (OSF III, Agriculture 1950-1954). The value of land has been calculated according to the same principles used by IнAмuotila (1983) but at the price level of 1980. According to that study, this value was FIM 9,163 per hectare of field in production, whereas uncultivated field was valued at one-third less (FIM 6,109 per hectare).

The values for field mentioned above may seem low and certain reservations should be made, as the figures express averages for the whole country. There are large regional discrepancies in the value of land. Table 5 shows the total area and its value in the price level of 1980.

In order to include the value of livestock, information on the stock of animals for 1950 - 1980 has been taken from the studies mentioned earlier, i.e. IHAMUOTILA and StaNton (1970) and Ihamuotila (1983). The index series in the former has been linked to the latter in 1961. The series obtained in this way has been multiplied by the value of livestock in 1980. The result is an estimation of the value of livestock for the period 1950-1980.

On the basis of the latter study, the development of livestock in 1981-1984 has been followed up using the same principles. The value of cattle has, accordingly, been calculated as follows.

The value of one dairy cow at constant prices cannot be measured by multiplying the unit price in 1980 by the number of cows, since milk yield per cow has improved continuously and slaughter weight has varied. The current
Table 5. The area and value of land 1950-1984 at the price level of 1980 .

\begin{tabular}{|c|c|c|c|}
\hline & \multicolumn{2}{|c|}{ Area $(1,000$ hectares $)$} & \multirow{2}{*}{$\begin{array}{c}\text { Value } \\
\text { of field } \\
\text { FIM mill. }\end{array}$} \\
\hline & $\begin{array}{l}\text { in } \\
\text { production }\end{array}$ & $\begin{array}{c}\text { not in } \\
\text { production }\end{array}$ & \\
\hline 1950 & $2,430.9$ & & 22,274 \\
\hline 1951 & $2,458.2$ & & 22,524 \\
\hline 1952 & $2,499.4$ & & 22,902 \\
\hline 1953 & $2,516.4$ & & 23,058 \\
\hline 1954 & $2,540.2$ & & 23,276 \\
\hline 1955 & $2,565.7$ & & 23,510 \\
\hline 1956 & $2,579.9$ & & 23,640 \\
\hline 1957 & $2,596.1$ & & 23,788 \\
\hline 1958 & $2,611.1$ & & 23,926 \\
\hline 1959 & $2,633.3$ & & 24,129 \\
\hline 1960 & $2,670.7$ & & 24,472 \\
\hline 1961 & $2,670.7$ & & 24,472 \\
\hline 1962 & $2,686.6$ & & 24,617 \\
\hline 1963 & $2,703.2$ & & 24,769 \\
\hline 1964 & $2,716.7$ & & 24,893 \\
\hline 1965 & $2,731.2$ & & 25,026 \\
\hline 1966 & $2,741.2$ & & 25,118 \\
\hline 1967 & $2,743.6$ & 2.8 & 25,157 \\
\hline 1968 & $2,746.1$ & 4.3 & 25,189 \\
\hline 1969 & $2,666.3$ & 86.5 & 24,960 \\
\hline 1970 & $2,577.2$ & 92.9 & 24,182 \\
\hline 1971 & $2,554.8$ & 113.0 & 24,100 \\
\hline 1972 & $2,463.7$ & 201.3 & 23,805 \\
\hline 1973 & $2,435.5$ & 223.8 & 23,684 \\
\hline 1974 & $2,446.8$ & 206.8 & 23,684 \\
\hline 1975 & $2,453.8$ & 187.5 & 23,630 \\
\hline 1976 & $2,463.9$ & 149.0 & 23,487 \\
\hline 1977 & $2,452.2$ & 191.0 & 23,636 \\
\hline 1978 & $2,412.3$ & 190.6 & 23,268 \\
\hline 1979 & $2,401.5$ & 187.5 & 23,150 \\
\hline 1980 & $2,372.0$ & 190.7 & 22,900 \\
\hline 1981 & $2,355.7$ & 184.2 & 22,711 \\
\hline 1982 & $2,327.7$ & 188.9 & 22,483 \\
\hline 1983 & $2,314.4$ & 152.2 & 22,137 \\
\hline 1984 & $2,292.7$ & 146.1 & 21,901 \\
\hline
\end{tabular}

value is first calculated as in the study of IHAMUOTILA (1983) with slaughter weight as the starting point. This minimum value for a dairy cow has been positively adjusted by $35 \%$ per year, a value considered to represent the difference between slaughter weight and the value of production in 1961 (IHAMUOTILA and Stanton 1970). This value has been raised by half of the index series showing the average milk yield per cow. The obtained value has been further adjusted by the price ratio of milk to meat, the result being the current value of one cow. 
In 1980 the value of one cow was FIM 4,918 according to this calculation procedure. Rearing cattle has been valued at $60 \%$, and a calf at $25 \%$ of the value of a dairy cow. This constant price for a young animal has been calculated on the basis of the price development of beef in the same manner as Ihamuotila (1983). Thus the price development is adjusted further by the price ratio of milk to beef. This figure, called the price component, is multiplied by the values current in 1981-1984, as mentioned earlier.

The value of pigs has been calculated simply on the basis of the volume of pork, using three different weight groups: $140 \mathrm{~kg}$ (over 6 months old), $72 \mathrm{~kg}$ (2-6 months old) and $15 \mathrm{~kg}$ (less than 2 months old). The volume of pork obtained in this way is multiplied by the price of pork in 1980 (FIM 10.09 per $\mathrm{kg}$ ). In the same way sheep have been divided into two groups: ewes (over 1 year old, $20 \mathrm{~kg}$ ) and lambs (under 1 year, $10 \mathrm{~kg}$ ). The volume of mutton has been multiplied by the unit price in 1980 (FIM 18.53 per $\mathrm{kg}$ ). The value of wool has not been considered. The value of one hen in 1980 was rated at 19 FIM per $\mathrm{kg}$, that of one broiler FIM 8.40 per $\mathrm{kg}$. The value of horses is simply based on the slaughter weight in 1980 , which was FIM 3,870.

Table 6. The total gross capital stock in 1950-1984 in the prices of 1980 (FIM. million).

\begin{tabular}{llll}
\hline 1950 & 56,448 & 1968 & 80,948 \\
1951 & 58,012 & 1969 & 82,234 \\
1952 & 60,097 & 1970 & 81,701 \\
1953 & 61,307 & 1971 & 82,749 \\
1954 & 62,861 & 1972 & 83,026 \\
1955 & 64,303 & 1973 & 83,763 \\
1956 & 65,401 & 1974 & 84,408 \\
1957 & 66,614 & 1975 & 85,071 \\
1958 & 67,845 & 1976 & 86,134 \\
1959 & 69,169 & 1977 & 86,876 \\
1960 & 70,868 & 1978 & 87,354 \\
1961 & 72,480 & 1979 & 88,278 \\
1962 & 74,124 & 1980 & 89,428 \\
1963 & 75,734 & 1981 & 90,524 \\
1964 & 77,075 & 1982 & 91,293 \\
1965 & 78,197 & 1983 & 92,276 \\
1966 & 79,626 & 1984 & 92,777 \\
1967 & 80,528 & & \\
\hline
\end{tabular}

All figures on the size of livestock in 1950 1980 have been taken from the previously mentioned studies (IHAMUotila and Stanton 1970), (Ihamuotila 1983). The period 1950-1960 has been linked to the period 1961-1980. The whole period 1950-1980 has been multiplied by the constant values of livestock in 1980.

The total gross capital stock (Table 6) is the sum total of the value of land, livestock and the gross capital stock figures obtained from the national income account (agricultural buildings, soil and water constructions, machines, inventories and means of transport).

\subsection{Labour and Education}

The labour input is measured in working days done by family members and hired labour. The data for the period 1950-1960 are based on the index series of IнAмuотіLA (1972), which has been linked to the series of the Board of Agriculture for total labour input in agriculture 1961-1984 (Official Statistics of Finland III-Annual Statistics of Agriculture, and Monthly Review of Agricultural Statistics 8, 1985). In 1971-1972 a new basis of calculation was introduced in these series. For this reason the former and the latter series have been linked at 1972 in order to observe the difference of level $(+29 \%$ in the latter). The time series so obtained shows the amount of working days put into production (see Figure 13 and Appendix 2).

The quality of labour has improved in the period 1950-1984 through increased education and through learning by doing, as was pointed out by GriLiches (1963 a). His method for adjusting labour input for these quality changes has been explained in section 2.3.2. A similar approach in this study proved to be difficult because of inadequate information on the number of years of schooling completed by the agricultural population.

The agricultural censuses of 1950, 1959 and 1969 (Official Statistics of Finland III) enquired into farmers' vocational and institute 
(first and second level) training as well as university education. From 1969 onwards this enquiry became part of the population censuses carried out every five years. The information from the censuses are not directly comparable. The census of 1950 shows that training had been received for farmer or the farmer's spouse only on $6.4 \%$ of the 234,432 farms which responded. In the census of 1959 only $5.7 \%$ of all 541,203 persons living on farms for which results were received had had

Table 7. Examination certificates granted at agricultural schools in $1950-1984$.

\begin{tabular}{|c|c|c|}
\hline Year & $\begin{array}{c}\text { National Board } \\
\text { of Vocational } \\
\text { Education }\end{array}$ & $\begin{array}{l}\text { Central } \\
\text { Statistical } \\
\text { Office }\end{array}$ \\
\hline 1950 & 2,063 & \\
\hline 1951 & 2,185 & \\
\hline 1952 & 2,230 & \\
\hline 1953 & 1,962 & \\
\hline 1954 & 2,029 & \\
\hline 1955 & 2,560 & \\
\hline 1956 & 2,248 & \\
\hline 1957 & 2,504 & \\
\hline 1958 & 2,369 & \\
\hline 1959 & 2,400 & \\
\hline 1960 & 2,287 & \\
\hline 1961 & 2,047 & \\
\hline 1962 & 2,032 & \\
\hline 1963 & 2,183 & \\
\hline 1964 & 2,675 & \\
\hline 1965 & 2,392 & \\
\hline 1966 & 2,324 & \\
\hline 1967 & 2,329 & \\
\hline 1968 & $3,120^{1}$ & \\
\hline 1969 & 3,040 & \\
\hline 1970 & 2,800 & \\
\hline 1971 & 2,310 & 2,388 \\
\hline 1972 & 2,268 & 2,354 \\
\hline 1973 & 2,302 & 2,377 \\
\hline 1974 & & 2,248 \\
\hline 1975 & & 2,020 \\
\hline 1976 & & 2,077 \\
\hline 1977 & & 2,221 \\
\hline 1978 & & 2,535 \\
\hline 1979 & & 2,913 \\
\hline 1980 & & 3,179 \\
\hline 1981 & & 3,518 \\
\hline 1982 & & 3,711 \\
\hline 1983 & & 3,774 \\
\hline 1984 & & 3,994 \\
\hline
\end{tabular}

1 Gardening, fur, fishery, dairy produce and other schools, not belonging to the sector of basic agriculture were not included before 1968 . training. In 1969 still only $7.5 \%$ of farmers or farmers' spouses $(454,228$ people) had received an examination certificate, whether agricultural or non-agricultural. In 1980 $17.6 \%$ of farmers $(203,201)$ had first, second or third level education of any sort, whereas the corresponding figure for the whole farm family $(422,873$ people) was $24.1 \%$. A very crude estimate would therefore be that the educational level of farmers has risen from $5 \%$ to $20 \%$ of farmers. Since adjustment of the labour input contains the subjective element of how to weigh an index series for the educational level, and since the effect of this adjustment would probably lead only to minor changes in the labour input index, the idea was totally abandoned.

Time series on the number of examination certificates granted at agricultural schools and institutes since 1971 are, however, collected by the Central Statistical Office. In addition, relatively rough figures on examination certificates prior to 1971 were obtained from the National Board of Vocational Education. These time series are shown in Table 7. A large proportion of the people obtaining a certificate go to sectors other than agriculture.

\subsection{External Inputs Used in Production}

Goods purchased by agriculture from other sectors of the economy comprise basic prerequisites e.g. fertilizer, concentrates, animal expenses including depreciation, obsolescence, and the maintenance of capital goods such as machinery and buildings. The time series on external inputs are based on the total accounts of agriculture by AERI, the sources being: IHAMUOTILA (1972) for 1950-1960; SILTANEN (1977) for 1961-1975; LaUrila (1981) for 1976-1980, and the corresponding figures of the Institute for 1981-1984. The series for the subperiods have been adjusted to make them correspond with each other. Thus animal expenses have been summed up with the series of Ihamuotila, while wage costs, social costs and rents have been subtracted 
from the series of Siltanen and Laurila. The period 1950 - 1969 has again been adjusted to correspond to calendar years. After this the subseries have been linked as gross production, again at the same points in time. The absolute values of the series on external inputs in constant prices are presented in Appendix 3 .

\subsection{Extension}

Farmers receive information about research results through extension services. The role of extension is thus to speed up the application of results from research. In the model extension has been observed explicitly through the inclusion of a separate extension variable.

The extension variable is estimated on the basis of total State expenditure to public extension agencies, including the following: the Association of Agricultural Centres; the agricultural centres; the Association for Agricultural Societies of Swedish Speaking Far- mers; the agricultural societies and the small farmer organizations (Pienviljelijäin keskusliitto, Pienviljelijäin liitto and Suomen pienviljelijäin liitto). Public expenditures for the specialized extension agencies, i.e. organizations giving extension services on a particular production line, e.g. bee, fur or lamb husbandry, have not been included. Strictly speaking, their inclusion would have been preferable since their share has been rising during the latter part of the period 19501984. The lack of available data on State support for these agencies limits the possibilities of including them in the total State expenditure for extension. The share of extension services paid by farmers themselves has not been included, the obvious reason being that farmers pay for these services themselves, and should thus not be accounted for. The extension activities of the private sector have been omitted for the same reason.

A complete time series for the period 1970 - 1984 was used in the study. The period 1951 - 1970, however, rests on data with five

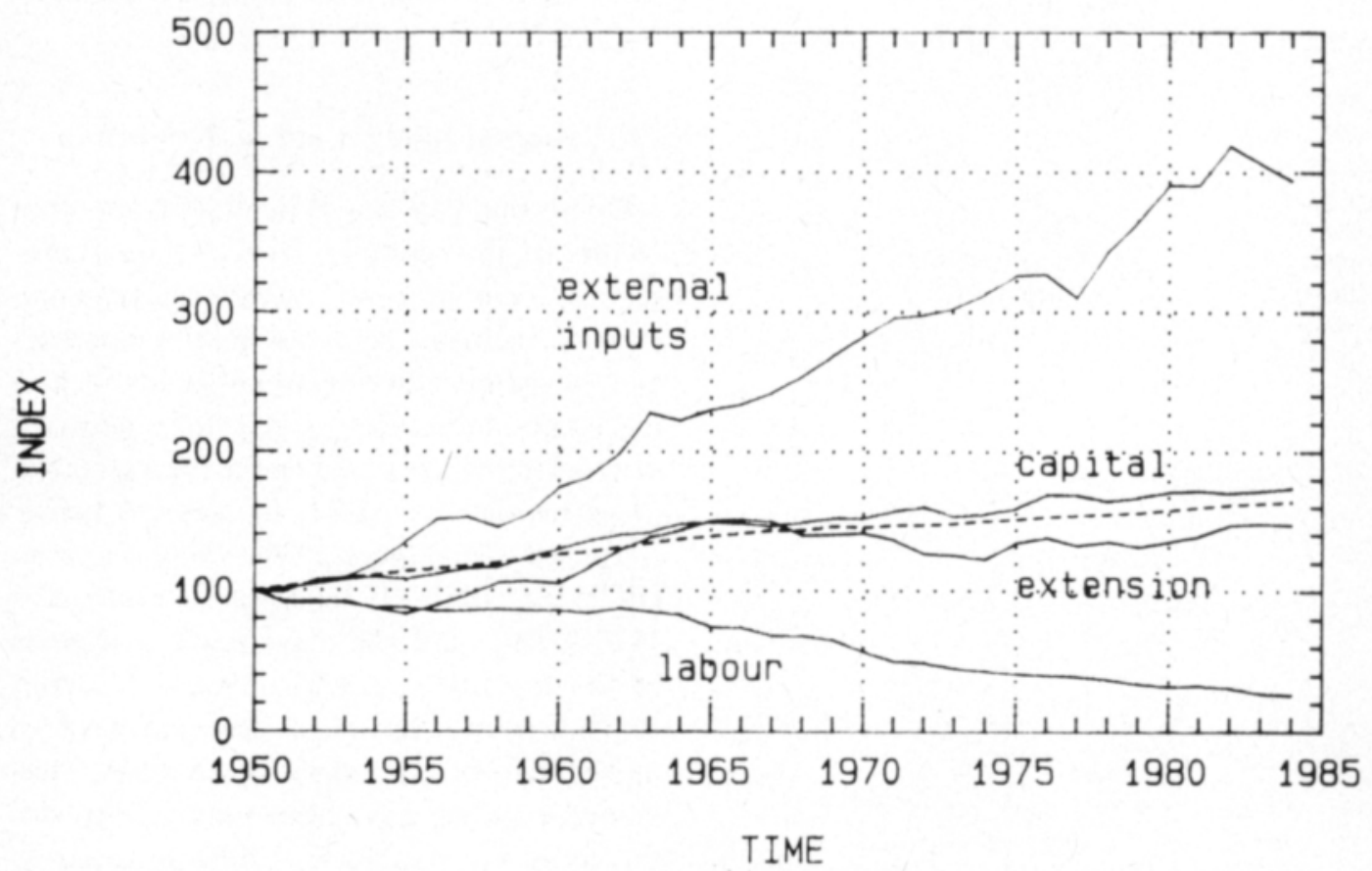

Fig. 13. Capital, labour, external inputs, extension and agricultural production (dotted line) in $1950-1984$. 
year intervals. The missing values have been estimated by linear interpolation. Extension expenditures in 1950 were assumed to be equal to those of 1951 .

The total expenditures (including services paid by farmers) and State expenditures are presented in Appendices 3 and 4. The share of State expenditure out of total expenditures was the greatest in 1970 (66.6 \% of expenditures) and has declined to $45.4 \%$ in 1984 .

The development of the capital stock, labour, external inputs, extension and gross output are presented in Figure 13.

\subsection{The Research Input in the Public Sector in $1950-1984$}

Public research is defined here as research financed by public funds and carried out mainly at public research institutes and universities. Agricultural research, in turn, is understood to be research connected with basic agriculture and focusing on crop production, animal husbandry, agricultural economics, policy and technology. Research on garden production, indigenous energy sources (peat, straw, willow etc.), forestry and subjects which in the broad sense could be considered agricultural are not included in the research input in this study.

A particularly difficult question is which items of public expenditures allocated to agricultural research should be included in the research input of the public sector. How should capital costs, for instance, be treated? In a way, they do not affect research results in the short term, yet buildings, for example, are necessary in order to carry out research. To be certain not to underestimate the funds allocated to research, capital costs have been included in the data to the extent information about these costs have been reported. This may give rise to discussion, since the estimated returns, obviously, will be lower than if capital costs were not included. As was mentioned earlier, a major criticism of the early studies in this field was that too little of the costs of research were taken into account.
Another issue difficult to handle is the role of universities and how to distinguish education from research. Most students completing an university degree do not go into research but move into other occupations, often outside agriculture. Inclusion of the expenses of university education in research expenses will cause negative bias in the returns. One could, of course, also argue that without university education there would be no researchers. Because of the difficulties in distinguishing research from education, all university expenditures for both agricultural research and education are included in the variable, which may, of course, give rise to criticism. As was pointed out earlier, university research and education represent $24-52 \%$ of total research input during the period studied.

No basic research (biological, chemical or mathematical) is included in the research variable. One can naturally uphold their appreciable value to applied research. The critical question is however: Through what channels does basic research affect applied research? The answer obviously, is through university education. The effects of basic research spread, through graduate education and research training, to applied agricultural research.

\subsubsection{Research at Institutions under the Ministry of Agriculture and Forestry}

The major share of public agricultural research carried out in Finland is done at institutions under the Ministry of Agriculture and Forestry. Only two of these institutions are research institutes in the real sense (the Agricultural Research Centre and the Agricultural Economics Research Institute), while the others are institutions mainly carrying out inspections. The Agricultural Research Centre is definitely the most important research institution. According to the estimate in this study, the Agricultural Research Center has represented three-fourths of the total research input carried out at institutions under the Ministry of Agriculture and Forestry during the 1970s. 
Table 8. Agricultural research percentage; share of all subsidies to the institutions.

Institution

Percentage share representing

research

Agricultural Research Centre

$100 \%$

Agricultural Economics Research

Institute

State Institute for Dairy Research

State Research Institute of Engineering

in Agriculture and Forestry

State Horse Breeding Institute

National Veterinary Institute

State Control Office for Dairy

Products

State Institute of Agricultural

Chemistry

$100 \%$

$70 \%$

$30 \%$

$25 \%$

$20 \%$

$10 \%$

$10 \%$

$10 \%$

State Seed Testing Station

Seed Investigation Institute'

$100 \%$

1 This figure is not based on the report of Lemola et al.

The values reported by Lemola et al. (1975) have been used to assess how much of the activities at each institution is devoted to research purposes. They found the percentage of research of all activities in 1970-1975 to be that shown in Table 8 . For the sake of simplification, the same percentage rates are assumed to have been relevant also in the 1950s.

This is obviously not the case since the research activities vary from one period to another. Because the Agricultural Research Centre is the institute accounting for the absolute major share of the expenditures and because $100 \%$ of its funds are included, the risk of error should be only moderate.

So-called jointresearch projects carried out by other institutions, private or public, have been financed by the Ministry since 1975 . The expenditures for these projects have been collected separately and added to the research input. All grants awarded to the Agricultural Development Fund, which has existed at the Board of Agriculture since 1975, have also been gathered and added to the sum. Moreover, some smaller issues, e.g. support for private laboratories, export control of agricultural produce, support for plant breeding and special grants, have been added to the final sum. Some minor issues may not be regarded as research in the strict sense, which may cause doubt. These issues are slight, however, and are included in order not to leave room for the accusation of having undervalued the allocations for agricultural research.

\subsubsection{The University of Helsinki and the College of Veterinary Medicine}

A considerable part of agricultural research and education is carried on at the Faculty of Agriculture and Forestry of the University of Helsinki. About an equal amount of money is granted to the College of Veterinary Medicine. According to the estimate in this study, the part of agriculture of the total funds for the University were about FIM 1 million in 1960 and about FIM 20 million in 1984. These figures include no other scientific discipline at the Faculty (forestry, food, environmental sciences etc.). The total funds for the College of Veterinary Medicine were FIM 1.3 million and FIM 24 million in the same years.

Collecting information about the funds spent on agricultural sciences in relation to the whole budget of the Faculty of Agriculture and Forestry proved to be very difficult. The largest share of the expenditures are, however, wages and salaries. The following simplification was made to calculate the share of the agricultural sciences. It was assumed that the number of agricultural professors and assistants in relation to the total number of professors and assistants in the University rather satisfactorily indicates the extent of resources spent on agriculture out of all grants to the University of Helsinki. This assumption includes the share of administration expenses in the agricultural sciences as well. Alternatively, the number of teachers could have been included. However, since the number of visiting lecturers was very high in the early 1950s, it would have led to an incorrect assessment of the development of funds for agricultural research and education.

On the whole, the size of the margin of 
error involved in this method for valuing university expenditures for agriculture is not known. It is noteworthy that the figure obtained for 1984 (FIM 20 million) for agricultural research and education is the same as the figure reported by the Central Statistical Office of Finland for all research activity in the whole faculty, i.e. including forestry, food and environmental sciences, without education and administration.

According to the above calculation method for university expenses, the College of Veterinary Medicine and the Faculty of Agriculture and Forestry represent the largest share of research input after the Agricultural Research Centre. These three institutions taken together stand for the absolute major share of research input in agriculture.

\subsubsection{The Academy of Finland}

The Academy of Finland consists of seven research councils including the Research Council for Agriculture and Forestry. Furthermore, there is one central committee for the research councils and an administration office. Before 1961 there were only two research councils: one for natural sciences and one for the humanities. The distribution of resources between different research councils at the Academy, including the agricultural and forestry sciences, are available for 1975-1984 and for 1964-1969. The figures for the period 1970 - 1974 have been valued on the basis of the information available on all resources granted for research and researcher training purposes and the percentage distribution of research grants (see the annual reports of the research councils in Valtion tieteelliset toimikunnat 1961-1969, Tieteen keskustoimikunta ja Tieteelliset toimikunnat 1970-1974, Kertomus Suomen Akatemian toiminnasta 1975-1983). The expenditures for the central committee for the research councils and administration have not been included because of the lack of more detailed information over time and the small share of total expenses (about $10 \%$ or less).
The share of the agricultural sciences out of all expenditures granted by the Research Council for Agriculture and Forestry is not given in the annual reports before 1977. During 1977-1984 the share of agricultural sciences of these resources rose from $29.9 \%$ to $44.8 \%$; see Table 9 :

Table 9. The share of agricultural sciences of all funds granted by the Research Council for Agriculture and Forestry in 1977-1984.

\begin{tabular}{cc}
\hline Year & Percentage \\
\hline 1977 & 29.9 \\
1978 & 29.6 \\
1979 & 33.1 \\
1980 & 38.8 \\
1981 & 30.2 \\
1982 & 34.5 \\
1983 & 36.7 \\
1984 & 44.8 \\
\hline
\end{tabular}

The arithmetic average during these years was $34.7 \%$, or roughly one-third. The simple assumption that the agricultural sciences have received one-third of all funds for the agricultural and forestry sciences also during the period of $1961-1976$ is therefore made. In current value, the funds amounted to FIM 3.5 million in 1983 and FIM 5.4 million in 1984.

The figures for the period 1950-1961 are based on the minutes of the Research Council for Natural Sciences. The information gathered on this period is very unreliable, and is partly mere guesswork. However, it probably reflects the order of the size of funds for agricultural sciences granted by the Academy to research, researcher training and scientific societies.

\subsubsection{Finnish National Fund for Research and Development and Public Foundations}

The funds granted by the Finnish National Fund for Research and Development (SITRA) as well as the Finnish Cultural Foundation (Suomen Kulttuurirahasto) and the Maj and Tor Nessling Foundation have been included 
in the the research input. SITRA has granted resources since 1968, and the funds reached their peak in 1981, when FIM 4.7 million were granted for agricultural research. In some years agricultural sciences received no funds at all from SITRA.

Because it proved to be very difficult to separate the agricultural and forestry sciences, all funds for these sciences granted by the Maj and Tor Nessling Foundation and the Finnish Cultural Foundation were included. The funds granted by the Finnish Cultural Foundation have only been around FIM 0.5 million (1983-1984) or less to all agricultural and forestry sciences, the grants of the Maj and Tor Nessling Foundation even smaller.

\subsubsection{Work Efficiency Association}

The Work Efficiency Association was founded in spring 1924. Alreday from the start the Association has received a certain amount of government support, but the major share of its activities has been financed by the Association's own means. The research activities have traditionally been divided into three areas: forestry, home economics, agricultural and construction research. A certain amount of extension is practised as well. The primary goal is to investigate rationalization methods in these areas.

The construction and agricultural research represents the type of research that is the focus of this study. In 1983 the expenses of the Association's agricultural and construction department were about FIM 2.8 million.

The research expenditures of the Work Efficiency Association have been based on the following assessments. The expenditures of the agricultural and construction department are reported in the annual reports for 1974-1984. This part of all research efforts is not separately reported for earlier years. The department's share of total expenditures in 1974-1983 equalled $10.0-16.5 \%$. The department seem to have received about the same share of resources also in earlier years. Based on the assumption that $14 \%$ of the
Associations' expenditures have been devoted to construction and agricultural research, a time series was constructed for 1950-1973. Minor cost items (rent, depreciation, the interest rate) and expenditures for the vocational centre have been subtracted from total expenditures. The total time series for 19501984 is added to the previous research input.

\subsubsection{Agricultural Research Outside the Research Definition}

The Technical Research Centre of Finland carries out a small amount of research in the primary sector. Lemola et al. (1975) stated that $1.1 \%$ of research expenditures in the operational plan 1976-1980 was devoted to agriculture and forestry, hunting and fishing. A large part of this share was research connected with forestry. At the Domestic Fuel Laboratory the major part of research work is connected with peat production, which very broadly could be regarded as agricultural research. The Biotechnical Laboratory and the Food Research Laboratory carry out some research relatively close to agriculture; for instance, malt barley has been bred in order better to suit the needs of malt houses. Research connected with gene technology will increase in the future, but so far the magnitude of this research has been very small. If agricultural research were defined very broadly, at the most FIM 1 million of the current research expenditures could be regarded as connected with agriculture. The research carried out at the Technical Research Centre, however, does not agree with the definition of agricultural research applied in this study.

The Ministry of Trade and Industry grants funds for research on domestic fuel resources. As mentioned above, this can hardly be considered agricultural research.

The expenditures of the Pellervo Economic Research Institute have not been included in the research input. Strictly speaking, these funds should have been included. The research institute has, however, existed only since 1979, and the volume of the research input has been 
small. Though the omission is probably not justifiable, it hardly affects the estimation.

\subsubsection{The Development of the Public Research Input in 1950-1984}

In order to obtain the aggregate research input, all the expenditures mentioned in the previous subsections of 4.7 . have been summed up. The sum has been deflated by the GDP market index and is expressed in the pricelevel of 1980 . The aggregate volume of public research is presented in Table 10 and Figure 14.

Table 10. Expenditures for public agricultural research in 1950-1984, deflated to the level of 1980 (FIM 1,000).

\begin{tabular}{cccc}
\hline Year & $\begin{array}{c}\text { Research } \\
\text { expenditures }\end{array}$ & Year & $\begin{array}{r}\text { Research } \\
\text { expenditures }\end{array}$ \\
\hline 1950 & 17,610 & 1968 & 70,080 \\
1951 & 24,180 & 1969 & 65,653 \\
1952 & 22,437 & 1970 & 60,882 \\
1953 & 20,936 & 1971 & 60,798 \\
1954 & 20,727 & 1972 & 69,325 \\
1955 & 24,934 & 1973 & 70,312 \\
1956 & 28,442 & 1974 & 65,222 \\
1957 & 27,151 & 1975 & 80,503 \\
1958 & 40,513 & 1976 & 84,423 \\
1959 & 39,713 & 1977 & 109,600 \\
1960 & 37,507 & 1978 & 92,712 \\
1961 & 39,130 & 1979 & 109,753 \\
1962 & 51,995 & 1980 & 111,538 \\
1963 & 53,319 & 1981 & 114,319 \\
1964 & 52,039 & 1982 & 107,503 \\
1965 & 62,740 & 1983 & 108,186 \\
1966 & 64,508 & 1984 & 109,123 \\
1967 & 64,221 & & \\
\hline
\end{tabular}

The research input has risen faster than other inputs since 1950. Therefore it seems natural that the effects of research have also grown more rapidly. Variations in the outlays for certain years can be noted. Funds for the University of Helsinki and the Agricultural Research Centre increased rapidly at the end of the 1970s, which can be seen from the time series. Since the peak in 1981, the funds have remained on the same level as at the end of the 1970s.

\subsection{The Research Input in the Private Sector in 1950-1984.}

The private sector carries out a considerable amount of research. The issue whether or not research carried out in the private sector should be included in research input is intricate. The arguments for taking the private research into account shall be discussed first.

Given the fact that means of production improve because of the research done in the private sector, it seems only natural to include private research. Because information about the volume of this research has been difficult to acquire, simple assumptions have often been made. To give an example, Peterson (1971) assumes that private research was equal to public research in the follow-up study of Schultz' (1953) pioneering calculation.

Peterson (1985) maintains that the value of the marginal product of newer inputs is higher than their prices, and that the impact of private research is thus higher than prices reflect. In other words, one kilogram of fertilizer in 1980 has a bigger effect on production than one kilogram of fertilizer in 1950. Public research may catch some of the quality improvements carried out in the private sector in case private research is not considered.

On the other hand, one could argue that the private sector transfers expenditures for research on the input prices (i.e. the external inputs), and that farmers in this way actually pay for the research carried out by private firms. One part of the prices of purchased inputs can be called a "research cost". To include the private research would be to count the same cost twice as a separate variable for external inputs has been included in the model. Most studies seem to neglect this important issue, since some studies account for private research while others do not.

In this study a middle road was chosen. Two different research variables are used parallelly in the estimation procedures. One measures only the public research input, whereas the other measures the total private 
and public research input. The data for the public sector has already been reported earlier in this chapter (4.7.).

The information about the research expenditures of the private sector is deficient, and the estimates of the elasticity with respect to total research must therefore be seen with caution. First of all, it has to be noted that expenditures only cover part of the aggregate expenditures invested in research by Finnish firms.

The following procedure was used to construct a variable for total agricultural research in 1950-1984 that would include both the private and the public sectors. To start with, eight of the most important companies dealing with agricultural research were contacted. Statements on research expenditures for improving inputs used in agricultural production were received. However, only a few firms gave information that covered the whole period. The data was therefore reliable for all the companies only for the 1980s. In addition, some of the companies could give exact in- formation only about operating expenditures, not on capital outlays. The companies that were willing to give statements on their capital outlays differed clearly as to the relation of operating costs to capital outlays.

A simplifying assumption is therefore necessary. It is assumed that capital costs equal half of the operating expenses. This assumption enables an estimation of all expenditures for the private sector. A time series of total private expenditures in 1950-1984 can be constructed for the private sector, based on the assumption that the expenditures have grown at the same rate as for the few companies that provided information about their expenses for the whole period 1950-1984. The time series calculated by such assumptions was then deflated by the GDP market price index. The index series obtained is presented in Appendix 2. In Figure 14 a graphic illustration of the index series is given.

A clear warning must be given that the data is unsatisfactory and that the calculated value marginal products for the total public and

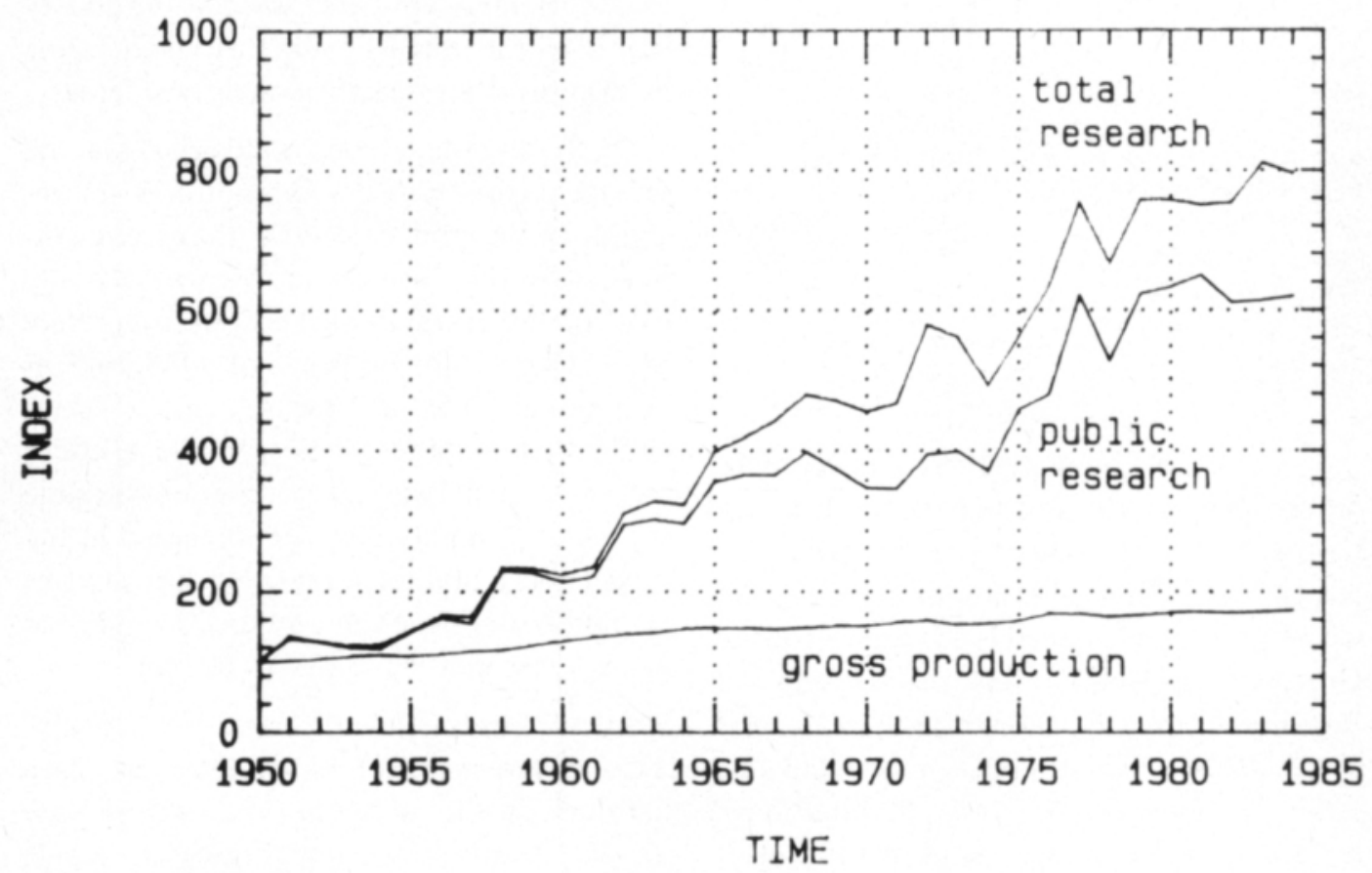

Fig. 14. The development of the public and the total research input and of agricultural production in $1950-1984$. 
private research should not be taken literally. Too little of the expenditures on research by the private sector have been included. The best way to interpret the estimates is therefore to see them in relation to the coefficients estimated only on the basis of the public research input. Seen in this way, the total research input provides some complementary facts to the results based solely on the public research expenditures. 


\section{Presentation of the Results}

\subsection{The Research Input Measured as a Flow}

Various specifications of the production function have been formulated in chapter 3 . The most important distinctions are those between

1. Specification of the research variable as a flow of annual funds or as a stock of research capital;

2. A linear or a Cobb-Douglas form of the production function;

3. An unlagged or a lagged research variable;

4. A public research variable or a total research variable;

5. Traditional input variables capital, labour, external inputs (and production) specified at aggregate or at per farm level.

The following Figure 15 illustrates the various alternatives for specification used in this study: reported in sections 5.1. and 5.2. The regressions that include a stock of research capital are presented in section 5.3.

Section 5.1. analyses the results of specifications with no lags included for the research variable specified as a flow. For each unlagged research variable the traditional inputs have been specified in two ways, on aggregate and on farm level. Sensitivity analysis is applied so that in the regressions, the extension factor is added later. The internal correlation between explaining variables is examined, and the results of ridge regressions are reported. The regression results from autoregressive models of the first and second order (without any lag) are reported, and Cobb-Douglas regressions for the shorter periods $1950-1969$ and 1965-1984 are finally summarized.

Section 5.2. reports the results of the models
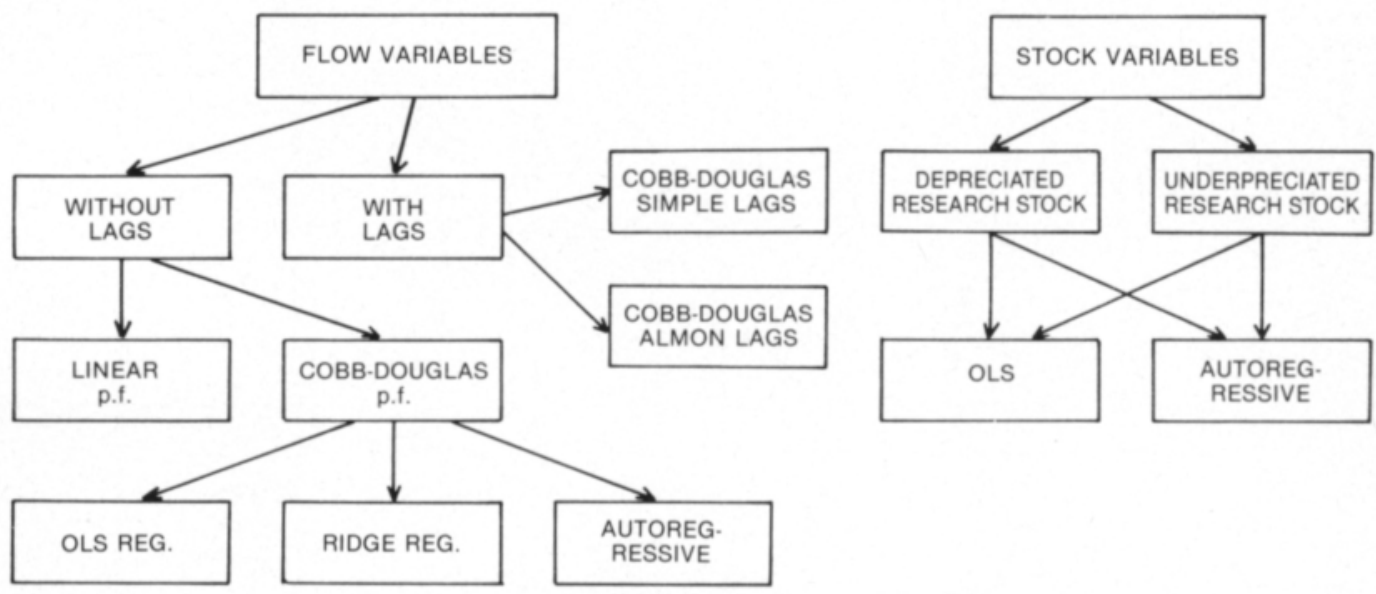

Fig. 15. Various alternatives of model specification and methods of regression.

The results of the regressions, including a specification of the research variable as a flow of annual public or total funds, are including simple lags and polynomial lags for the public research variable.

The results of the regression specifications 
including the research variable as an undepreciated or depreciated stock are discussed in section 5.3. In subsection 5.3.3., the results of regressions which include a total productivity index as the dependent variable are presented.

Finally, in chapter 6, a value marginal product and a marginal internal rate of return are computed.

\subsubsection{Linear Flow Models without Lags}

The results of the linear functions specified as (3.10) are presented in Tables 11 and 12 (public research) and in Appendices 6 and 7 (total research). The parameter estimates of the inputs should be interpreted as marginal physical products.

The linear models specifying the three traditional variables at aggregate level (Table 11) have fairly high coefficients of determination, exceeding 0.98. Analysis of variance for the full regression shows a high F-ratio, with a level of significance less than $0.001 \%$. The Durbin-Watson test value of $0.96-1.02$ indicates a heavy autocorrelation between the residuals. The standard error of the estimate is approximately 3.3 in both regressions.

An examination of the correlation matrix (Tables 15) shows that the independent variables are highly correlated. Except for the extension, all the simple correlation coefficients are over 0.90 , a fact which seriously limits the reliability of the coefficients. The parameter estimate of capital could be accepted on a level of significance less than 0.001 (i.e. a confidence level of over $99.9 \%$ ). The external parameter estimates of inputs and labour prove to be problematic. The labour coefficients are insignificant with high standard errors, while the parameter estimate of external inputs is negative. One reason could be the collinearity between variables, as it is difficult to sort out the influence of one regressor, e.g. external inputs from another. Thus the parameter estimate of capital seems

Table 11. Linear production functions with public research. All variables measured at aggregate level. Regression coefficients and their standard errors in parenthesis below the coefficients, significance levels, coefficient of determination, F-ratio and Durbin-Watson test values.'

\begin{tabular}{|c|c|c|c|c|}
\hline \multirow[t]{2}{*}{ Regression } & \multirow[t]{2}{*}{ (1) } & \multirow[b]{2}{*}{ s.1. ${ }^{2}$} & \multirow[t]{2}{*}{ (2) } & \multirow[b]{2}{*}{ s.l. } \\
\hline & & & & \\
\hline Constant & $\begin{array}{l}-43.460 \\
(15.464)\end{array}$ & 0.009 & $\begin{array}{l}-20.674 \\
(23.351)\end{array}$ & 0.383 \\
\hline Capital & $\begin{array}{c}1.277 \\
(0.149)\end{array}$ & 0.000 & $\begin{array}{c}1.081 \\
(0.211)\end{array}$ & 0.000 \\
\hline Labour & $\begin{array}{c}0.116 \\
(0.098)\end{array}$ & 0.250 & $\begin{array}{c}0.006 \\
(0.129)\end{array}$ & 0.963 \\
\hline External inputs & $\begin{array}{r}-0.010 \\
(0.043)\end{array}$ & 0.820 & $\begin{array}{r}-0.014 \\
(0.043)\end{array}$ & 0.750 \\
\hline $\begin{array}{l}\text { Public aggregate } \\
\text { research }\end{array}$ & $\begin{array}{c}0.018 \\
(0.012)\end{array}$ & 0.154 & $\begin{array}{c}0.016 \\
(0.012)\end{array}$ & 0.200 \\
\hline Extension & & & $\begin{array}{c}0.094 \\
(0.073)\end{array}$ & 0.207 \\
\hline $\mathbf{R}^{2}$ & 0.982 & & 0.983 & \\
\hline Stand.error of estimate & 3.354 & & 3.317 & \\
\hline F-ratio ${ }^{3}$ & $420.86^{* * *}$ & & $344.52^{* * *}$ & \\
\hline D-W test value & 0.960 & & 1.023 & \\
\hline
\end{tabular}

These coeffients, the F-ratio and D-W test-value will be presented in all the regression tables.

2 Significance levels with t-test. The abbreviation applies to all regression tables.

${ }^{3 * * *}=$ Significance level for F-ratio $\leq 0.001 \%$. The abbreviation applies to all regression tables. 
Table 12. Linear production functions with public aggregate research. Output, capital, labour, external inputs measured at farm level, research and extension at aggregate level.

\begin{tabular}{lcccc}
\hline Regression & $(3)$ & & $(4)$ & s.l. \\
\hline Constant & & s.l. & -18.553 & 0.098 \\
& -19.053 & 0.091 & $(10.836)$ & \\
Capital & $(10.904)$ & & 1.061 & 0.000 \\
& 1.091 & 0.000 & $(0.119)$ & \\
Labour & $(0.117)$ & & -0.024 & 0.818 \\
& 0.031 & 0.738 & $(0.104)$ & \\
External inputs & $(0.093)$ & & -0.019 & 0.601 \\
& -0.023 & 0.531 & $(0.036)$ & \\
Public aggregate & $(0.036)$ & & 0.040 & 0.101 \\
research & 0.046 & 0.053 & $(0.024)$ & \\
Extension & $(0.023)$ & & 0.090 & 0.243 \\
& & & $(0.075)$ & \\
$\mathrm{R}^{2}$ & & & 0.997 & \\
Stand.error of estimate & 0.997 & & 5.267 & \\
F-ratio & 5.303 & & $1902.1^{* * *}$ & \\
D-W test value & $2344.6^{* * *}$ & & 1.164 & \\
\hline
\end{tabular}

to be rather high, the values varying between 1.08 and 1.28 . The inclusion of a trend factor in the regressions did not improve the coefficient of determination.

Figure 16 shows how the regression line of regression (2) fits the observations. From the Figure it is evident that autocorrelation occurs. In Figure 17 the distribution of residuals for regression (2) is presented.

The parameter estimate of the research variable is of particular interest in this study. The size of the estimate is approximately the same in the aggregate regressions, $0.016-0.018$. The level of significance for this estimate varies from 0.154 to 0.200 thus not being significant.

Table 12 shows that when models with the traditional variables specified at farm level were estimated, the coefficient of determination rose to 0.997 , while the standard errors of the estimates rose to approximately 5.3. The residuals are autocorrelated to a slightly lesser degree than in Table 11. The parameter estimates of the research variable gain confidence, being modestly significant and clearly higher, ranging from 0.040 to 0.046 . The parameter esimate of external inputs is still negative, and after the inclusion of the extension factor the sign for the parameter estimate of labour also becomes negative. The interpretation of the parameter estimates of traditional variables must be treated differently when defined at farm level. The parameter estimate of research has the same interpretation, since it is defined at aggregate level in both cases. The observed values and the corresponding values estimated by regression (4) are illustrated in Figure 18.

The results of the regressions including a total research variable differ somewhat from the previous results (see Appendices 6 and 7). The parameter estimates of labour are higher than in Tables 11 and 12, with a better significance. When traditional inputs are specified at aggregate level, the parameter estimate of total research varies from 0.022 to 0.025 , with a clearly higher significance $(0.057$ and 0.102 ) than in regressions (1) and (2). When traditional variables are specified at farm level, the parameter estimate of research rises to 0.054 and respectively, 0.047 and the parameter significance increases to 0.020 , 


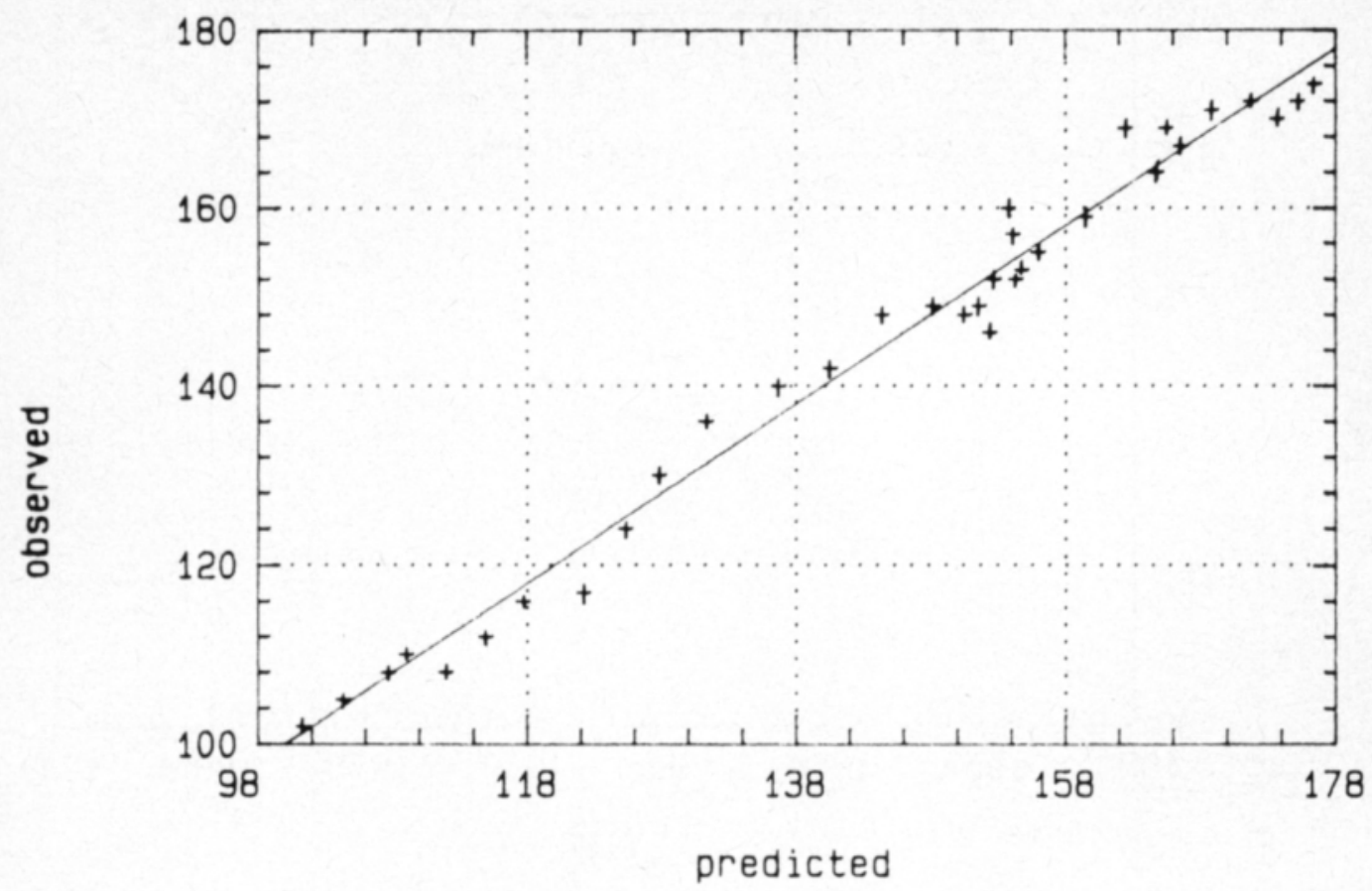

Fig. 16. Regressions for the linear model (2).

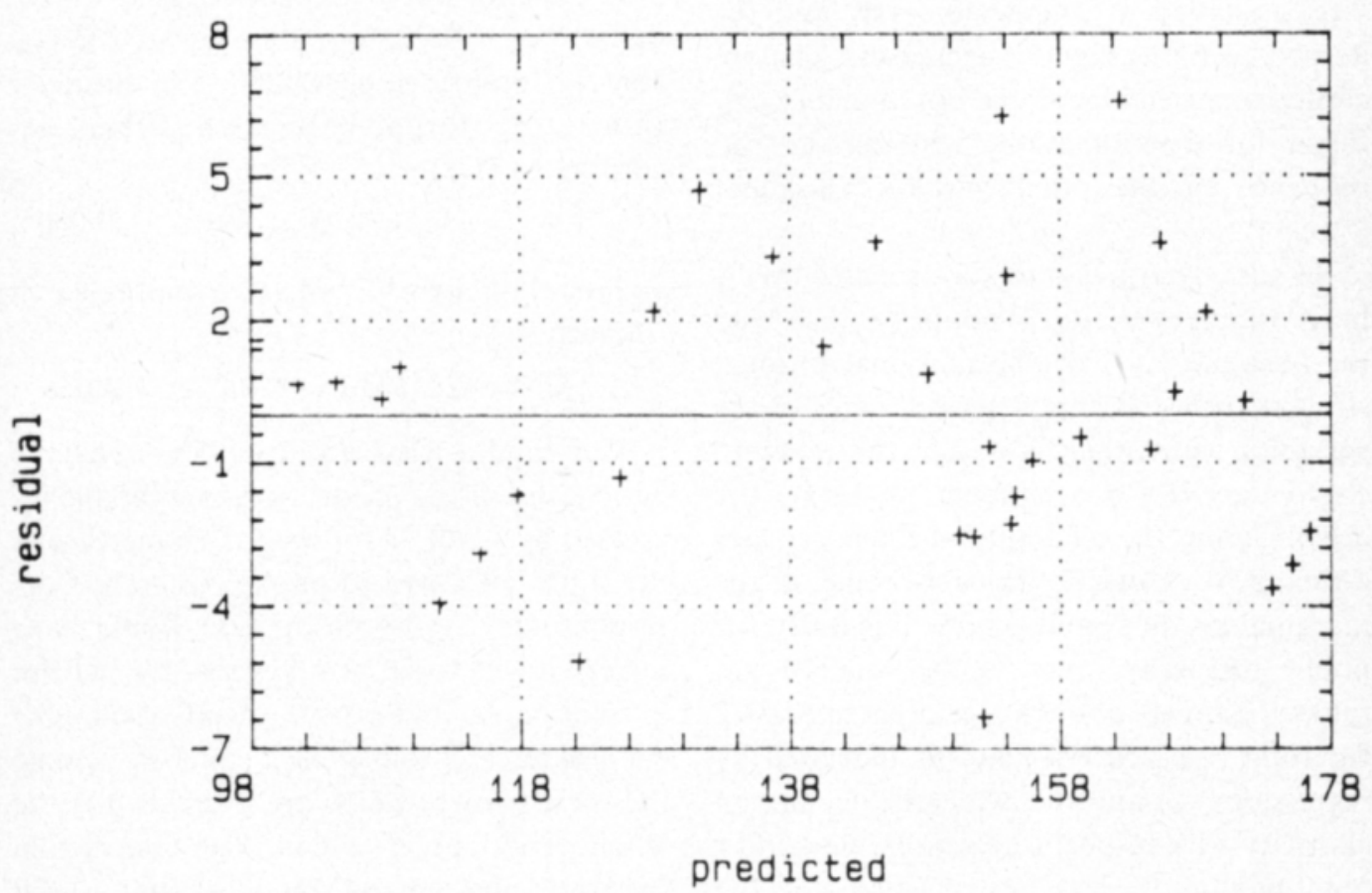

Fig. 17. Residuals for the linear model (2). 


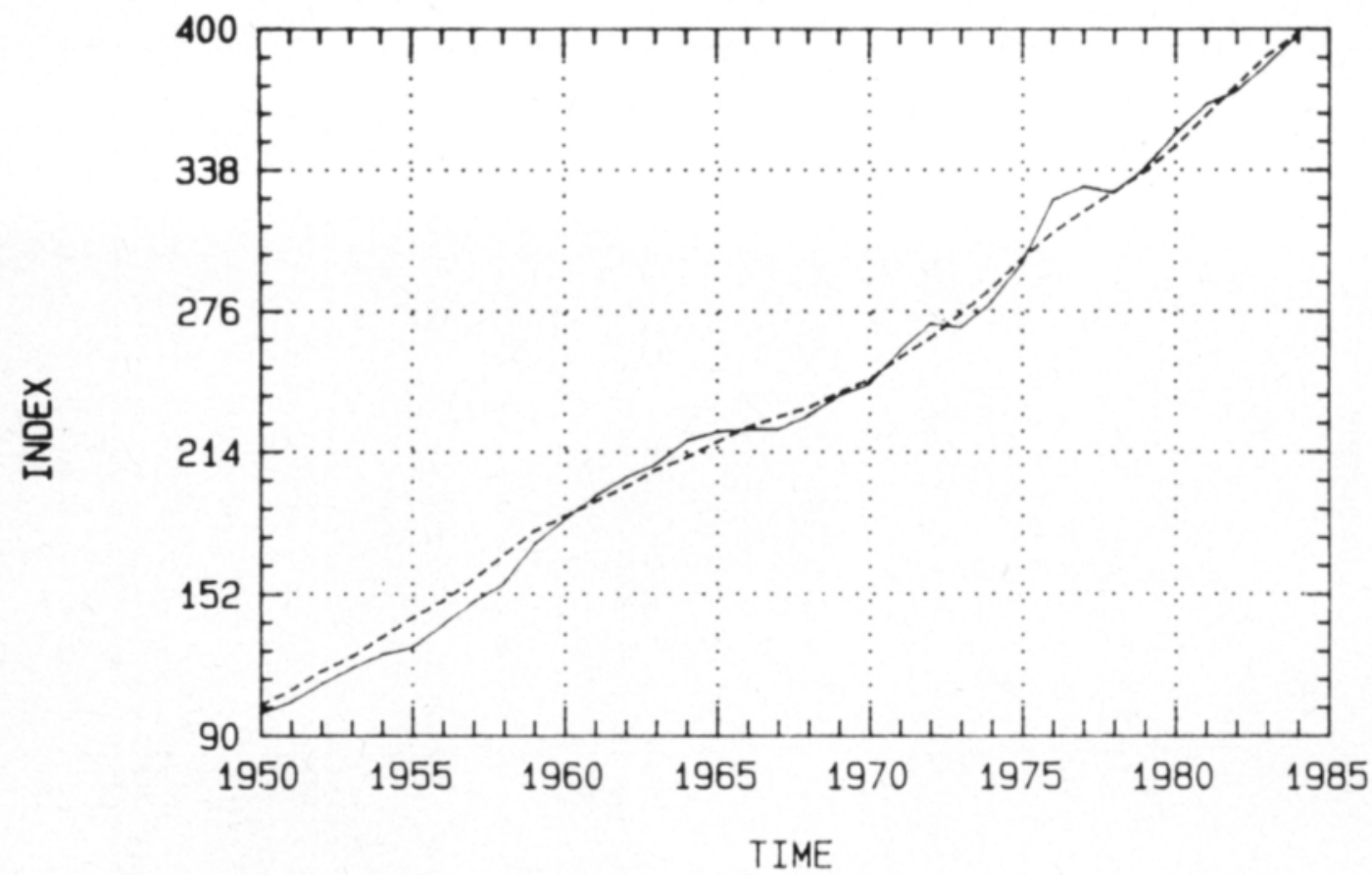

Fig. 18. Observed values of production and corresponding values estimated by regression (4) (dotted line).

and respectively, 0.067 . The coefficient of determination rises to 0.997 , compared with $0.983-0.984$ when the traditional variables were specified at aggregate level, and the autocorrelation slightly decreases. The inclusion of a trend factor did not raise the coefficient of determination, whereas the significance of the other variables becomes lower.

Because the regressions are estimated on the basis of index series, it is not possible to read the absolute level of the marginal product straight from the parameter estimates of the variables; rather they have to be changed into elasticities. If for a moment we forget the doubts about the reliability of the parameter estimate of research, which is equal to the marginal product, and assume it is 0.016 for public research, which is the smallest parameter estimate of public research, and 0.022 for total research estimate, as indicated by regressions (2) and (6), we can calculate an elasticity with respect to research input. For the function $y=f(x)$, the elasticity of the change in $\mathrm{y}$ to changes in $\mathrm{x}$ is given by:
(5.1) $\quad E=\frac{d y}{y}: \frac{d x}{x}=\frac{x}{y} \times \frac{d y}{d x}=\frac{x}{y} \times b$

The average for gross production in the index series is 143.03 , for public research 354.00 and for total research 428.00 . The elasticity with respect to public research is then, according to (5.1):

$$
\mathrm{E}_{\mathrm{p}}=354 / 143.03 \times 0.016=0.040
$$

and the elasticity with respect to total research similarly:

$$
E_{1}=428 / 143.03 \times 0.022=0.066
$$

This implies that during 1950-1984 the agricultural gross production would have increased by $0.040 \%$ for every $1 \%$ increase in the funds allocated to public research. Correspondingly, gross production would have increased with $0.066 \%$ for every $1 \%$ increase in total public and private spending on agricultural research. To make it easier we assume these elasticities, which are averages for the whole period, to be valid in 1984 . Subtracting the State subsidies and compensations as well as outdoor production from the gross produc- 
tion in agriculture in 1984, one obtains FIM $19,403.9$ million as the value of gross production. Since the public funds for research were FIM 157.0 million and total public and private research spending was FIM 230.1 million a preliminary value marginal product can be computed according to expression (6.2).

Public research: VMP $=$

$$
\frac{0.040 \% \times \text { FIM 19,403.9 million }}{1 \% \times \text { FIM } 157.0 \text { million }}=4.94
$$

Total research: VMP =

$$
\frac{0.066 \% \times \text { FIM 19,403.9 million }}{1 \% \times \text { FIM } 230.1 \text { million }}=5.57
$$

In case the reservations made concerning the linear production function are accepted and the elasticities with respect to public and total research are valid, a value marginal product of 4.94 for public research and 5.57 for total research is obtained. This means that every additional FIM allocated to public research would return as an annual value of FIM 4.94. Similarly total private and public research would yield a return of FIM 5.57 for an additional increase of FIM 1 in research spending. This is clearly not the true value marginal product, since the costs of extension not have been included, no lags are accounted for, and research expenditures are undervalued on the part of total research. Despite these deficiencies, the very high value marginal products still gives some preliminary information about the returns from research.

\subsubsection{Cobb-Douglas Models without Lags}

The Cobb-Douglas function is the most common form of the production function used in estimating the returns to research. The estimates of the parameters in (3.9) are presented in Tables 13 and 14. According to a well-known theorem in price theory, the exponent in the Cobb-Douglas function is equal to the production elasticity of that input. The parameter estimates of the variables should therefore be interpreted as elasticities.

The coefficient of determination is 0.984 in regression (9) and increases to 0.986 when extension is added. The total variation explained is thus slightly higher than in the linear regression. The inclusion of a trend factor did not improve the coefficient of determination. The standard errors of estimates lie in the

\begin{tabular}{|c|c|c|c|c|}
\hline \multirow[t]{2}{*}{ Regression } & \multirow[t]{2}{*}{ (9) } & \multirow[b]{2}{*}{ s.l. } & \multirow[t]{2}{*}{ (10) } & \multirow[b]{2}{*}{ s.l. } \\
\hline & & & & \\
\hline Constant & $\begin{array}{r}-0.343 \\
(0.926)\end{array}$ & 0.714 & $\begin{array}{c}0.026 \\
(0.906)\end{array}$ & 0.977 \\
\hline Capital & $\begin{array}{l}0.902 \\
(0.305)\end{array}$ & 0.007 & $\begin{array}{c}0.765 \\
(0.303)\end{array}$ & 0.017 \\
\hline Labour & $\begin{array}{c}0.043 \\
(0.024)\end{array}$ & 0.085 & $\begin{array}{c}0.008 \\
(0.030)\end{array}$ & 0.800 \\
\hline External inputs & $\begin{array}{c}0.064 \\
(0.094)\end{array}$ & 0.503 & $\begin{array}{c}0.064 \\
(0.090)\end{array}$ & 0.483 \\
\hline $\begin{array}{l}\text { Public aggregate } \\
\text { research }\end{array}$ & $\begin{array}{c}0.059 \\
(0.037)\end{array}$ & 0.120 & $\begin{array}{c}0.034 \\
(0.037)\end{array}$ & 0.374 \\
\hline Extension & & & $\begin{array}{c}0.121 \\
(0.062)\end{array}$ & 0.061 \\
\hline $\mathbf{R}^{2}$ & 0.984 & & 0.986 & \\
\hline Stand.error of estimate & 0.024 & & 0.023 & \\
\hline F-ratio & $452.16^{* * *}$ & & $396.29 * * *$ & \\
\hline D-W test value & 1.039 & & 1.106 & \\
\hline
\end{tabular}

Table 13. Cobb-Douglas production functions with public research. All variables measured at aggregate level. 
Table 14. Cobb-Douglas production functions with public research. Output, capital, labour, external inputs measured at farm level, research and extension at aggregate level.

\begin{tabular}{|c|c|c|c|c|c|c|}
\hline \multirow[t]{2}{*}{ Regression } & \multirow[t]{2}{*}{ (11) } & \multicolumn{3}{|c|}{ (12) } & \multirow[t]{2}{*}{ (13) } & \multirow[b]{2}{*}{ s.l. } \\
\hline & & s.l. & & s.l. & & \\
\hline Constant & $\begin{array}{r}-0.418 \\
(0.336)\end{array}$ & 0.223 & $\begin{array}{c}-0.225 \\
(0.350)\end{array}$ & 0.526 & $\begin{array}{r}-0.560 \\
(0.381)\end{array}$ & 0.152 \\
\hline Capital & $\begin{array}{c}0.933 \\
(0.142)\end{array}$ & 0.000 & $\begin{array}{c}0.853 \\
(0.147)\end{array}$ & 0.000 & $\begin{array}{c}0.947 \\
(0.150)\end{array}$ & 0.000 \\
\hline Labour & $\begin{array}{c}0.057 \\
(0.027)\end{array}$ & 0.042 & $\begin{array}{c}0.044 \\
(0.027)\end{array}$ & 0.118 & $\begin{array}{c}0.010 \\
(0.031)\end{array}$ & 0.762 \\
\hline External inputs & $\begin{array}{c}0.095 \\
(0.079)\end{array}$ & 0.241 & $\begin{array}{c}0.088 \\
(0.094)\end{array}$ & 0.266 & $\begin{array}{c}0.035 \\
(0.079)\end{array}$ & 0.663 \\
\hline Public research & & & $\begin{array}{c}0.059 \\
(0.037)\end{array}$ & 0.121 & $\begin{array}{c}0.018 \\
(0.041)\end{array}$ & 0.661 \\
\hline Extension & & & & & $\begin{array}{r}0.107 \\
(0.057)\end{array}$ & 0.070 \\
\hline$R^{2}$ & 0.997 & & 0.997 & & 0.997 & \\
\hline Stand.error of estimate & 0.025 & & 0.024 & & 0.023 & \\
\hline F-ratio & 3026.5 & & $2383.7^{* * *}$ & & $2068.8^{* * *}$ & \\
\hline D-W test value & 0.833 & & 1.011 & & 0.990 & \\
\hline
\end{tabular}

range of 0.024 . The level of significance for the F-value is less than $0.001 \%$, indicating a strong linear-logarithmic relation between the whole group of explanatory variables and the independent variable. The Durbin-Watson test value shows a heavy autocorrelation also for the Cobb-Douglas function.

The parameter estimate of capital is significant and seems to be high, $0.77-0.90$. The parameter estimate of labour is relatively significant in regression (9) but becomes insignificant when the extension factor is added. The parameter estimate of external inputs has the same value in both regressions, 0.064 , but is clearly insignificant. The parameter estimate of the research variable is almost significant at the $10 \%$ level in (9), but confidence decreases when the significant variable extension is added. The total sum of parameter estimates for the explaining variables is 1.068, and respectively 0.992 , which does not indicate economies of scale. This could be expected, since farm size has increased during the period studied only to a relatively small degree.

Although the sum of the parameter estimates appears acceptable, one could question the size of the parameter estimate for capital.
Because of the multicollinearity, the capital estimate could erroneously be attributed to some influence originating from one of the other factors. Some experiments with ridge regressions (see section 5.1.4.) suggest this to be the case.

The coefficient of determination rises to 0.997 when specifying the traditional variables on farm level in the Cobb-Douglas model (the same happened in the linear model). The most notable difference is that the regression coefficient for research falls from 0.059 in (12) to 0.018 when extension is added (in 13). There is not a big difference in most other measures. Remarkable, however, is that the coefficient of determination is 0.997 even before the research coefficient is added. This shows that the research coefficient does not improve the explanatory power of the model when the traditional inputs are defined on farm level.

Regressions (14) and (15), which include a variable for total public and private research with the traditional variables specified at aggregate level, are presented in Appendix 8. The regression coefficients do not differ much from the regressions measuring only public research. The parameter estimate of total re- 
search is, as could be expected, somewhat greater and slightly more significant than the coefficient for only public research. It is 0.078 (s.l. 0.079), respectively 0.050 (s.1. 0.261 ), depending on whether or not the extension factor is included.

Regressions (16) and (17) measuring the traditional production factors on farm level are presented in Appendix 9. Compared to the regressions measuring research with the public funds, differences can be noted in the size of the coefficients for external inputs and for research. The regression coefficient for total research is 0.061 (s.l. 0.089 ) respectively 0.021 (0.602).

The following summary of the size and significance levels of the research variable can be made: The public research elasticity for the linear production function is $0.040-0.044$ when transformed from the marginal product in regressions (1) and (2). When the traditional variables are measured at farm level in regression (3) and (4), the estimate of elasticity with respect to public research becomes $0.099-$ 0.114 . Both the latter research elasticity estimates in the linear production function are accepted at a confidence level of at least $90 \%$. In the Cobb-Douglas function the elasticity with respect to research in (9) and (10) varies between 0.034 and 0.059 , and in (12) and (13) between 0.018 and 0.059 . The marginal product of 0.016 was transformed according to (5.1) to an elasticity of 0.040 . This was used as a crude estimate to compute a value marginal product of $494 \%$ for public research. The estimate cannot, however, be taken seriously because of lack of reliability owing to autocorrelation problems, intercorrelation between explanatory variables and positive bias because of the omission of all lags.

In the linear production functions the coefficient of total research can be transformed into an elasticity of $0.066-0.075$ when traditional inputs are measured in aggregate, and an elasticity of $0.14-0.16$ when traditional inputs are measured at farm level. The inclusion of a significant extension factor decreases the elasticity to a certain degree. The higher the elasticity is, the better the significance level appears to be (for an estimate of the elasticity with respect to total research, 0.16 , the corresponding confidence is almost $98 \%$ ). Cobb-Douglas functions give the corresponding elasticities of $0.050-0.078$ (traditional variables specified at aggregate level) and $0.021-0.061$ (at farm level). The estimates of elasticity with respect to total research seem to be higher than the estimates of elasticity with respect to public research, but this is perfectly logical since total research also include private research in addition to the public funds. The same serious limtations mentioned in connection with the public research estimates concern the reliability of these nonlagged total research coefficients.

\subsubsection{Multicollinearity and Ridge Analysis}

One of the most common difficulties occurring in time series analysis is intercorrelation between the explaining variables. This study was no exception. When the internal correlation between the regressors was examined, a strong multicollinearity could be observed for both the linear variables and their logarithmic transformations. The correlation matrix for the variables is illustrated in Table 15.

All of the explaining variables except extension show a high linear relationship. Capital, labour, external inputs and public research correlate by more than 0.90 . Public research correlates $0.77-0.96$ with the other regressors (and, naturally, the total public and private research do so as well). The correlation between the dependent variable and the explaining variables on the contrary, forms the basis of the whole regression analysis. The internal correlation between the regressors, however, probably leads to unstable coefficients, which implies that the real values may be substantially different.

To examine further the internal correlation between the logarithmic transformations of the variables their correlation matrix are shown in the next Table 16. 
Table 15. Correlation matrix for the variables,

\begin{tabular}{|c|c|c|c|c|c|c|}
\hline \multirow[t]{2}{*}{ Variable } & \multirow{2}{*}{$\begin{array}{c}\text { Dependent } \\
\text { variable } \\
\text { Y }\end{array}$} & \multicolumn{5}{|c|}{ Regressors X } \\
\hline & & Capital & Labour & $\begin{array}{c}\text { External } \\
\text { inputs }\end{array}$ & $\begin{array}{l}\text { Public } \\
\text { research }\end{array}$ & Extension \\
\hline Output & 1.000 & & & & & \\
\hline Capital & 0.990 & 1.000 & & & & \\
\hline Labour & -0.909 & -0.929 & 1.000 & & & \\
\hline External inputs & 0.963 & 0.977 & -0.967 & 1.000 & & \\
\hline Public research & 0.944 & 0.948 & -0.935 & 0.962 & 1.000 & \\
\hline Extension & 0.877 & 0.862 & -0.659 & 0.785 & 0.775 & 1.000 \\
\hline
\end{tabular}

Table 16. Correlation matrix for the logarithms of the variables

\begin{tabular}{|c|c|c|c|c|c|c|}
\hline \multirow[t]{2}{*}{ Variable } & \multirow{2}{*}{$\begin{array}{c}\text { Dependent } \\
\text { variable } \\
\text { Y }\end{array}$} & \multicolumn{5}{|c|}{ Regressors X } \\
\hline & & Capital & Labour & $\begin{array}{c}\text { External } \\
\text { inputs }\end{array}$ & $\begin{array}{l}\text { Public } \\
\text { research }\end{array}$ & Extension \\
\hline Output & 1.000 & & & & & \\
\hline Capital & 0.990 & 1.000 & & & & \\
\hline Labour & -0.848 & -0.873 & 1.000 & & & \\
\hline External inputs & 0.982 & 0.993 & -0.899 & 1.000 & & \\
\hline Public research & 0.976 & 0.979 & -0.872 & 0.972 & 1.000 & \\
\hline Extension & 0.903 & 0.882 & -0.622 & 0.854 & 0.878 & 1.000 \\
\hline
\end{tabular}

No major difference can be noticed between the ordinary expressions of the variables and their logarithmic tranformations. The reason why extension is less correlated with the other variables is probably because it has been derived by interpolation with five-year intervals for the period 1950-1970.

The strong correlation between the regressors introduce some heavy doubts about the reliability of the estimated parameters. The estimates may have the wrong sign, or may be of completely wrong size. Methods to investigate multicollinearity have been developed, however. One such method is ridge analysis. An overview of ridge analys is given in Draper and SMith (1981), while a shorter summary is found in FomBy et al. (1984). The original presentation was made by Hoerl and Kennard in 1970.

The ridge procedure is intended for situations where the correlation between regressors causes the $\mathrm{X}^{\prime} \mathrm{X}$ matrix to be close to singular, thereby giving rise to unstable parameters which are unreasonably high or have the wrong sign. By introducing a slight bias the parameters may, in case of correlated independent variables, be closer to the true parameters than the unbiased ordinary least squares (OLS) estimates. The ridge parameter $\theta$ (theta) is allowed to control the bias.

The normal equations in the OLS procedure are given by

$$
X^{\prime} X \beta=X^{\prime} y
$$

and

$$
\text { (5.3) } \quad \mathrm{b}=\left(\mathrm{X}^{\prime} \mathrm{X}\right)^{-1} \mathrm{X}^{\prime} \mathrm{y}
$$

In the ridge procedure the ridge parameter $\theta \geq 0$ is introduced as follows

$$
\text { (5.4) } b(\theta)=\left(X^{\prime} X+\theta I\right)^{-1} X^{\prime} y
$$

In applications the interesting numbers of $\theta$ are usually found in the range of 0.1 , though values up to 1.0 are used. When $\theta=0$ the resulting ridge estimator is the same as the OLS estimator. For different values of $\theta$ we can 
plot different values of the estimates, i.e. we can plot a ridge trace to enable a direct comparision to be made between the relative effect of the various coefficients. As $\theta$ is increased the estimates become smaller in absolute value, tending to zero in infinity. At a certain value of $\theta$ the system will stabilize and have the general characteristics of an orthogonal system. Cofficients with incorrect signs will change to become correct (DrAPER and Sмгтн 1981).

According to Draper and Smith, blind use of ridge regression can be dangerous and misleading. They suggest two cases for which it is absolutely correct to use ridge regressions in spite of the subjective element involved (the choice of $\theta$ ). The first is when prior knowledge (or belief) exist that smaller values of the estimates are more likely than larger ones. If a small value is used for $\theta$ it means that we believe the OLS is not producing unreasonably big values. The second case we need not deal with here. We note two dangers involved in ridge regressions:

1. Are we really sure about the prior knowledge of too high coefficients?

2. The nonsignificant estimated regression coefficients change to a greater extent than the significant estimated coefficients.

On the basis of the OLS estimates presented in subsections 5.1.1 and 5.1.2., prior questions on the size of the capital estimate could have been raised. In the linear production function, the estimate of capital (the marginal product) was slightly above or below 1.00 . In the Cobb-
Douglas functions the estimate (the elasticity) was approximately $0.7-0.9$. This is rather much, as the sum of elasticities not should exceed 1.00 in the case of constant returns to scale over time. The external inputs had a negative sign in many cases. This prior knowledge makes it reasonable to believe that the capital coefficient is likely to be too high.

The aim of our use of the ridge regressions is still a different. We can hypothetisize that the estimated research elasticities are too high as a consequence of the intercorrelation between explaining variables. If this is the case their value should drop in ridge regressions. Our actual purpose in doing this is, however, the opposite. If the values of the research coefficients do not fall, it means that the estimates of research are not overvalued because of multicollinearity. If this holds true, we do not speculate whether the estimates are too low, but simply accept the estimates as not being overestimated. This means that ridge regressions are not used in order to produce new biased estimates but are used to investigate in which direction the serial correlation affects the elasticity of research.

In order to avoid the second danger outlined above, parameters which are insignificant to a large degree should not be tested. The significance determined by the t-test is a partial guide as to which of the regressions should be analysed. In the OLS regressions chosen for investigation by ridge regressions, the significance of the research coefficient (public or total) was according to Table 17:

Table 17. Research coefficient and significance level for different regressions.

\begin{tabular}{llcc}
\hline Regression & $\begin{array}{l}\text { Traditional } \\
\text { variables }\end{array}$ & $\begin{array}{c}\text { Research } \\
\text { coefficient }\end{array}$ & Significance \\
\hline (1) linear & aggregate & 0.018 & 0.154 \\
(4) linear & per farm & 0.040 & 0.101 \\
(5) linear & aggregate & 0.025 & 0.057 \\
(9) Cobb-Douglas & aggregate & 0.059 & 0.120 \\
(10) Cobb-Douglas & aggregate & 0.034 & 0.374 \\
(12) Cobb-Douglas & per farm & 0.059 & 0.121 \\
(14) Cobb-Douglas & aggregate & 0.078 & 0.079 \\
\hline
\end{tabular}


a)
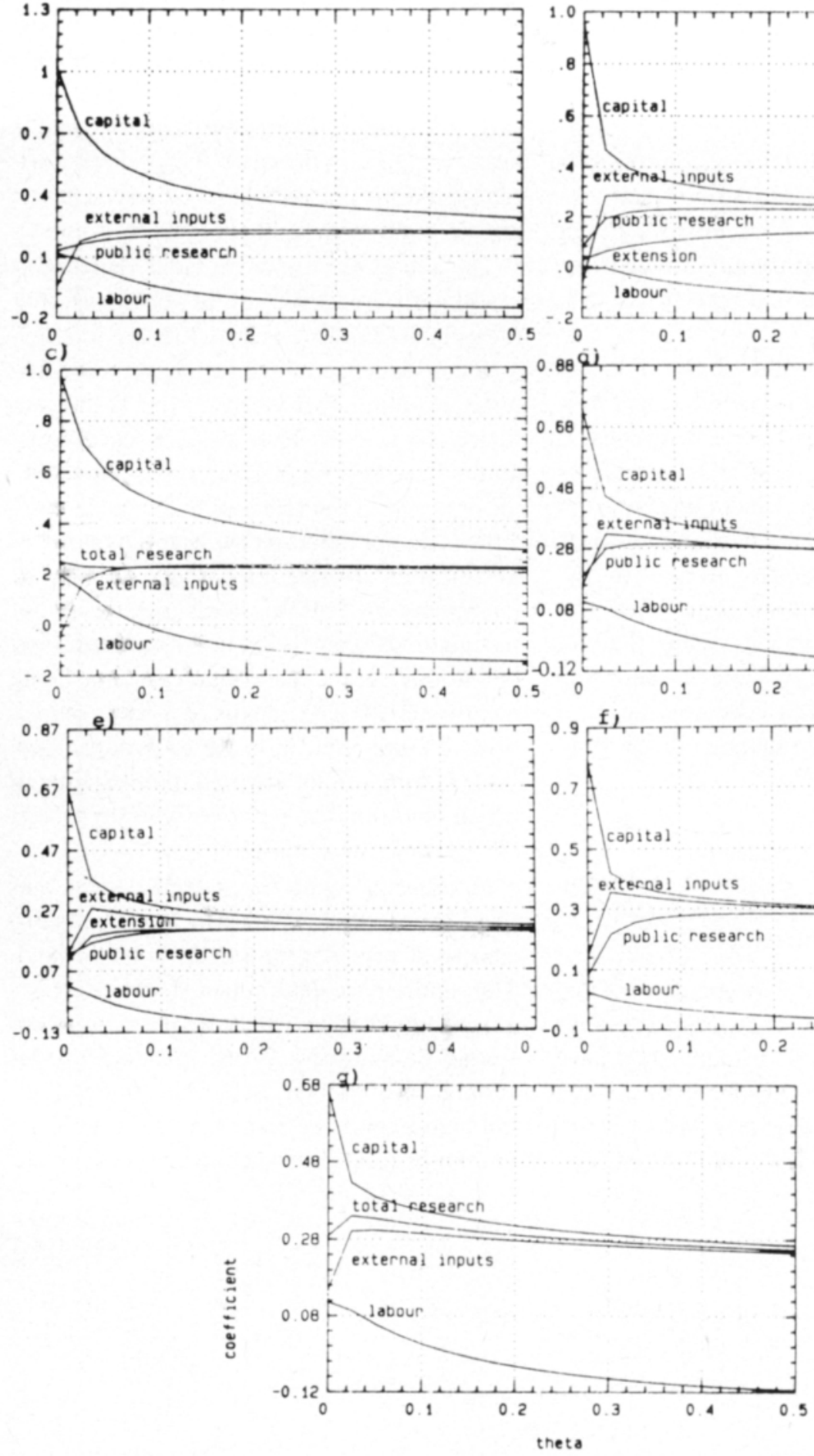

Fig. 19. Ridge traces. Horizontal axis value for ridge parameter theta, vertical axis corresponding values for the coefficients. The ridge regressions correspond to the following OLS regressions: $a)=(1), b)=(4)$, c) $=(5), d)=(9), e)=(10), f)=(12), g)=(14)$.

b)
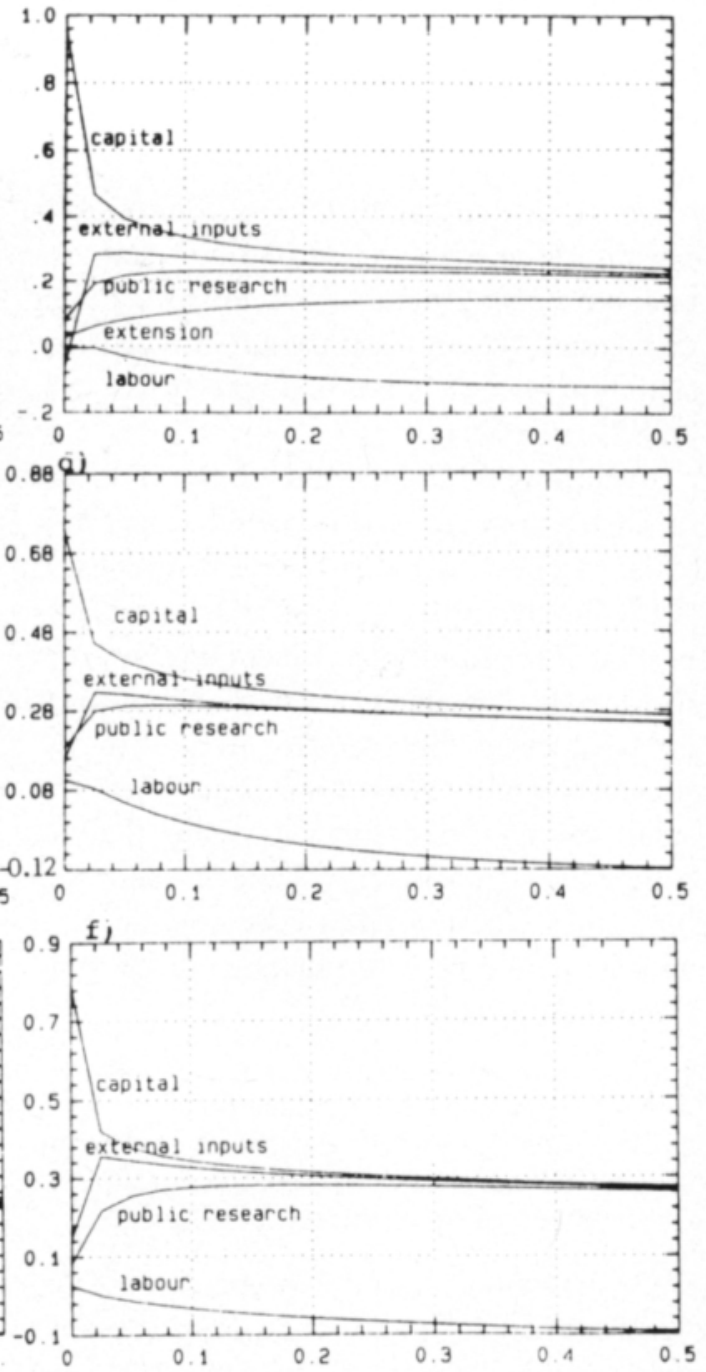
Table 18. The research coefficient by OLS and by ridge regressions.'

\begin{tabular}{lccccccc}
\hline & \multicolumn{7}{c}{ Regression } \\
\cline { 2 - 7 } & $(1)$ & $(4)$ & $(5)$ & $(9)$ & $(10)$ & $(12)$ & $(14)$ \\
\hline OLS & 0.018 & 0.040 & 0.025 & 0.059 & 0.034 & 0.059 & 0.078 \\
Ridge parameter & & & & & & & \\
$\theta=0.000$ & 0.132 & 0.080 & 0.249 & 0.189 & 0.108 & 0.082 & 0.289 \\
$\theta=0.025$ & 0.164 & 0.192 & 0.229 & 0.280 & 0.178 & 0.217 & 0.341 \\
$\theta=0.050$ & 0.185 & 0.217 & 0.226 & 0.293 & 0.191 & 0.253 & 0.333 \\
$\theta=0.100$ & 0.204 & 0.230 & 0.225 & 0.294 & 0.199 & 0.277 & 0.317 \\
\hline
\end{tabular}

I "Statgraphics", the data program used here, standardizes and centers all variables at the same time so that the resulting estimates differ from the OLS for $\theta=0$ (the values for $\theta=0$ should be equal to the OLS). This will not affect its use here, since only the development of $\theta$ is relevant, not the absolute values of $\theta$.

Next these seven different ridge traces for the unlagged production functions earlier estimated are examined. It should be noted that the elasticities are not directly comparable, since the interpretation differ for the various regressions.

\subsubsection{Ridge Traces}

The seven regressions chosen for ridge analysis are presented in Figure 19. As $\theta$ increases, the effects of multicollinearity decreases at the same time as the bias of the estimates increases. The estimates decrease, tending to zero in infinity. For values on $\theta \leq 0.05$ the coefficients change rapidly, stabilizing at $\theta=0.05$ or slightly less. After this the increased effects of the bias can be seen in sinking curves. Obviously the critical values for $\theta$ should lay between 0 and 0.05 . As was mentioned earlier, values of $\theta \geq 1.00$ are seldom used because of the stronger bias.

A general feature of all the figures is the fall in the regression coefficients of capital and labour. The prior belief that the capital coefficient is too big is supported by the ridge traces. It is difficult to understand that the coefficient of labour in some regressions becomes negative for $\theta \geq 0.05$ or even less. Obviously, values of $\theta \geq 0.05$ should be considered critically and with caution. The external inputs seem to increase and turn from negative (in some of the OLS regressions) to positive.
The estimate of the research parameter does not change much. In all regressions except (5) (where it stays almost constant) it increases slightly. Taking into account the purpose of the ridge analysis stated in the preceding section, it is now possible to draw a conclusion: rather small values for the ridge parameter $\theta$ show that the internal correlation between explanatory variables does not lead to overestimated coefficients of the research parameter.

Table 18 gives the ridge estimates a numerical description.

The trend in the development of the research coefficient is that it grows as the bias increases. The coefficient starts to decrease when the bias becomes sufficiently large.

The use of ridge analysis may be subject to criticism. Taking into account what has been stated above, it is put to careful use here; it is not, e.g. used to produce separate elasticities. Still we cannot be completely sure whether or not the multicollinearity is a problem. But at least the incidence given by ridge analysis shows that the multicollinearity need not be problematic.

\subsubsection{Autocorrelated Errors and Autoregressive Models}

The models (3.9) and (3.10) are based on the assumptions stated in section 3.4. One of these assumptions was that errors were not serially correlated. In case such autocorrelation occurs, the coefficient may be overes- 
timated or underestimated. The results of the estimation show that this basic assumption was erroneous. A misspecification of the model results in autocorrelation, which may depend on the omission of variables or an incorrect form of the production function. Because of the wrong specification, some of the information appears as serial correlation in the errors. The Durbin-Watson test value in the flow models with no lags varied from 0.96 to 1.16 , thus showing substantial autocorrelation.

The autocorrelation is further examined through the use of autoregressive models. In these models the correlation in the errors is used to explain the variation in the dependent variable.

If the basic form of the Cobb-Douglas function is

$$
Q=A L^{b_{i}} K^{b_{k}} I^{b_{i}} R^{a} N^{o}+\varepsilon_{t}
$$

where the number of observations is t, the simplest assumption on the form of correlation between errors is

(5.6) $\varepsilon_{\mathrm{t}}=\theta \varepsilon_{\mathrm{t}-1}+\mathrm{v}_{\mathrm{t}} \quad \theta \leq \theta \leq 1$ where $\mathrm{v}_{\mathrm{t}}$ is normally distributed $\mathrm{N}\left(0, \sigma^{2}\right)$ and not dependent on other errors. In this autoregressive model of first order, the residuals $\varepsilon_{t}$ in the period $t$ are explained only with the use of the residuals in the preceding period $\mathrm{t}-1$ (times $\theta$ ) and a and a random variable $v_{1}$. Instead of using only a single residual, $\varepsilon_{t}$ can be explained by a larger number of residuals located further back in time:

$$
\begin{aligned}
& \varepsilon_{\mathrm{t}}=\theta_{1} \varepsilon_{\mathrm{t}-1}+\theta_{2} \varepsilon_{\mathrm{t}-2}+\ldots \\
& +\theta_{\mathrm{t}} \varepsilon_{\mathrm{t}-\mathrm{p}}+\mathrm{v}_{\mathrm{t}}
\end{aligned}
$$

A model like (5.7) is called an autoregressive model of order p. In order to determine whether the influence on the serial correlation of the residuals decreases, autoregressive Cobb-Douglas models of first and second order were applied.

Table 19 shows results for the first order and Table 20 those for the second order models for public research. The autocorrelation diminishes considerably compared to the normal OLS regressions (9) and (10). In the first order models the Durbin-Watson test value increases to approximately 1.75 . In the

Table 19. First order autoregressive Cobb-Douglas production functions with public research. All variables measured at aggregate level.

\begin{tabular}{lcccc}
\hline Regression & $(18)$ & & $(19)$ & s.l. \\
\hline Constant & & s.l. & -1.550 & 0.241 \\
& -2.037 & 0.087 & $(1.295)$ & \\
Capital & $(1.151)$ & & 1.246 & 0.003 \\
& 1.398 & 0.000 & $(0.384)$ & \\
Labour & $(0.330)$ & & 0.026 & 0.535 \\
& 0.044 & 0.207 & $(0.041)$ & \\
External inputs & $(0.034)$ & & -0.014 & 0.877 \\
& -0.025 & 0.779 & $(0.091)$ & \\
Public aggregate & $(0.090)$ & & 0.010 & 0.771 \\
research & 0.013 & 0.694 & $(0.033)$ & \\
Extension & $(0.032)$ & & 0.060 & 0.464 \\
& & & $(0.081)$ & \\
$\theta_{1}$ & & 0.500 & 0.002 \\
R & 0.519 & 0.001 & $(0.149)$ & \\
Stand.error of estimate & $(0.147)$ & & 0.988 & \\
F-ratio & 0.986 & & 0.020 & \\
D-W test value & 0.020 & & $451.22^{* * *}$ & \\
\hline
\end{tabular}


Table 20. Second order autoregressive Cobb-Douglas production functions with public research. All variables measured at aggregate level.'

\begin{tabular}{lcccc}
\hline Regression & $(20)$ & & $(21)$ & s.l. \\
\hline Constant & & s.l. & -0.640 & \\
& -0.875 & & $(0.896)$ & \\
Capital & $(0.913)$ & & 0.990 & $<0.002$ \\
& 1.088 & $<0.001$ & $(0.291)$ & \\
Labour & $(0.291)$ & & 0.011 & n.s. \\
& 0.033 & n.s. & $(0.033)$ & \\
External inputs & $(0.030)$ & & 0.030 & n.s. \\
& 0.047 & n.s. & $(0.089)$ & \\
Public aggregate & $(0.088)$ & & 0.014 & n.s. \\
research & 0.016 & n.s. & $(0.031)$ & \\
Extension & $(0.031)$ & & 0.092 & n.s. \\
& & & $(0.061)$ & \\
$\theta_{1}$ & & & 0.599 & $<0.001$ \\
& 0.685 & $<0.001$ & $(0.163)$ & \\
$\theta_{2}$ & $(0.161)$ & & -0.257 & n.s. \\
$R^{2}$ & -0.288 & $<0.100$ & $(0.163)$ & \\
Stand.error of estimate & $(0.161)$ & & 0.989 & \\
D-W test value & 0.989 & & 0.020 & \\
I S & 0.019 & & 1.980 & \\
\hline
\end{tabular}

1 n.s. = not significant. s.l. $>0.01$

autoregressions of second order it ranges from 1.91 to 1.98 , thereby indicating that practically all of the serial correlation is explained.

From the tables it is evident that the estimate of elasticity with respect to research decreases to $0.011-0.013$ in the first order models and to $0.014-0.016$ in the second order models. The significance also decreases. This should be compared with regressions (9) and (10), where the estimate was $0.034-0.059$. The coefficient of determination slightly increases. The regression coefficients of the residuals are big, about $0.05-0.07$ and significant, thus explaining a large part of the variations. It is evident, therefore that the explaining power of the error term is considerable, indicating a certain degree of misspecification in the basic model (3.9). It is still possible that some of the information in the errors is connected with the research coefficient. On the whole, the second order autoregressive models seem to have a better explanatory power, though none of the research coefficients in either model is significant.
In addition to the elasticity estimate with respect to research, the elasticity estimate with respect to extension decreases. The sign of external inputs shifts to negative in the first order models, which is hardly understandable, but changes to positive again in the second order models. The effects of intercorrelated variables should be the same as explained earlier.

Using autoregressive models on the research measure, total funds give much the same results as for public research (Appendices 10 and 11). The elasticity estimates with respect to total research decrease to $0.022-0.025$ in the autoregressions of first order and to $0.028-0.031$ in the autoregressions of second order, again with insignificant values. The influence of autocorrelation decreases in the first order autoregressions and virtually disappears in those of second order. Correspondingly, the coefficients of the residuals $\theta_{1}$ and $\theta_{2}$ are big, especially for the first one. The coefficient of determination reaches a level of 0.990 in (25). The inclusion of extension in the regressions changes the coef- 
ficients of neither public nor total research more than slightly.

To summarize the section, it is concluded that the elasticity estimate with respect to research decreases in the autoregressive models. The OLS estimates may therefore be overvalued because of serial correlation in the errors. In the autoregressive models the regression coefficients of research are between onehalf and one-fourth of the values in the OLS regressions. But because of the high regression coefficients of the residuals, which may include some information connected with the research variable, the estimates in this section are not necessarily more correct. The estimates in the autoregressive models are not necessarily closer to the real parameter values, but give an explanation where the influnce of serial correlation is not allowed to exert influence on the coefficients of the other parameters. What we have gained in this section is a picture of the possible effects of the autocorrelation.

\subsubsection{Cobb-Douglas Regressions for Shorter Periods}

In the preceding section unlagged elasticities with respect to research were estimated for the period 1950-1984. During the same period the funds for agricultural research have grown manifold. From this point of view the following question arise: How have the elasticity and value marginal product developed over time? Have the returns increased or decreased since the 1950s? Has the elasticity changed or has it stayed on the same level as previously even though more resources were allocated to research?

Cobb-Douglas functions were estimated for shorter periods of 20 years, i.e. 1950-1969 and 1965-1984. The estimates of the elasticity with respect to public research in Table 21 correspond to the regressions (9) and (10) in Table 13. The estimates of the elasticity with respect to total research in Appendix 12 correspond, in turn to regressions (14) and (15) in Appendix 8.

Table 21. Cobb-Douglas production functions with public research for shorter periods. All variables measured at aggregate level.

\begin{tabular}{|c|c|c|c|c|c|c|c|c|}
\hline Regression & $\begin{array}{c}(26) \\
1950-69\end{array}$ & s.l. & (27) & s.l. & $\begin{array}{c}(28) \\
1965-84\end{array}$ & s.1. & (29) & s.l. \\
\hline Constant & $\begin{array}{r}-2.497 \\
(1.697)\end{array}$ & 0.162 & $\begin{array}{r}-2.721 \\
(1.230)\end{array}$ & 0.044 & $\begin{array}{c}4.311 \\
(2.559)\end{array}$ & $\begin{array}{c}0.113 \\
(3.035)\end{array}$ & 4.351 & 0.174 \\
\hline Capital & $\begin{array}{c}1.231 \\
(0.450)\end{array}$ & 0.015 & $\begin{array}{c}1.216 \\
(0.325)\end{array}$ & 0.002 & $\begin{array}{c}0.089 \\
(0.555)\end{array}$ & 0.874 & $\begin{array}{c}0.079 \\
(0.699)\end{array}$ & 0.912 \\
\hline Labour & $\begin{array}{c}0.242 \\
(0.103)\end{array}$ & 0.034 & $\begin{array}{c}0.194 \\
(0.076)\end{array}$ & 0.023 & $\begin{array}{r}-0.087 \\
(0.070)\end{array}$ & 0.229 & $\begin{array}{r}-0.088 \\
(0.084)\end{array}$ & 0.309 \\
\hline $\begin{array}{l}\text { External } \\
\text { inputs }\end{array}$ & $\begin{array}{c}0.029 \\
(0.131)\end{array}$ & 0.828 & $\begin{array}{c}0.004 \\
(0.095)\end{array}$ & 0.965 & $\begin{array}{c}0.015 \\
(0.120)\end{array}$ & 0.905 & $\begin{array}{c}0.016 \\
(0.129)\end{array}$ & 0.906 \\
\hline Public research & $\begin{array}{c}0.034 \\
(0.052)\end{array}$ & 0.523 & $\begin{array}{r}-0.059 \\
(0.045)\end{array}$ & 0.215 & $\begin{array}{c}0.092 \\
(0.043)\end{array}$ & 0.050 & $\begin{array}{c}0.092 \\
(0.045)\end{array}$ & 0.059 \\
\hline Extension & & & $\begin{array}{c}0.235 \\
(0.061)\end{array}$ & 0.002 & & & $\begin{array}{c}0.003 \\
(0.096)\end{array}$ & 0.979 \\
\hline $\mathbf{R}^{2}$ & 0.977 & & 0.989 & & 0.920 & & 0.920 & \\
\hline $\begin{array}{l}\text { Stand.error } \\
\text { of estimate }\end{array}$ & 0.025 & & 0.018 & & 0.019 & & 0.020 & \\
\hline F-ratio & $160.65^{* * * *}$ & & $248.28 * * *$ & & $43.22^{* * *}$ & & $32.27^{* * * *}$ & \\
\hline D-W test value & 0.905 & & 1.425 & & 1.708 & & 1.711 & \\
\hline
\end{tabular}


It is interesting to note that the estimate of the elasticity with respect to research seems to have increased in the period studied. The estimate for the earlier period of 1950-1969 is insignificant and even becomes negative when extension is added. This negative sign is illogical and must be attributed to the inclusion of the extension variable. The estimate for the period 1965-1984 is significant, with a confidence of approximately $95 \%$. The latter period has a low coefficient of determination (0.92) and the error terms are not very serially correlated, as is the case for the whole period. The F-value for the whole model has dropped in the latter period, but is still significant at a level of $0.001 \%$.

We can compare the elasticities for the period 1965-1984, 0.092 with the ones for the whole period $1950-1984$, which were 0.059 and respectively 0.034 in Table 13. Taking into account the sixfold rise in research input, it should not be surprising to find that the elasticity has increased over time. The low tvalues of regressions (26) and (27), however, limit our conclusions, so that it is not possible to compute a reliable value marginal product for the period 1950-1969.

Contrary to the research coefficient, the table shows significant parameter estimates for capital, labour and extension in the period 1950 - 1969 and insignificant estimates for the period 1965-1984. The sign of labour becomes negative for the latter period. If any conclusion could be drawn on the basis of Table 28, it is that research has taken over part of the importance as a production factor earlier possessed by capital and labour.

Interpretation of the total research regressions (see Appendix 12) are much similar to Table 21. Many of the coefficients are again insignificant, and some of them have illogical signs. The elasticity estimate with respect to total research seems to increase, as did the public research estimate. A negative sign appears again in the earlier period. The elasticities with respect to capital and labour once more seem to decrease, as does extension. It is difficult to say anything about the external inputs estimate. The same explanation is likely for the regressions including a total research variable; part of the role earlier played by traditional production factors has been taken over by research. Since the total research input has increased eightfold this has not necessarily led to a higher value marginal product, however.

\subsection{Cobb-Douglas Flow Models with Lags}

There will be a lag between the point in time when money is being funded for research purposes and the final effects in the form of higher production per input unit (or less inputs per produced unit). The previous estimations are based on the obviously unrealistic implicit assumption of research funds immediately affecting production results. One step forward towards a closer resemblance to the real world, therefore, is to take a lag into account in the model. The lag structure of agricultural research seems to be a problematic issue in studies of returns from research and thus far most production function studies make assumptions concerning the length and form of a distributed lag function. Naturally this does not apply to the welfare economics approach.

Estimations which include lags are examined in this sections. Simple lags were used to start with, after which Almon lags of degree two and three according to (3.37) were included in the model.

\subsubsection{Regressions with Simple Lags}

The simple lags estimated are based on the lag operator $x_{t-i}=\beta^{k} x_{t}$. The research input is thus allowed to affect the gross production only a certain number of years after the funds have been allocated. The effects of research thus take place at once instead of being distributed over a period of years, as in the case of a distributed lag. The estimated lags are allowed to vary between two and 15 years.

The results of the estimations are not very encouraging. When simple lags of less than ten 
years were included in the previous regressions (1) - (17), almost all of them showed the same tendency. The coefficient of determination falls, the drop being greater the longer the lag is. The research coefficient decreases in the beginning and partly becomes negative when lags of four to eight years are added and so does the significance, which makes it hard to believe the coefficients. For lags less than ten years the same autocorrelation problem as earlier appears. The highest coefficient of determination $(0.991-0.997)$, the best significance and the least serially correlated errors are achieved in regressions where the traditional variables are defined on farm level.

Estimations using lags of $12-13$ years are somewhat more encouraging, since they are both positive and significant. The serial correlation of errors is also less here (DurbinWatson test value $=1.45-1.75$ for the regressions in next table). Closer inspection of Figure 17, however, shows this should not be surprising, as the autocorrelated errors seem to appear mostly in the early part of the time series. Lags of ten years or more only make it possible to estimate the period of 19601984, which automatically eliminates the problematic period of serially correlated errors. It can therefore be doubted whether the longer simple lags of $12-13$ years are any better. In order to illustrate the simple lags, the estimates for public research for two different sets of regressions are presented in Table 22. When no lags are included the regressions are similar to regressions (9) and (12) in Tables 13 and 14.

From the table it is clear that only estimates which include lags of 13 years are both positive and significant. These elasticity estimates were also higher than the estimates in regressions (9) and (12). It was, however, already pointed out that there is reason to believe this is because of the problems inherent in the time series. In addition, the above table does not show the negative parameter estimates of the other elasticities, which appeared regularly in the regressions (the intercorrelation problem is the same as earlier).
Table 22. The coefficient of research for different values on the simple lags. The table corresponds to (9) and (12).

\begin{tabular}{crrrr}
\hline $\begin{array}{l}\text { Length of } \\
\text { the lag, } \\
\text { in years }\end{array}$ & \multicolumn{5}{c}{ Coefficient of research } \\
\cline { 2 - 5 } & $(9)$ & s.l. & $(12)$ & s.l. \\
\hline 2 & 0.016 & 0.694 & 0.035 & 0.296 \\
3 & 0.013 & 0.741 & 0.028 & 0.401 \\
4 & -0.041 & 0.318 & 0.002 & 0.941 \\
5 & -0.088 & 0.027 & -0.034 & 0.312 \\
6 & -0.046 & 0.194 & -0.014 & 0.629 \\
7 & -0.048 & 0.163 & -0.009 & 0.763 \\
8 & -0.021 & 0.555 & 0.016 & 0.629 \\
9 & 0.000 & 0.991 & 0.014 & 0.630 \\
10 & 0.013 & 0.663 & 0.008 & 0.762 \\
11 & 0.003 & 0.931 & 0.010 & 0.752 \\
12 & 0.033 & 0.359 & 0.046 & 0.194 \\
13 & 0.092 & 0.005 & 0.089 & 0.006 \\
14 & 0.089 & 0.019 & 0.084 & 0.033 \\
15 & -0.021 & 0.642 & -0.038 & 0.432 \\
\hline
\end{tabular}

A conlusion of the simple lag regressions is that the lag structure should be subject to more advanced methods of analysis. In spite of the problems encountered, some estimations including Almon lags are presented in the next section.

\subsubsection{Regressions with Almon Lags}

The a priori assumption of a polynomially distributed (Almon) lag revealed significant drawbacks. Not only were the estimates of elasticity with respect to research including a polynomial lag mostly insignificant; they were also negative, indicating a negative coefficient for research, which is most improbable. In addition, the size of the estimated coefficients varied to a large degree. This may be caused by intercorrelation between the various research variables in the lag structure, but it is more likely that the Almon lags do not fit the data and thus cannot give any sensible results. The polynomial lag behaved similarly when applied to a linear function. The coefficient of determination was clearly lower than for the unlagged functions except when traditional variables were measured at farm level where this difference not was as noticeable. The results for Almon lags of degree two and 
three for three different lengths of the lag are illustrated in Appendix 13.

A cumulated elasticity can be summed up on the basis of (3.36). The sum of estimated lag coefficients according to this are as follows (see Table 23):

Table 23. Sum of Almon lag coefficients. $a=$ aggregated conventional variables, $\mathrm{p}=$ conventional variables per farm.

\begin{tabular}{lccc}
\hline $\begin{array}{l}\text { Regres- } \\
\text { sion }\end{array}$ & $\begin{array}{c}\text { Length } \\
\text { of lag }\end{array}$ & Degree & $\begin{array}{c}\text { Sum of } \\
\text { coefficients }\end{array}$ \\
\hline$(34)$ & 3 & $2 \mathrm{a}$ & 0.047 \\
$(35)$ & 3 & $2 \mathrm{p}$ & 0.044 \\
$(36)$ & 3 & $3 \mathrm{a}$ & 0.046 \\
$(37)$ & 3 & $3 \mathrm{p}$ & 0.042 \\
$(38)$ & 7 & $2 \mathrm{a}$ & -0.266 \\
$(39)$ & 7 & $2 \mathrm{p}$ & -0.047 \\
$(40)$ & 7 & $3 \mathrm{a}$ & -0.266 \\
$(41)$ & 7 & $3 \mathrm{p}$ & -0.049 \\
$(42)$ & 13 & $2 \mathrm{a}$ & -0.041 \\
$(43)$ & 13 & $2 \mathrm{p}$ & -0.064 \\
$(44)$ & 13 & $3 \mathrm{a}$ & 0.019 \\
$(45)$ & 13 & $3 \mathrm{p}$ & -0.026 \\
\hline
\end{tabular}

From Table 23 it is evident that the negative sum of estimated lag coefficients is very illogical. In addition, the positive estimates are often found in the beginning or at the end of each lag, thus indicating an upside down bellshaped structure (a positive parable) of the lag. The choice of estimated polynomial sum of elasticities cannot be made upon any rational criteria. Thus the Almon lag does not provide any help in estimating a research elasticity.

Why doesn't the Almon lag fit the data? Why are estimates of the elasticity with respect to research for the simple lags negative? The reason may be the aggregated data, which do not consider that different types of research have different lengths of the lag. Research on machine technology may have a more immediate effect on production than, for instance, crop breeding, which depends on the vegetation period. Since the aggregated data include research institutions which have been founded during the period 1950-1984, the proportions of different types of research have changed, and the average aggregate lag has probably changed accordingly. One way of dealing with this problem could have been to split up the data into different branches, each of which would be estimated separately for different lengths of the lags.

A more plausible hypothesis is, however, connected with the distinction between research stocks and research flows. By far the most common way of measuring the research input in production function analysis has been in the form of an annual flow of research funds (Peterson 1985). It is obvious that the research input for one year does not represent the total stock of research capital accumulated over the years. If the relevant measure is the research stock and not the annual research flow, an initial basis value should be found for 1950 . This initial value should grow with the annual research funds and depreciate according to the formulas (3.12) - (3.14) presented in section 3.3.2. Conceptually, computation of the research stock is similar to the calculation of a stock of tractors. An annual flow of tractors bought does not measure the same thing as the total stock of tractors. Because the earlier tractors are omitted, the production effects measured neglect the effects of all previously purchased tractors. The annual flows of tractors fluctuate considerably more than the total stock of tractors. As a consequence, the fluctuations of the research flow vary more than the fluctuations of the research stock.

The research stock is a kind of proxy for all the physical, scientific, and intellectual resources that exist at a point in time. If one thinks of the research stock concept in this sense, it will possess a computational advantage, since lags seem not to be needed. The gathered effect of an accumulated stock is immediate. It is more troublesome to decide on the right rate of depreciation. On the one hand, there is a view that all research accumulates and contributes to an ever-growing stock of knowledge (which according to Popper approaches truth in infinity). Accordingly, research would have a value that does not 
depreciate at all. On the other hand, there is the view that research results replace each other totally, either through obsolescence or as a result of changes in the environment. A third view, somewhere between these two standpoints, states that some research results lose their relevance while other provide useful knowledge for later scientists to build upon. The three different standpoints can be thought of as a $0 \%$, a $50 \%$ and a $100 \%$ depreciation 20 years after funding, as formulated in (3.12)-(3.14). All three cases are examined next.

\subsection{The Research Input Measured as a Stock}

The estimations of elasticities with respect to research analyzed up to this point have been based on the research flow concept. This section presents estimations specifying the research input as a research capital. The CobbDouglas function (3.9) serves as the basic model of regression. Contrary to the research flow models, no lag structure seems to be needed with a research stock. This is because of the different nature of the research capital. A stock which mainly includes investments in research made several years earlier does not seem to need an additional lag.

The initial figure for the research capital was derived by simple trend analysis from 1950 - 1984 back to 1920 . The period 19401944 was, however, excluded because of the Second World War, when normal research activities were seriously disrupted. This initial figure is used to formulate a research capital for the three different rates of research depreciation formulated in expressions (3.12), (3.13) and (3.14) in section 3.3.2.

The research carried out is accumulated on the basis of three different assumptions:

a) no depreciation

b) a $50 \%$ depreciation 20 years after the research funding and finally

c) a $100 \%$ depreciation (total obsolescence) 20 years after funding.

At first a research capital is constructed only for public research, whereafter a total research capital is derived. The derivation and the index series obtained by this procedure are found in Appendices 14 and 15.

\subsubsection{Undepreciated Research Stock.}

When the public research stock is $R_{k}=$ $\Sigma\left(R_{t}-d_{t} R_{t}\right)$ and $d_{t}=0$, the estimations of the Cobb-Douglas model (3.9) will be according to Table 24. All the variables are measured at aggregate level. The table should be compared with Table 13, since all variables except the research input are estimated with the same series. The results from the regressions specifying research as an undepreciated research stock for total research are presented in Appendix 16.

Compared to the estimations with research measured as a flow, the coefficient of determination is slightly higher and, respectively, the standard error of total estimation slightly lower. The F-ratio is high, and the model is again acepted at a level of significance of less than $0.001 \%$. The autocorrelation decreases as the Durbin-Watson test value shows (it rises from $0.96-1.02$ to $1.09-1.11$ ), but is still high. The estimate of the research capital parameter seems to fit the model slightly better than does the research flow estimate.

Inspection of the elasticity estimates with respect to the different variables immediately draws attention to the considerably lower estimates for capital, which, however, has also lost confidence. The significance of the elasticity with respect to labour is modest, while the external inputs estimate is clearly insignificant and in the former regression has a negative sign. Inclusion of an extension variable does not affect the model very much.

The elasticity estimate with respect to the research capital changes in an interesting way. First of all, compared to the flow elasticities the estimate increases to 0.338 in regression (46) and 0.247 in regression (47). This is natural, since the estimate represents an elasticity relating a percentage change in production to a percentage change in the research input. 
Table 24. Cobb-Douglas production functions with public research measured as an undepreciated stock.

\begin{tabular}{lcccc}
\hline Regression & $(46)$ & s.l. & $(47)$ & s.l. \\
\hline Constant & 1.326 & 0.286 & 1.224 & 0.313 \\
& $(1.219)$ & & $(1.193)$ & \\
Capital & 0.171 & 0.714 & 0.242 & 0.598 \\
& $(0.462)$ & & $(0.454)$ & \\
Labour & 0.207 & 0.007 & 0.135 & 0.117 \\
& $(0.071)$ & & $(0.834)$ & \\
External inputs & -0.005 & 0.953 & 0.015 & 0.868 \\
& $(0.090)$ & & $(0.089)$ & 0.093 \\
Research stock & 0.338 & 0.016 & $(0.142)$ & \\
& $(0.133)$ & & 0.096 & 0.131 \\
Extension & & & $(0.062)$ & \\
& & & 0.987 & \\
R 2 & 0.985 & & 0.022 & \\
Stand.error of estimate & 0.023 & & $425.876^{* * *}$ & \\
F-ratio & $507.71^{* * *}$ & & 1.115 & \\
D-W test value & 1.094 & & & \\
\hline
\end{tabular}

Since a percentage change in the whole research capital is considerably higher than a percentage change in the annual funds, the elasticity is naturally higher. The second interesting feature is the rise in the confidence of the research coefficient. In regression (9) the significance was 0.120 , and in (46) it is 0.016 . The significance in (10), was, analogously, about 0.374 , and in (47) it is 0.093 . Obviously, the elasticity estimate with respect to the undepreciated research capital seems to be more reliable than the research flow estimate as the significance is higher.

The results from the total research stock in Appendix 16 mainly show the same results as for the public research. The most obvious feature is the slightly smaller estimate of elasticity with respect to the total research stock than the elasticity estimate of the public research stock. The difference is, however, not large.

\subsubsection{Depreciated Research Stock}

In the following the estimations including a depreciated research stock are reported. Research results were assumed to become obsolescent or superfluous because of changes in the environment 20 years after research grants were made. The two alternative assumptions of depreciation for $R_{k}=\Sigma\left(R_{t}-\right.$ $d_{1} R_{t-20}$ ) were $d_{t}=0.5$ and $d_{t}=1.0$, i.e. a $50 \%$ and a $100 \%$ rate of depreciation. The results when the research stock includes only public research are presented in Tables 25 and 26.

Only minor changes take place in the parameter estimates. The coefficient of determination, the F-ratio and the Durbin-Watson test value in Table 24 are slightly better than in Table 25. The significance of capital in Table 25 is, however, better and no negative signs for external inputs appeared. The elasticity of the research capital in Table 25 is almost the same in size, or $0.212-0.297$, and the confidence is a little lower. The differences are so small, however, that it is difficult to judge which table gives more reliable results.

Table 26 shows that a total depreciation of the research capital does not improve the regressions. The same tendencies continue as when research capital was depreciated by $50 \%$. The estimate of the research coefficient decreases to $0.174-0.252$, the former value 
Table 25. Cobb-Douglas production functions with public research measured as a stock with $50 \%$ depreciation after 20 years.

\begin{tabular}{lcccc}
\hline Regression & $(50)$ & & $(51)$ & s.l. \\
\hline Constant & & s.l. & 0.774 & 0.463 \\
& 0.757 & 0.482 & $(1.040)$ & \\
Capital & $(1.063)$ & & 0.387 & 0.344 \\
& 0.349 & 0.402 & $(0.403)$ & \\
Labour & $(0.411)$ & & 0.116 & 0.144 \\
& 0.185 & 0.007 & $(0.077)$ & \\
External inputs & $(0.064)$ & & 0.021 & 0.813 \\
& 0.002 & 0.979 & $(0.089)$ & \\
Research stock & $(0.090)$ & & 0.212 & 0.113 \\
& 0.297 & 0.018 & $(0.129)$ & \\
Extension & $(0.119)$ & & 0.096 & 0.137 \\
& & & $(0.063)$ & \\
$\mathrm{R}^{2}$ & & & 0.986 & \\
Stand.error of estimate & 0.985 & & 0.022 & \\
F-ratio & 0.023 & & $421.38^{* * *}$ & \\
D-W test value & $503.63^{* * *}$ & & 1.105 & \\
\hline
\end{tabular}

Table 26. Cobb-Douglas production functions with public research measured as a stock with $100 \%$ depreciation after 20 years.

\begin{tabular}{lcccc}
\hline Regression & $(52)$ & & $(53)$ & s.l. \\
\hline Constant & & s.l. & 0.368 & 0.692 \\
& 0.215 & 0.820 & $(0.020)$ & \\
Capital & $(0.936)$ & & 0.530 & 0.146 \\
& 0.535 & 0.151 & $(0.355)$ & \\
Labour & $(0.363)$ & & 0.093 & 0.186 \\
& 0.158 & 0.009 & $(0.069)$ & \\
External inputs & $(0.057)$ & & 0.025 & 0.785 \\
& 0.006 & 0.951 & $(0.090)$ & \\
Research stock & $(0.091)$ & & 0.174 & 0.142 \\
& 0.252 & 0.023 & $(0.115)$ & \\
Extension & $(0.106)$ & & 0.098 & 0.133 \\
& & & $(0.063)$ & \\
$\mathrm{R}^{2}$ & & & 0.986 & \\
Stand.error of estimate & 0.985 & & 0.022 & \\
F-ratio & 0.023 & & $416.05 * * *$ & \\
D-W test value & $496.44^{* * *}$ & & 1.084 & \\
\hline
\end{tabular}

being insignificant, however. The capital coefficient continues to increase.

The depreciated research stock for the total research capital at both depreciation rates is presented in Appendices 17 and 18. The estimate of elasticity with respect to the total research stock for some reason seems to be slightly smaller than the elasticity estimate with respect to the public research stock.

In order to investigate the autocorrelation for the three different cases of research capital, autoregressive models of first order 
were also investigated. The autoregressions corresponded to the regressions (46) - (57) reported above. Autocorrelation declined substantially in these regressions. This could be noticed from the Durbin-Watson test value which showed values of $1.68-1.71$. The research coefficient in these autoregressive estimations varied from 0.10 to 0.15 for public research and from 0.08 to 0.12 for the total research. In the autoregressions the estimate of the elasticity with respect to the research stock was clearly insignificant, and the regression coefficient of the residual was high (approximately 0.50 ) and significant. The autocorrelation procedure has been explained in section 5.1.5.

As a summary of the estimates of elasticity with respect to the research capital, it is now possible to state that resasonably reliable elasticity estimates of the research capital seem to be found in the range of $0.15-0.30$ depending on depreciation rate. The autocorrelation, however, is still a problem since the model assumes that the residuals are not correlated. The total research coefficient is slightly lower than the public research coefficient despite good t-value for both, a result which is hard to explain. Autocorrelation disappears in the autoregressive models, and the elasticity falls to $0.10-0.15$ for public research and to $0.08-0.12$ for total research, but is insignificant.

\subsubsection{Productivity Index Model}

In order to avoid the problem caused by multicollinearity an alternative model using a productivity index as dependent variable was specified in subsection 3.3.3. Through the specification of (3.17), the number of regressors was reduced to two variables, the research capital and a time factor. The dependent variable was a production/input index which included labour, capital costs $(4 \%$ of the stock of gross capital) and external inputs in the inputs. The results for this regression are presented in Table 27.

Table 27. Cobb-Douglas functions with productivity index as dependent variable. Research stock undepreciated.

\begin{tabular}{lcr}
\hline Regression & $(58)$ & \\
\hline Constant & 3.036 & 0.000 \\
& $(0.563)$ & \\
Public research stock & 0.346 & 0.008 \\
& $(0.122)$ & \\
Time factor & -0.002 & 0.787 \\
& $(0.008)$ & \\
$\mathrm{R}^{2}$ & 0.973 & \\
Stand.error of estimate & 0.036 & \\
F-ratio & $575.18 * * *$ & \\
D-W test value & 0.807 & \\
\hline
\end{tabular}

The estimate of elasticity with respect to public research shows a good significance at a level of 0.008 (i.e., a confidence level over $99 \%$ ). The time factor is insignificant and has an illogical sign. The coefficient of determination is slightly lower than in the regressions with gross production as dependent variable. The autocorrelation is, however, substantial. The elasticity estimate with respect to research should be interpreted in a different way from previous estimates. The simplest way is to say that for a $1 \%$ increase in research funds, the relation of production to input rises by $0.346 \%$. 


\section{The Returns to Agricultural Research and University Education}

\subsection{The Selection of an Elasticity}

The primary question to be answered was stated in the introduction as:

- What has been the value marginal product (marginal rate of return) and the marginal internal rate of return for public expenditure in agricultural research and for total public and private expenditures on agricultural research in 1950-1984?

To be able to draw a conclusion, a set of parameter estimates with respect to public and to total research was estimated in the previous chapter, and is used to calculate the value marginal product, which is easily changed to a marginal rate of return. Various options for the estimations were presented in Figure 15. It was possible to use either a flow elasticity or a stock elasticity. For the research flow it is possible to distinguish between an unlagged elasticity and an elasticity that includes a lag. For research stock it is possible to use either an undepreciated or a depreciated parameter estimate. Which estimate, then, should be used?

\subsection{Research Flow Elasticities}

On the basis of the coefficients of the linear production function, an unlagged marginal product for public research of 0.016 was estimated which, however, was insignificant. This parameter estimate of the marginal product is equal to an elasticity 0.04 with respect to public research. When the capital, labour and purchased input variables were specified on farm level, marginal products of 0.046 and 0.040 were estimated (the latter when the extension variable was added). Both these unlagged marginal products could be accepted by the t-test at reasonable significance levels. Converting them into elasticities (according to expression 5.1) gives elasticities of 0.099 and 0.114 with respect to public research.

The Cobb-Douglas function elasticities with respect to public research were 0.034 and 0.059 in the regressions where capital, labour and external inputs variables were specified on the aggregate level. If these conventional variables were specified on farm level, the parameter estimate of the elasticity with respect to research was 0.059 without the extension factor and 0.018 if extension was added. It is noteworthy that the lower elasticities, 0.018 (conventional variables on the farm level) and 0.034 (conventional variables on the aggregate level), which appear when extension is added have very low t-values and therefore are not reliable.

Multicollinearity between the explaining variables was strong. Ridge regressions, however, showed that the internal correlation did not lead to overestimated research coefficients.

The problem with all the unlagged parameter estimates of elasticities was heavy autocorrelation. In the autoregressive models of first degree, the autocorrelation declined and practically disappeared when models of degree two were used to explain the output. The parameter estimates of elasticities with respect to public research in these unlagged models were $0.010-0.016$. The regression coefficients of the lagged residuals were high, however, and their content is unclear. In addition, the elasticity estimates with respect to research were clearly insignificant.

The parameter estimates of the unlagged elasticities with respect to public research thus vary between 0.010 and 0.114 . Taking the pos- 
sibility of errors into account, an estimate of elasticity of 0.040 , previously used in section 5.1.1. may be too high. A modest approximation of the unlagged elasticity estimate may therefore lie in the range of $0.015-0.025$. This approximation, however, suffers from lack of reliability because of the omission of a lag.

The estimation of total research parameters by linear functions with conventional variables specified at the aggregate level gave an estimate of the marginal product of $0.022-$ 0.025 , which was converted to an elasticity of $0.066-0.075$. When traditional variables are specified at the farm level, the research marginal product estimate varies from 0.047 to 0.054 and the estimate of elasticity is consequently higher $(0.141-0.162)$. The significance was good. The Cobb-Douglas functions produced estimates of elasticities with respect to total research of $0.050-0.078$ when the conventional variables were specified on the aggregate level, and of $0.021-0.061$ on the farm level. Both the higher parameter estimates of 0.078 and 0.061 were accepted by the t-test at a $10 \%$ confidence level. In the autoregressive models, autocorrelation declined and insignificant estimates of elasticity with respect to total research of $0.022-0.031$ were obtained. The estimate of the unlagged elasticity of total research thus ranges from 0.021 to 0.162 . Taking into account the deficient data an approximation of 0.030 for the estimate of the unlagged elasticity for total research seems appropriate.

The estimation of elasticities with respect to public research including simple lags (Table 22) proved to be troublesome as many negative signs appeared, and they were also statistically insignificant in most cases. The only estimates of elasticities which could be accepted by the t-test were an estimate for a simple five-year lag with a negative sign $(-0.088)$ anc four rather high estimates of elasticities $(0.084-0.092)$ for lags of 13 to 14 years.

The results for estimations including Almon lags of degrees two and three were discouraging. The total inconsistency of signs for dif- ferent lengths of the lag proved to be no better than for the simple lags. As to the estimates of lagged elasticities with respect to the research flow, no acceptable estimate could thus be found. Thus the estimations carried out in this respect have clearly failed.

\subsection{Research Capital Elasticities}

On the basis of three different assumptions of depreciation of the stock of research capital $(0 \%, 50 \%$ and $100 \%$ depreciated 20 years after research grants were made), elasticities with respect to a research capital of $0.252-$ 0.338 were estimated at a significance of $0.016-0.023$. The inclusion of an extension variable in the regression decreased this estimate of elasticity to $0.174-0.247$ and decreased the significance to $0.093-0.142$. Autocorrelation problems appeared in all cases.

In the autoregressive models of first order, research elasticities of $0.10-0.15$ were estimated and autocorrelation decreased substantially. These estimates suffered from being clearly insignificant. Taking these facts into consideration, approximation of the estimate of elasticity with respect to an undepreciated research capital at a value of 0.20 seems acceptable. In case a depreciation rate of $50 \%$ and $100 \%$ after 20 years is practised, the estimate of elasticity should be in the range of 0.17 and, respectively, 0.15 .

The estimates of elasticities with respect to total research stock were smaller than with respect to public research, a result which is hard to explain since the flow estimates indicated the opposite. The coefficients varied from $0.219-0.278$, with a significance of $0.017-0.022$. When extension was added the estimates declined to $0.169-0.222$, with a significance of $0.052-0.074$. The autoregressive models of first order gave insignificant estimates $(0.08$ and 0.12$)$ of the elasticities with respect to total research stock.

The estimate of the elasticity of an undepreciated total research capital could, on this basis be approximated to 0.15 , or slightly 
lower than public research. Depending on the rate of depreciation, the elasticity estimate is approximated by $0.12-0.13$. The reason for the lower value of total research probably depends on deficiencies in data, and a clear warning concerning this point is in order.

\subsection{Value Marginal Product}

On the basis of the elasticities discussed in the previous sections of this chapter, it is now possible to calculate a value marginal product VMP (a marginal rate of return) for agricultural research. This is done by relating the increase in output to the costs of the marginal increase in research costs. As agricultural and veterinary university-level education has been included in research costs, the calculated value marginal product concerns both research and university education. Extension activities carried out to speed up the adaption of innovations by farmers also need to be considered in some way. To do so, the public expenditures for extension services are included in the costs.

The formula for calculation of the marginal product is, according to DAvis (1981):

(6.1) $\mathrm{MP}=\mathrm{d} \frac{\mathrm{Q}}{\mathrm{R}}$

where

$\mathrm{MP}=$ marginal product of research

$\mathrm{Q}=$ gross production

$\mathrm{R}=$ research expenditures

$\mathrm{d}=$ elasticity of research

If research has been measured as a flow, research expenditures are the average annual expenditures. Research capital must be regarded as research expenditures when a stock elasticity is used.

If the original production level is $\mathrm{Q}_{1}$ the value marginal product is the MP priced by product price $\mathrm{P}_{1}$ :

$$
V M P=d \frac{Q_{1} P_{1}}{R}
$$

When extension costs are added the value marginal product is:

$$
V M P=d \frac{Q_{1} P_{1}}{R+N}
$$

DAvis (1981) points out two assumptions underlying the VMP calculations (6.1), (6.2) and (6.3).

The first is that the level of use of all other inputs remains the same. This assumption can, on the one hand, be questioned, since it implies that technological change is neutral (neither capital nor labour intensive) to a change in research intensity. It means that the marginal products of the other inputs do not change as a consequence of research activities. But in reality new research results affect the volume of capital, labour and external inputs. On the other hand, as we are only dealing with a marginal increase in the research input, this assumption may be acceptable.

This assumption of fixed input levels also implies a divergent shift in the supply curve, caused by research. If the supply curve in reality shifts in a parallell direction, the VMP may be underestimated by up to half.

The second implicit assumption is that the product price is not affected by the change in output and that demand is perfectly elastic. In reality demand is unlikely to be perfectly elastic and so the VMP overestimates the benefits. The overestimation caused by this latter assumption is, according to Davis, relatively small in comparison to the first possibility of underestimation.

The volume of gross production for the period 1950-1984 is derived by the same index series as were used to measure independent variables in the regressions. The volume of this production was reported by KETTUNEN (1985) to have been FIM 21,022.3 million in 1984. Because State subsidies, State compensations and outdoor garden production are included in this figure, they are subtracted. The gross production figure derived is then FIM 19,403.9 million at the domestic price level of 1984.

Public expenditures for research and university education in 1984 were FIM 157.028 million, the value of total research FIM 230.132 million. Public expenditures for extension were FIM 60.557 million. Use of the explaining index series for research and ex- 
tension gives the cumulated total value of these inputs in 1950-1984 at the price level of 1984 . This results in following figures (see Table 28):

Table 28. Cumulated and average volume in 19501984 of gross production, research flow and State expenditures for extension, (FIM million).

Cum.vol. Average

1. Volume of gross production in 1950-1984

$558,252 \quad 15,950$

2. Public research flow in 1950-1984

$3,138 \quad 89.7$

3. Total research flow in 1950-1984

4,336

123.9

4. State expenditures for extension in 1950-1984

$1,791 \quad 51.2$

If the unlagged estimate of elasticity with respect to the public research flow, approximated at 0.020 , is used, the VMP according to $(6.3)$ will be

$$
\begin{aligned}
\mathrm{VMP}_{\mathrm{p}} & =\frac{0.020 \% \times \text { FIM } 15,950 \text { million }}{1 \% \times \text { FIM }(89.7+51.2) \text { million }} \\
& =2.26
\end{aligned}
$$

The value marginal product of 2.26 would imply that every additional Finnish mark invested in agricultural research and university education would have returned by 2.26 mark annually since that moment. This value marginal product is equal to a marginal rate of return of $226 \%$, which seems to be exceedingly high. Since no lag was applied this is obviously an overvalued estimate.

Applying the same formula to the total research flow with an unlagged elasticity of 0.030 gives

$$
\begin{aligned}
\mathrm{VMP}_{1} & =\frac{0.030 \% \times \text { FIM } 15,950 \text { million }}{1 \% \times \text { FIM }(123.9+51.2) \text { million }} \\
& =2.73
\end{aligned}
$$

The value marginal product of total public and private research thus seems somewhat higher than for only public research.

So far, the research flow concept has been considered. If the focus is changed to the research capital, do these high estimates gain validity from the estimations of the stock of research capital?

In order to calculate the rate of return to research capital, we need to sum up the research capital existing each year in 19501984. The accumulated sums as well as the figures for the derivation of research capital are found in Appendices 14 and 15. Table 29 presents the summed up research capitals and averages for different assumptions of the depreciation:

Table 29. The sum and average of accumulated research capitals 1950-84 mill. FIM.

\begin{tabular}{llllll}
\hline \multirow{2}{*}{$\begin{array}{l}\text { Rate of } \\
\text { depreciation } \\
\text { after 20 years }\end{array}$} & Sum & Average & & & \multicolumn{2}{c}{ Sum } & Average \\
\cline { 2 - 3 } \cline { 5 - 6 } & & & & & \\
\hline $0 \%$ & 56,685 & $1,619.6$ & & 70,272 & $2,007.8$ \\
$50 \%$ & 50,122 & $1,432.1$ & & 63,284 & $1,808.1$ \\
$100 \%$ & 43,559 & $1,244.5$ & & 56,295 & $1,608.4$ \\
\hline
\end{tabular}

The sum of accumulated undepreciated research capitals during the whole period 1950-1984 was FIM 56,685 million (public) and, respectively, FIM 70,272 million (total). On average the undepreciated public research capital was FIM 1,619.6 million, the undepreciated total research capital FIM 2,007.8 million. The value of the undepreciated research capital only in 1984 was estimated to FIM 3,480.0 million (public) and, respectively, FIM 4,688.3 million (total).

The estimates of elasticities with respect to the undepreciated public research capital and the undepreciated total research capital were approximated at 0.2 and 0.15 . If these approximations are used in formula (6.3), the following value marginal products are obtained:

Research stock depreciation rate $=0 \%$

$$
\begin{aligned}
\mathrm{VMP}_{\mathrm{p}} & =\frac{0.2 \% \times \text { FIM } 15,950 \text { million }}{1 \% \times \text { FIM }(1,619.6+51.2) \text { million }} \\
& =1.91 \\
\mathrm{VMP}_{\mathrm{t}} & =\frac{0.15 \% \times \text { FIM } 15,950 \text { million }}{1 \% \times \text { FIM }(2,007.8+51.2) \text { million }} \\
& =1.16
\end{aligned}
$$


In the case of a $50 \%$ and a $100 \%$ depreciated research capital, the estimates of elasticities with respect to the public research were approximated at 0.17 and, respectively 0.15 . The elasticity estimates with respect to the total research capital for both depreciation rates are 0.13 and 0.12 . Since the estimations carried out would not give reason to more than minor change in these coefficients, there is reason to say the elasticities chosen well represent the depreciated research capital. The value marginal product then becomes:

Research stock depreciation rate $=50 \%$

$$
\begin{aligned}
\mathrm{VMP}_{\mathrm{p}} & =\frac{0.17 \% \times \text { FIM } 15,950 \text { million }}{1 \% \times \text { FIM }(1,432.1+51.2) \text { million }} \\
& =1.83
\end{aligned}
$$$$
\begin{aligned}
\mathrm{VMP}_{\mathrm{t}} & =\frac{0.13 \% \times \text { FIM } 15,950 \text { million }}{1 \% \times \text { FIM }(1,808.1+51.2) \text { million }} \\
& =1.12
\end{aligned}
$$

Research stock depreciation rate $=100 \%$

$$
\begin{aligned}
\mathrm{VMP}_{\mathrm{p}} & =\frac{0.15 \% \times \text { FIM } 15,950 \text { million }}{1 \% \times \text { FIM }(1,244.5+51.2) \text { million }} \\
& =1.85
\end{aligned}
$$$$
\mathrm{VMP}_{\mathrm{t}}=\frac{0.12 \% \times \text { FIM } 15,950 \text { million }}{1 \% \times \text { FIM }(1,608.4+51.2) \text { million }}
$$$$
=1.15
$$

The VMP for public research thus varies between 1.83 and 1.91 for public research depending on the assumed depreciaton rate. Correspondingly, the VMP for total research varies between 1.12 and 1.16. In fact, the undepreciated and depreciated research stocks give almost identical value marginal products. This is an interesting feature. The value marginal product of the public research stock is $80 \%$ of the research flow VMP. The value marginal product for the total research capital is only about $40 \%$ of the flow VMP. Since the research stock conceptually does not need any lag, the estimates in this respect are more reliable than the flow estimates. The research stock estimates are also more reliable with respect to significance and autocorrelation.

The critical issue is: Are we sure the stock of research capital needs no lag? Further assessment of the returns to research estimated on the basis of a research capital would seem interesting.

There is one more way to determine a marginal rate of return. Through the production/input elasticity with respect to public research, 0.346 as reported in subsection 5.3.3., it is possible to calculate the value of the improved production/input ratio. This ratio would have risen with $0.346 \%$ for an additional $1 \%$ of research capital. In other words, with the same set of inputs production would have risen with $0.346 \%$ for a $1 \%$ increase in research capital. The production/input index was measured in the prices of 1970; the average annual production in 1950-1984 was FIM 3,503.3 million in this price level, with an average annual undepreciated research capital of FIM 381.5 million in the prices of 1970 (FIM 1,619.6 million in the prices of 1980, deflated by the market price index), and extension, respectively, FIM 12.1 million. The value marginal product becomes:

$\frac{0.346 \% \times \text { FIM 3,503.3 million }}{1 \% \times \text { FIM }(381.5+12.1) \text { million }}=3.08$

In other words, if the whole stock of research capital had increased by FIM 1, then FIM 3.08 more of production would have been gained. The difference from the former VMPs is partly caused by the fact that relatively minor differences in the elasticities are reflected as large differences in VMPs. It is also necessary to take into account that the errors were heavily autocorrelated in the regression, which casts some doubt on the reliability of the elasticity estimate.

\subsection{Marginal Internal Rate of Return}

The internal rate of return (IRR) is a method of investment analysis which explicitly considers the time value of money. The method is best understood with the net present value (NPV) method as a starting point. With the NPV method the cash flows of an investment project are discounted at a minimum ac- 
ceptable compound annual rate. If the present value of net cash returns exceeds the initial investment outlays, i.e the net present value is greater or equal to zero the investment is accepted. The IRR method in turn, computes the discount rate for which the net present value equals zero. The discount rate is thus the maximum interest rate a project can pay out and still cover total outlays (LEE et al., 1980).

According to (2.2) the IRR was formulated as

$$
\sum_{t=0}^{T} \frac{\left(R_{t}-C_{t}\right)}{\left(1+r_{i}\right)^{t}}=0
$$

$R_{t}=$ the social benefit (return) in year $t$

$\mathrm{C}_{\mathrm{t}}=$ the research cost in year $\mathrm{t}$

$\mathrm{T}=$ the year the research ceases to produce returns

$r_{i}=$ the internal rate of return

Besides the value marginal product this measure is the most widely used rate of return for the returns to agricultural research. In general an average IRR is computed, but PETERSON $(1967,1971)$ and RuSSELl (1987) have computed a marginal internal rate of return (MIRR). For shorter periods, the MIRR is very sensitive to the length of the period discounted (i.e. the value of $\mathrm{T}$ ). If $\mathrm{T}$ grows, however, the MIRR stabilizes around a certain value.

MIRRs for the estimates, with respect to the unlagged research flow elasticities of 0.02 (public research) and 0.03 (for total research), are computed according to (2.2). A lag is incorporated afterwards, assuming that the unlagged elasticity affects production alternatively, four, six or ten years later. In other words, a four-year lag assumes that the research input in 1950-1980 has affected production in 1954-1984. Extension is thought to have an immediate effect, i.e. the costs are credited for the same year as the production increase. The returns are assumed to stop at 1984.

The results of the MIRR calculation on the various assumptions of the lag are presented in Table 30.

Table 30. The marginal internal rate of return (MIRR), $\%$.

\begin{tabular}{ccc}
\hline $\begin{array}{l}\text { Assumed } \\
\text { length of lag }\end{array}$ & $\begin{array}{c}\text { Public } \\
\text { research }\end{array}$ & $\begin{array}{c}\text { Total } \\
\text { research }\end{array}$ \\
\hline 4 years & 62.2 & 76.8 \\
6 years & 37.7 & 46.0 \\
10 years & 20.9 & 25.9 \\
\hline
\end{tabular}

The MIRR for public research according to this would be in the range of $20-62 \%$ (above inflation) for various assumptions of the length of the lag. The corresponding MIRR for total research is approximately $25-76 \%$. It is noteworthy that this is a marginal figure, not an average. If the assumption that benefits stop at 1984 is eased, the change in MIRR is minor (less than $1 \%$ ). The MIRR for total research may be overestimated because too few costs have been included. On the other hand, extension expenditures are included for both public and total MIRR, which substantially decreases the estimates. This MIRR falls in the same range as the average IRRs (cf. Appendix 1) computed in other studies. The difference from the VMP and corresponding marginal rates of return (226 \% for public research and $273 \%$ for total research) seems to depend on the fact that the flow measure took no account of lags and the estimates were biased upwards. The VMP and the corresponding marginal rates of return estimated by research capital, 183-191 \% for public research and $112-116 \%$ for total research, rest on the assumption of a research stock which can be estimated. The different rates of return give different expressions of the same phenomenon. 


\section{Summary and Conclusions}

This study undertook to estimate the returns to investment in agricultural research in Finland in 1950-1984. The primary reason motivating this investigation is the fact that public research funds are limited. A measure for assessing the allocation of resources to research could be created, in part based on these study results, if the monetary value of agricultural research could be estimated. A second reason is the current interest of administrators in research evaluation.

More specifically the purpose of the study was to estimate the following two measures of returns to agricultural research:

1. The value marginal product (VMP, a marginal rate of return)

2. The marginal internal rate of return (MIRR).

These rates of return were estimated for two different definitions of resource expenditures:

a) Public expenditures on agricultural research and university education and

b) Total public and private expenditures on agricultural research and university education.

Two major approaches - production function analysis and welfare economics - have been used in most studies estimating the returns to investment in agricultural research. These approaches and studies, carried out in North America, Asia and Australia, were reviewed in chapter 2 .

In the production function analysis, a separate variable for research is included in the production function. A value marginal product can be computed on the basis of the estimate of elasticity with respect to research.

The welfare economics approach is based on the changes in consumers' and producers' surpluses. Welfare economics makes it possible to determine an average rate of return and the distribution of benefits from research between producers and consumers.

This study used the production function approach. Two models, a linear and a CobbDouglas model, were specified. Gross production was the dependent variable, and the explanatory variables were capital, labour, purchased inputs, extension and research. Capital included buildings, machinery, water constructions, land and livestock. The research input was measured in two alternative ways: firstly, as a flow of annual funds granted for research and university education; secondly, as a stock of research capital, which consisted of funds accumulated since 1920 with three different assumed rates of depreciation. Almon lags of second and third degree were specified for the former way of measuring the research input. Finally, a third model with a productivity index as the dependent variable was specified.

The time series data for public research expenditures included the agricultural research institutes and other institutions under the Ministry of Agriculture and Forestry, the Faculty of Agriculture and Forestry of the University of Helsinki for the part of agriculture, the College of Veterinary Medicine, the Academy of Finland, the Finnish National Fund for Research and Development (SITRA), public foundations, the Work Efficiency Association and joint research projects financed by the Ministry. In the final calculation of the VMP and the MIRR, public expenditures for extension agencies were accounted on the cost side.

Because of deficiencies in the data on the research input of the private sector, the total 
public and private research VMPs and MIRRs should be interpreted with care. The expenditures accounted for on the side of the private sector did not cover the total expenditures. This biased the estimate positively.

The results of the estimations are presented in chapter 5. Models measuring the research input as a flow of expenditures were analysed first, whereafter the models measuring research input as a stock of accumulated expenditures were examined. Finally, four different return measures were calculated. The results were as follows:

The results for estimations with the research input specified as a flow including no lags were discussed first. A preliminary VMP was derived on the basis of the linear models, though because lags were omitted it was an overestimation. The results for the linear and the Cobb-Douglas models were somewhat ambiguous. Multicollinearity between explanatory variables as well as serial correlation in the residuals posed problems. The multicollinearity was investigated by ridge regressions, which strongly indicated that the internal correlation between explanatory variables does not lead to overestimated estimates of the research elasticity. The autocorrelated errors were analysed by autoregressive models of first and second order. In the autoregressive models of the first order, the autocorrelation decreased considerably, and it virtually disappeared in the second order models. The estimate of elasticity with respect to research also decreased considerably, and the regression coefficients for the error terms increased.

The results for models including either simple lags or Almon lags were somewhat paradoxical: Negative signs appeared for the estimate of elasticity with respect to research. The estimate was also insignificant. The biggest problem encountered in the study, therefore, was the failure to determine a satisfactory lag structure.

The study proceeded to report results for Cobb-Douglas models measuring the research input as a stock of research capital based on a $0 \%$, a $50 \%$ and a $100 \%$ depreciation of the research capital 20 years after grants were made. Reliable elasticity estimates of the research capital were located in the range of $0.15-0.30$, depending on the depreciation rate. The estimates of total research elasticity were somewhat lower. The research capital concept was thought to have an advantage, since it needs no lags.

The estimates of returns presented in this study were based on the assumption that no research results were imported, which biased the returns positively. The total university education and the public expenditures for extension, however, constituted a substantial share of the cost side, which may have underestimated the rate of return. At the risk of oversimplifying the entire interpretation, the following conclusions on the returns to research, discussed at length in chapter 6 , can be made:

1. Estimations using the flow measure of research input give a VMP for public research of 2.26 and of 2.73 for total public and private research. The marginal rates of return according to these estimates have been $226 \%$ for public research and $273 \%$ for total research (both over the inflation rate) from the moment the investment was made. The lack of any lag, however, biases the estimate positively, making additional measures necessary.

2. The estimates of elasticity with respect to a research capital give a VMP of 1.831.91 for public research and a VMP of 1.12 1.16 for total research. These figures are interpreted as follows: Every additional public investment in agricultural research in $1950-1984$ would have returned by $183 \%$ to $191 \%$ annually over the inflation rate from the moment the investment was made. An additional investment in the total public and private research input would correspondingly have returned by $112 \%$ to $116 \%$ annually. These research capital estimates are likely to be closer to the real VMPs than the flow estimates, since the lack of a lag should not be problematic conceptually.

3. A model using a production/input index as the dependent variable, and in which the 
number of explaining variables are reduced to only two (a research capital and a time factor) gives a marginal rate of return of $308 \%$. The errors, however, were heavily autocorrelated in this model.

4. A fourth measure of returns is the marginal internal rate of return (MIRR). This method is used to calculate the discount rate for which the net present value equals zero. On the basis of the research flow elasticity estimates, MIRRs are calculated, with lags of alternatively 4, 6 and 10 years included in these computations. MIRRs of $62.2 \%$, $37.7 \%$ and $20.9 \%$ for public research are obtained for the respective lags. The correspond- ing MIRRs for total public and private research are $76.8 \%, 46.0 \%$ and $25.9 \%$.

When funding agencies decide upon the allocation of support for research, mere rates of return are useful but, however, insufficient. They are intended to supplement other value judgements. In a situation of growing national food surpluses, special attention should be paid to alternative ways of making production effective. This implies that greater consideration should be given in the future to input-saving techniques, environmental and ecological concerns, agricultural produce for non-agricultural purposes, and new sources of livelihood for the rural population. 


\section{References}

Akıno, M. \& Hayami, Y. 1975. Efficiency in Public Research: Rice Breeding in Japans Economic Development. Amer. J. Agric. Econ. 57 (1): 1-10.

Arndt, T.M. \& Ruttan, V.M. 1977. Valuing the Productivity of Agricultural Research: Problems and Issues (pp. 3-25 in Ed. Arndt et al. 1977).

Arndt, T.M., Dalrymple, D.G. \& Ruttan, V.W. 1977. Resource Allocation and Productivity in National and International Agricultural Research. 610 p. Minneapolis. USA.

Bredahl, M. \& Peterson, W.L. 1976. The Productivity and Allocation of Research: U.S. Agricultural Experiment Stations. Amer. J. Agric. Econ. 58 (4): 684-692.

Chen, D., Courtney, R. \& Schmitz, A. 1972. A Polynomial Lag Formulation of Milk Production Response. Amer. J. Agric. Econ. 54 (1): 77-83.

Dalrymple, D.G. 1977. Evaluating the Impact of International Research on Wheat and Rice Production in the Developing Nations (pp. 171-207 in Ed. ARndT et al. 1977).

Davis 1981. The Relationship Between the Economic Surplus and Production Function Approaches for Estimating Ex-Post Returns to Agricultural Research. Rev. Marketing Agric. Econ. 42 (2): 95-105.

Doll, J.P. \& Orazem, F. 1978. Production Economics. 470 p. 2nd. Ed. USA.

Draper, N. \& Smith, H. 1981. Applied Regression Analysis. 2nd. Ed. USA.

Duncan, R.C. 1972. Evaluating Returns to Research in Pasture Improvement. Austr. J. Agric. Econ. 16 (3): 153-168.

Edwards, G.W. \& Freebairn, J.W. 1981. Measuring a Country's Gains from Research: Theory and Application to Rural Research in Australia. 154 p. Canberra.

Evenson, R.E. 1967. The Contribution of Agricultural Research to Production. J. Farm Econ. 49 (5): 14151434.

- 1971. Economic Aspects of the Organization of Agricultural Research (pp. 163-182 in Ed. FisHel. 1971).

- 1977. Comparative Evidence on Returns to Investment in National and International Research Institutions. (pp. 237-263 in Ed. Arndt et al.)

Evenson, R.E. \& Kislev, Y. 1975. Agricultural Research and Productivity. 205 p. USA.

Evenson, R.E., Waggoner, P.E. \& Ruttan, V.W. 1979. Economic Benefits from Research: An Example from Agriculture. Science 205: 1101-1107.

Fishel, W.L. 1971. Resource Allocation in Agricultural Research. 391 p. Minneapolis. USA.
Fomby, T.B., Carter Hill, R. \& Johnson, S.R. 1984. Advanced Econometric Methods. 624 p. USA.

Freebairn, J.W., Davis, J.S. \& Edwards, G.W. 1982. Distribution of Research Gains in Multistage Production Systems. Amer. J. Agric. Econ. 64 (1): 39-46.

Griliches, Z. 1958. Research Costs and Social Returns: Hybrid corn and Related Innovations. Journal of Political Economy 66: 419-341.

- 1963 a. Sources of Measured Productivity Growth. Journal of Political Economy 71: 331-346.

- 1963 b. Estimates of the Aggregate Agricultural Production Function from Cross-Sectional Data. 3. Farm Econ. 45: 419-428.

- 1964. Research Expenditure, Education and the Aggregate Agricultural Production Function. Amer. Econ. Rev. 54 (6): $961-974$.

- 1980. Returns to Research and Development Expenditures in the Private Sector (pp. 419-461 in Ed. KENDRICK \& VACCARA 1980).

Hayami, Y. \& Ruttan, V.W. 1971. Agricultural Development, An International Perspective. 367 p. USA.

Heady, E.O. \& Dillon, J.L. 1961. Agricultural Production Functions. 667 p. Ann Arbor, USA.

Heertje, A. 1977. Economics \& Technical Change. 334 p. London,

Helander, E. 1985. Vad är bra forskning. Report from Workshop on Research on Agricultural Research, Ekenäs gård, Sweden 19.-22. 3. 1985. Assoc. Nordic Agric. Scient. Sect. IX.

Hemilä, K. 1982. Measuring Technological Change in Agriculture. An application based on the CES production function. J. of Scient. Agric. Soc. Finl. 54 (3): $171-223$.

Herruzo, A.C. 1985. Returns to agricultural research: The case of rice breeding in Spain. Eur. R. agr. Econ. 12 (3): 265-282.

Hertford, R. \& Schmitz, A. 1977. Measuring Economic Returns to Agricultural Research (pp. 148-167 in Ed. ARndt et al. 1977).

Iнamuotila, R. 1972. Productivity and Aggregate Production Functions in the Finnish Agricultural Sector 1950-1969. Publ. Agric. Econ. Res. Inst. Finl. 25. 88 p. Helsinki.

- 1983. Suomen maatalouselinkeinon paaăomakanta ja velkaisuusaste 1961-1980. Helsingin yliopiston maatalousekonomian laitoksen julk. 10, 138 p. Helsinki.

Ihamuotil., R. \& Stanton, B.F. 1970. A Balance Sheet of Agriculture for Finland 1948-1964. Publ. Agric. Econ. Res. Inst. Finl. 20. 122 p. Helsinki. 
JARRETt, F. \& Lindner, R.K. 1977. Research Benefits Revisited. Rev. Marketing Agric. Econ. 45 (4): 167-178.

Kahlon, A.S., Saxena, P.N., Bal, H.K. \& Dayanath, J. 1977. Returns to Investment in Agricultural Research (pp. 124-147 in Ed. Arndt et al. 1977).

Kendrick, J.W. \& Vaccara, B.N. 1980. New Developments in Productivity Measurement and Analysis. 717 p. Chicago. USA.

Kertomus Suomen Akatemian toiminnasta 1975-83. Annual reports from the Academy of Finland.

Kettunen, L. 1985. Finnish Agriculture 1985. Publ. Agric. Econ. Res. Inst. 50. 42 p. Helsinki.

Kettunen, L. \& Rouhiainen, J. 1972. Aggregate Livestock and Total Production Functions in Finnish Agriculture in 1956/57-1969/70. Publ. Agric. Econ. Res. Inst. 28. 71 p. Helsinki.

Knutson, M. \& Tweeten, L.G. 1979. Toward an Optimate Rate of Growth in Agricultural Production Research and Extension. Amer. J. Agric. Econ. 61 (1): $70-75$.

LAURILA 1981. Maatalouden kokonaislaskelmat 1975-80. Agric. Econ. Res. Inst. Res. Rep. 77. 25 p. Helsinki.

Lee, W.F., Boehlue, M.D., Nelson, A.G. \& Murray, W.G. 1980. Agricultural Finance. 437 p. 7 th. Ed. Ames, lowa.

Lemola, T., Räty, T. \& Vesikansa, E. 1975. Valtion tutkimusmenot vuosina 1970-75. TUTKA projektin raportti 1. 193 p. Helsinki.

Lindner, R.K. \& JARRetT, F.O. 1978. Supply Shifts and the Size of Research Benefits. Amer. J. Agric. Econ. 60 (1): 48-58.

- 1980. Supply Shifts and the Size of Research Benefits. Reply. Amer. J. Agric. Econ. 62 (4): 841-844.

Lund, P.J., Irving, R.W. \& Chapman, W.G. 1980. The Economic Evaluation of Public Funded Agricultural Research and Development. Oxford Agr. studies IX: 14-33.

Martin, L.R. 1977. A Survey of Agricultural Economics Literature 1. 540 p. Minneapolis. USA.

Monthly Review of Agricultural Statistics 1955-85. Board of Agric. Helsinki.

Nagy, J.G. \& Furtan, H.W. 1978. Economic Costs and Returns from Crop Development Research: The Case of Rapeseed Breeding in Canada. Can. J. Farm. Econ. 26 (1): 1-14.

NeVAlA, M. 1976. Vaakilannoitteiden kysyntaa. Jakautuneita viiveitä sisältävien mallien sovellutuksia Suomen väkilannoitteiden käyttömäärien vaihteluiden selittämisessä ja ennakoinnissa. J. Agric. Sci. 48: 45-89.

Norton, G.W. \& DAvis, J.S. 1981. Evaluating Returns to Agricultural Research: A Review. Amer. J. Agr. Econ. 63 (4): $685-699$.

Official Statistics of Finland III. Agriculture 1950-84. Official Statistics of Finland III. Agricultural censuses 1950, 1959 and 1960.

Pasour, E.C., Jr. \& Johnson, M.A. 1982. Bureaucratic
Productivity: The Case of Agricultural Research Revisited. Public Choice 39: 301-317.

Paulsen, A.A. 1971. The Pricing of Research Output (pp. 80-89 in Ed. Fishel. 1971).

Peterson, W.L. 1967. Return to Poultry Research in the United States. J. Farm. Econ. 49 (3): 656-669.

- 1971. The Returns to Investment in Agricultural Research in the United States (pp. 139-162 in Ed. FisHEL. 1971).

- 1985. Measuring the Costs and Returns to Agricultural Research: Historical Perspective. Report from Workshop on Research on Agricultural Research, Ekenăs gård, Sweden 19.-22. 3. 1985. Assoc. Nordic Agric. Scient. Sect. IX.

Peterson, W.L. \& Hayami, Y. 1977. Technical Change in Agriculture (pp. 497-540 in MARTIN Ed. 1977).

Pindyck, R.S. \& Rubinfeld, D.L. 1981. Econometric Models \& Economic Forecasts. 630 p. USA.

Pinstrup-Andersen, P. 1979. Modern agricultural technology and income distribution: The market price effect. Eur. Rev. Agric. Econ. 6 (1): 17-46.

- 1982. Agricultural Research and Technology in Economic Development. 261 p. Singapore.

Ravenscraft, D. \& Scherer, F.M. 1982. The lag structure of returns to research and development. Applied Economics 14: 603-620.

Rose, R.N. 1980. Supply Shifs and the Size of Research Benefits: Comment. Amer. J. Agric. Econ. 62 (4): $841-844$.

RosenberG, N. 1982. Inside the Black Box: Technology and Economics. 304 p. Cambridge, USA.

Rosine, J. \& Helmberger, P. 1975. An Aggregative Analysis of the U.S. Farm Sector: Past Trends and Future Prospects. Research Bulletin R2733. 22 p. Agriculture Bulletin Building, Wisconsin, USA.

Rouniainen, J. 1972. Aggregate Crop Production Functions in Finnish Agriculture in 1956/57-1968/69. Publ. Agric. Econ. Res. Inst. 28, 2. 54 p. Helsinki.

RuSSELL, N.P. 1987. Measuring the Impact of Research and Development Expenditure - The Case of Oilseed Rape. (pp. $12-28$ in Working group A8, Vth Eur. Congr. Agric. Econ. Balatonszeplak. Budapest.)

Ruttan, V. 1982. Agricultural Research Policy. 370 p. Minnesota.

Schmitz, A. \& Seckler, D. 1970. Mechanized Agriculture and Social Welfare: The Case of the Tomato Harvester. Amer. J. Agric. Econ. 52 (4): 569-577.

Schultz, T.W. 1953. The Economic Organization of Agriculture. 374 p. USA.

- 1956. Reflections on Agricultural Production, Output and Supply. J. Farm. Econ. XXXVIII (3): $748-762$.

- 1958. Output-Input Relationships Revisited. J. Farm. Econ. XL (4): 924-932.

- 1971. The Allocation of Resources to Research (pp. 90-120 in Ed. Fishel. 1971).

- 1977. Uneven Prospects for Gains from Agricultural 
Research related to Economic Policy (pp. 578-589 in Ed. Arndt 1977).

ScoBiE, G.M. 1976. Who Benefits from Agricultural Research? Rev. Marketing Agric. Econ. 44 (4): 197-202.

Scobie, G.M. \& Posada, R.T. 1978. The Impact of Technical Change on Income Distribution: The Case of Rice in Colombia. Amer. J. Agric. Econ. 60 (1): 85-22.

Siltanen, L. 1977. Maatalouden kokonaislaskelmat 1960-1975. Agric. Econ. Res. Inst. Res. Rep. 44. 86 p. Helsinki.

Terlecky, N.E. 1980. Direct and Indirect Effects of Industrial Research and Development on the Productivity Growth of Industries. (pp. 359-386 in Ed. KENDRICK, J.W. \& VACCARA, B.N. 1980).

Tieteen keskustoimikunta ja tieteelliset toimikunnat 1970-74. Annual reports from the central of research councils and the research councils.

Tweeten, L.G. \& Hines, F.K. 1965. Contributions of Agricultural Productivity to National Economic Growth. Agric. Science Rev. 3 (2): 40-45.

UhLin, H-E. 1985. Concepts and Measurement of Technical and Structural Change in Swedish Agriculture. Swedish University of Agricultural Sciences. Dept. Econ. Statist. 184 p. Uppsala.

Valtion tieteelliset toimikunnat 1961-1969. Annual reports from the research councils.
Vihavainen, H., Valppu, P., Suokko, S. \& Bjök, B-C. 1980. Pääomakanta vuosina 1965-1977. Central Statistical Office of Finland. Studies no. 58. 100 p. Helsinki.

VUORı, S. 1984. Kokonaistuottavuus ja tutkimus- ja kehitystoiminnan tuottoaste Suomen ja Ruotsin teollisuustoimialoilla v. 1964-80. ETLA series C 32. 108 p. Helsinki.

WISE, W.S. 1981. The Theory of Agricultural Research Benefits. J. Agric. Econ. 32 (2): 147-157.

- 1984 a. The Shift of Cost Curves and Agricultural Research Benefits. J. Agric. Econ. 35 (1): 21-30.

- 1984 b. Quantitative Methods for Assessing Research Programs. OECD.AGR/REE (84)5. 16 p. Paris,

WISE, W.S. \& FelL, E. 1980. Supply Shifts and the Size of Research Benefits: Comment. Amer. J. Agric. Econ. 62 (4): $838-840$.

WonnacotT, R.J. \& Wonnacott, T.H. 1970. Econometrics. John Wilay \& Sons. 580 p. 2nd Ed. USA.

WYATT, G. 1983. Multifactor Productivity Change in Finnish and Swedish Industries, 1960 to 1980 . ETLA serie B 38. 119 p. Helsinki.

Zentner, R.P. \& Peterson, W.L. 1984. An Economic Evaluation of Public Wheat Research and Extension Expenditures in Canada. Can. J. of Agric. Econ. 32 (2): $327-353$. 
Appendix 1. Estimated rates of return from investment in agricultural research. (PINSTRUP-ANDERSEN 1982).

\begin{tabular}{|c|c|c|c|c|}
\hline Commodity & Country & Period & $\begin{array}{l}\text { Annual rate } \\
\text { of return }(\%)\end{array}$ & Source \\
\hline Aggregate & India & $1953-71$ & 40 & Evenson and Jha (1973) \\
\hline Aggregate & India & - & 63 & Kahlon et al. (1977) \\
\hline Aggregate & Japan & $1880-1938$ & 35 & Tang (1953) \\
\hline Aggregate & USA & $1949-59$ & $35-40$ & Griliches (1964) \\
\hline Aggregate & USA & $1949-59$ & 47 & Evenson (1969) \\
\hline Aggregate & USA & $1937-42$ & 50 & Peterson and Fitzharris (1977) \\
\hline Aggregate & USA & $1947-52$ & 51 & Peterson and Fitzharris (1977) \\
\hline Aggregate & USA & $1957-62$ & 49 & Peterson and Fitzharris (1977) \\
\hline Aggregate & USA & $1967-72$ & 34 & Peterson and Fitzharris (1977) \\
\hline Aggregate & USA & $1938-48$ & 30 & Lu, Cline and Quance (1979) \\
\hline Aggregate & USA & $1949-59$ & 28 & Lu, Cline and Quance (1979) \\
\hline Aggregate & USA & $1959-69$ & 26 & Lu, Cline and Quance (1979) \\
\hline Aggregate & USA & $1969-72$ & 24 & Lu, Cline and Quance (1979) \\
\hline Hybrid maize & USA & $1940-55$ & $35-40$ & Griliches (1958) \\
\hline Maize & Chile & $1940-77$ & $32-34$ & $\begin{array}{l}\text { Yrarrazaval, Navarrete and } \\
\text { Valdivia (1979) }\end{array}$ \\
\hline Maize & Peru & $1954-67$ & $35-40$ & Hines, (1972) \\
\hline Maize and sorghum & Mexico & $1943-64$ & $26-59$ & Ardito-Barletta (1970) \\
\hline Hybrid sorghum & USA & $1940-57$ & 20 & Griliches (1958) \\
\hline Wheat & Mexico & $1943-64$ & $69-104$ & Ardito-Barletta (1970) \\
\hline Wheat & Colombia & $1953-73$ & $11-12$ & Hertford et al. (1977) \\
\hline Wheat & Bolivia & $1966-75$ & -48 & $\begin{array}{l}\text { Wennergren and } \\
\text { Whitaker (1977) }\end{array}$ \\
\hline Wheat & Chile & $1949-77$ & & $\begin{array}{l}\text { Yrarrazaval, Navarrete and } \\
\text { Valdivia (1979) }\end{array}$ \\
\hline Rice & Colombia & $1957-72$ & $60-82$ & Hertford et al. (1977) \\
\hline Rice & Colombia & $1957-74$ & 94 & Scobie and Posada (1978) \\
\hline Rice & Japan & $1915-50$ & $25-27$ & Akino and Hayami (1975) \\
\hline Rice & Japan & $1930-61$ & $73-75$ & Akino and Hayami (1975) \\
\hline Rice & Asia & $1950-65$ & $32-39$ & Evenson and Flores (1978) \\
\hline Rice & Asia & $1966-75$ & $73-78$ & Evenson and Flores (1978) \\
\hline Rice & Tropics & $1966-75$ & $46-71$ & Flores-Moya et al. (1978) \\
\hline Rice & Philippines & $1966-75$ & 27 & Flores-Moya et al. (1978) \\
\hline Cash grains & USA & 1969 & 36 & Bredahl and Peterson (1976) \\
\hline Soybeans & Colombia & $1960-71$ & $79-96$ & Hertford et al. (1977) \\
\hline Potatoes & Mexico & $1943-64$ & 69 & Ardito-Barletta (1970) \\
\hline Sugar cane & South Africa & $1945-62$ & 40 & Evenson (1969) \\
\hline Sugar cane & Australia & $1945-58$ & 50 & Evenson (1969) \\
\hline Sugar cane & India & $1945-58$ & 60 & Evenson (1969) \\
\hline Cocoa & Brazil & $1923-74$ & 16 & Monteiro (1975) \\
\hline Cocoa & Brazil & $1958-74$ & 60 & Monteiro (1975) \\
\hline Cotton & Brazil & $1924-67$ & $77+$ & Ayer (1970) \\
\hline Cotton & Colombia & $1953-72$ & Negative & Hertford et al. (1977) \\
\hline Rubber & Malaysia & $1932-73$ & 25 & Pee (1977) \\
\hline Rapeseed & Canada & $1964-75$ & $95-105$ & Nagy and Furtan (1978) \\
\hline Pastures & Australia & $1948-69$ & $65-80$ & Duncan (1972) \\
\hline Poultry & USA & $1915-60$ & $21-25$ & Peterson (1967) \\
\hline Poultry & USA & 1969 & 37 & Bredahl and Peterson (1976) \\
\hline Sheep & Bolivia & $1966-75$ & 44 & $\begin{array}{l}\text { Wennergren and } \\
\text { Whitaker (1977) }\end{array}$ \\
\hline Dairy & India & $1963-75$ & 29 & Kumar, Maji and Patel (1977) \\
\hline Dairy & USA & 1969 & 43 & Bredahl and Peterson (1976) \\
\hline Livestock & USA & 1969 & 47 & Bredahl and Peterson (1976) \\
\hline Tomato harvest & USA & $1958-69$ & $37-46$ & Schmitz and Seckler (1970) \\
\hline
\end{tabular}


Appendix 2. Index series used in the regressions.

\begin{tabular}{|c|c|c|c|c|c|c|c|}
\hline Year & $\begin{array}{l}\text { Agricultural } \\
\text { gross } \\
\text { production }\end{array}$ & $\begin{array}{l}\text { Deflated } \\
\text { public } \\
\text { research } \\
\text { input } \\
\text { and univ. } \\
\text { education }\end{array}$ & $\begin{array}{l}\text { Deflated } \\
\text { total } \\
\text { research } \\
\text { input } \\
\text { and univ. } \\
\text { education }\end{array}$ & $\begin{array}{l}\text { Deflated } \\
\text { extension' }\end{array}$ & Capital & Labour & $\begin{array}{c}\text { External } \\
\text { inputs }\end{array}$ \\
\hline 1950 & 100 & 100 & 100 & 100 & 100 & 100 & 100 \\
\hline 1951 & 102 & 137 & 133 & 100 & 103 & 92 & 99 \\
\hline 1952 & 105 & 127 & 128 & 99 & 106 & 93 & 108 \\
\hline 1953 & 108 & 119 & 123 & 102 & 109 & 91 & 109 \\
\hline 1954 & 110 & 118 & 125 & 95 & 111 & 88 & 120 \\
\hline 1955 & 108 & 142 & 145 & 91 & 114 & 88 & 135 \\
\hline 1956 & 112 & 162 & 167 & 99 & 116 & 85 & 151 \\
\hline 1957 & 116 & 154 & 164 & 107 & 118 & 86 & 153 \\
\hline 1958 & 117 & 230 & 235 & 116 & 120 & 87 & 145 \\
\hline 1959 & 124 & 226 & 233 & 117 & 123 & 86 & 155 \\
\hline 1960 & 130 & 213 & 225 & 114 & 126 & 86 & 174 \\
\hline 1961 & 136 & 222 & 236 & 128 & 128 & 84 & 182 \\
\hline 1962 & 140 & 295 & 311 & 141 & 131 & 88 & 199 \\
\hline 1963 & 142 & 303 & 329 & 151 & 134 & 85 & 228 \\
\hline 1964 & 148 & 296 & 323 & 157 & 137 & 83 & 222 \\
\hline 1965 & 149 & 356 & 399 & 164 & 139 & 74 & 230 \\
\hline 1966 & 148 & 366 & 419 & 166 & 141 & 74 & 234 \\
\hline 1967 & 146 & 365 & 443 & 163 & 143 & 68 & 242 \\
\hline 1968 & 149 & 398 & 479 & 152 & 143 & 68 & 254 \\
\hline 1969 & 152 & 373 & 470 & 153 & 146 & 65 & 269 \\
\hline 1970 & 152 & 346 & 454 & 155 & 145 & $57^{2}$ & 283 \\
\hline 1971 & 157 & 345 & 467 & 149 & 147 & 50 & 296 \\
\hline 1972 & 160 & 394 & 579 & 138 & 147 & 49 & 298 \\
\hline 1973 & 153 & 399 & 561 & 136 & 148 & 45 & 303 \\
\hline 1974 & 155 & 370 & 491 & 134 & 150 & 43 & 313 \\
\hline 1975 & 159 & 457 & 562 & 147 & 151 & 41 & 326 \\
\hline 1976 & 169 & 479 & 634 & 150 & 153 & 40 & 327 \\
\hline 1977 & 169 & 622 & 754 & 145 & 154 & 39 & 310 \\
\hline 1978 & 164 & 526 & 665 & 148 & 155 & 37 & 343 \\
\hline 1979 & 167 & 623 & 758 & 143 & 156 & 34 & 365 \\
\hline 1980 & 171 & 633 & 758 & 148 & 158 & 32 & 391 \\
\hline 1981 & 172 & 650 & 750 & 152 & 160 & 33 & 391 \\
\hline 1982 & 170 & 610 & 754 & 160 & 162 & 31 & 419 \\
\hline 1983 & 172 & 614 & 811 & 161 & 163 & 27 & 406 \\
\hline 1984 & 174 & 620 & 795 & 161 & 164 & 26 & 394 \\
\hline
\end{tabular}

1 Before 1970 interpolated with five years intervals. The value 1950 assumed to be equal to 1951 .

2 The labour input of 1970 calculated as an average of 1969 and 1971. 
Appendix 3. The absolute figures for the index series.

\begin{tabular}{|c|c|c|c|c|c|c|c|c|}
\hline Year & $\begin{array}{l}\text { Nominal } \\
\text { public } \\
\text { research } \\
\text { input and } \\
\text { university } \\
\text { education } \\
\text { (FIM 1000) }\end{array}$ & $\begin{array}{l}\text { GDP } \\
\text { price } \\
\text { index to } \\
\text { market } \\
\text { price }\end{array}$ & $\begin{array}{l}\text { Deflated } \\
\text { public } \\
\text { research } \\
\text { input and } \\
\text { university } \\
\text { education } \\
\text { in prices } \\
\text { of } 1980 \\
\text { (FIM 1000) }\end{array}$ & $\begin{array}{l}\text { Nominal } \\
\text { interpol. } \\
\text { public } \\
\text { extension } \\
\text { support } \\
\text { (FIM 1000) }\end{array}$ & $\begin{array}{l}\text { Deflated } \\
\text { interpol. } \\
\text { public } \\
\text { extension } \\
\text { support } \\
\text { in prices } \\
\text { of } 1980 \\
\text { (FIM 1000) }\end{array}$ & $\begin{array}{c}\text { External } \\
\text { inputs in } \\
\text { prices of } \\
1970 \\
\text { (FIM 1000) }\end{array}$ & $\begin{array}{l}\text { Gross } \\
\text { capital } \\
\text { stock in } \\
\text { prices of } \\
1980 \\
\text { (FIM } \\
\text { million) }\end{array}$ & $\begin{array}{l}\text { Number } \\
\text { of farms' }\end{array}$ \\
\hline 1950 & 2,087 & 11.85 & 17,610 & 3,396 & $28,658.2$ & 650,465 & 56,448 & 465,655 \\
\hline 1951 & 3,133 & 12.96 & 24,180 & 3,396 & $26,203.7$ & 643,413 & 58,012 & $450,723^{*}$ \\
\hline 1952 & 3,008 & 13.40 & 22,437 & 3,484 & $26,000.0$ & 700,746 & 60,097 & $435,790^{*}$ \\
\hline 1953 & 2,810 & 13.42 & 20,936 & 3,572 & $26,617.0$ & 710,871 & 61,307 & $420,858^{*}$ \\
\hline 1954 & 3,034 & 14.64 & 20,727 & 3,660 & $25,000.0$ & 778,143 & 62,861 & $405,925^{*}$ \\
\hline 1955 & 3,925 & 15.74 & 24,934 & 3,749 & $23,818.3$ & 876,732 & 64,303 & $390,993^{*}$ \\
\hline 1956 & 4,566 & 16.05 & 28,442 & 4,150 & $25,856.7$ & 984,696 & 65,401 & $376,060^{*}$ \\
\hline 1957 & 4,425 & 16.30 & 27,151 & 4,551 & $27,920.2$ & 995,795 & 66,615 & $361,128^{*}$ \\
\hline 1958 & 6,597 & 16.28 & 40,513 & 4,953 & $30,423.8$ & 941,957 & 67,845 & $346,195 *$ \\
\hline 1959 & 6,936 & 17.47 & 39,713 & 5,354 & $30,646.8$ & $1,007,398$ & 69,169 & 331,263 \\
\hline 1960 & 7,201 & 19.20 & 37,507 & 5,756 & $29,979.2$ & $1,133,112$ & 70,868 & $327,826^{*}$ \\
\hline 1961 & 7,904 & 20.20 & 39,130 & 6,749 & $33,410.9$ & $1,184,491$ & 72,480 & $324,462^{*}$ \\
\hline 1962 & 10,919 & 21.00 & 51,995 & 7,743 & $36,871.4$ & $1,294,008$ & 74,124 & $321,061^{*}$ \\
\hline 1963 & 11,784 & 22.10 & 53,319 & 8,736 & $39,529.4$ & $1,482,652$ & 75,734 & $317,661^{*}$ \\
\hline 1964 & 12,333 & 23.70 & 52,039 & 9,730 & $41,054.9$ & $1,442,212$ & 77,075 & $314,260^{*}$ \\
\hline 1965 & 15,622 & 24.90 & 62,740 & 10,723 & $43,064.3$ & $1,494,078$ & 78,197 & $310,859^{*}$ \\
\hline 1966 & 16,837 & 26.10 & 64,508 & 11,324 & $43,387.0$ & $1,520,249$ & 79,626 & $307,459^{*}$ \\
\hline 1967 & 17,982 & 28.00 & 64,221 & 11,925 & $42,589.3$ & $1,575,007$ & 80,528 & $304,058^{*}$ \\
\hline 1968 & 22,005 & 31.40 & 70,080 & 12,527 & $39,894.9$ & $1,653,091$ & 80,948 & $300,658^{*}$ \\
\hline 1969 & 21,469 & 32.70 & 65,653 & 13,128 & $40,146.8$ & $1,746,600$ & 82,234 & 297,257 \\
\hline 1970 & 20,639 & 33.90 & 60,882 & 13,729 & $40,498.5$ & $1,840,000$ & 81,701 & $289,640^{*}$ \\
\hline 1971 & 22,191 & 36.50 & 60,798 & 14,205 & $38,917.8$ & $1,927,600$ & 82,749 & $282,023^{*}$ \\
\hline 1972 & 27,453 & 39.60 & 69,325 & 14,332 & $36,191.9$ & $1,937,900$ & 83,026 & 274,406 \\
\hline 1973 & 31,711 & 45.10 & 70,312 & 16,132 & $35,769.4$ & $1,972,900$ & 83,763 & 265,938 \\
\hline 1974 & 36,068 & 55.30 & 65,222 & 19,376 & $35,038.0$ & $2,036,100$ & 84,408 & 258,200 \\
\hline 1975 & 50,959 & 63.30 & 80,503 & 24,304 & $38,394.9$ & $2,121,839$ & 85,071 & 248,736 \\
\hline 1976 & 60,194 & 71.30 & 84,423 & 28,110 & $39,425.0$ & $2,129,517$ & 86,134 & 242,682 \\
\hline 1977 & 86,145 & 78.60 & 109,600 & 29,824 & $37,944.0$ & $2,019,477$ & 86,876 & 237,679 \\
\hline 1978 & 78,435 & 84.60 & 92,712 & 32,731 & $38,689.1$ & $2,229,699$ & 87,354 & 232,820 \\
\hline 1979 & 100,534 & 91.60 & 109,753 & 34,432 & $37,589.5$ & $2,375,850$ & 88,278 & 229,349 \\
\hline 1980 & 111,538 & 100.00 & 111,539 & 38,775 & $38,775.0$ & $2,546,052$ & 89,428 & 224,721 \\
\hline 1981 & 127,430 & 111.40 & 114,390 & 44,328 & $39,791.7$ & $2,541,191$ & 90,525 & 218,904 \\
\hline 1982 & 130,617 & 121.50 & 107,503 & 51,079 & $42,040.3$ & $2,726,488$ & 91,293 & 212,630 \\
\hline 1983 & 142,914 & 132.10 & 108,186 & 55,849 & $42,277,8$ & $2,642,618$ & 92,276 & 208,229 \\
\hline 1984 & 157,028 & 143.90 & 109,123 & 60,556 & $42,082.0$ & $2,562,952$ & 92,777 & 203,933 \\
\hline
\end{tabular}

1* $=$ interpolated 
Appendix 4. Total expenditures and State support for the agricultural extension agencies (Association of Agricultural Centres, the Agricultural Centres, Association for Agricultural Societies of Swedish Speaking Farmers, the Agricultural Societies and the small farmer organizations) (FIM 1000).

\begin{tabular}{cccc}
\hline Year & $\begin{array}{c}\text { Total } \\
\text { expendi- } \\
\text { tures }\end{array}$ & $\begin{array}{c}\text { Total } \\
\text { State } \\
\text { support }\end{array}$ & $\begin{array}{c}\text { State support } \\
\text { in \% of total } \\
\text { expenditures }\end{array}$ \\
\hline
\end{tabular}

\begin{tabular}{lrrl}
\hline 1950 & & & \\
1951 & 6,581 & 3,396 & 51.61 \\
1955 & 8,249 & 3,748 & 45.44 \\
1960 & 11,281 & 5,756 & 51.03 \\
1965 & 19,143 & 10,723 & 56.01 \\
1970 & 20,613 & 13,729 & 66.60 \\
1971 & 22,229 & 14,205 & 63,90 \\
1972 & 23,563 & 14,332 & 60.82 \\
1973 & 28,421 & 16,132 & 56.76 \\
1974 & 32,292 & 19,376 & 60.00 \\
1975 & 41,762 & 24,304 & 58.20 \\
1976 & 53,563 & 28,110 & 52.48 \\
1977 & 54,940 & 29,824 & 54.28 \\
1978 & 64,380 & 32,730 & 50.84 \\
1979 & 72,671 & 34,432 & 47.38 \\
1980 & 81,668 & 38,775 & 47.47 \\
1981 & 95,489 & 44,328 & 46.42 \\
1982 & 107,333 & 51,079 & 47.60 \\
1983 & 120,374 & 55,849 & 46.40 \\
1984 & 133,013 & 60,557 & 45.40 \\
\hline
\end{tabular}

Appendix 5. Gross capital stock in basic agriculture according to the national accounts in prices of 1980 (FIM million).

\begin{tabular}{llll}
\hline 1950 & $28,381.2$ & 1968 & $49,899.6$ \\
1951 & $29,625.0$ & 1969 & $50,931.7$ \\
1952 & $31,232.4$ & 1970 & $51,719.2$ \\
1953 & $32,492.3$ & 1971 & $52,608.2$ \\
1954 & $33,708.5$ & 1972 & $53,240.7$ \\
1955 & $34,975.7$ & 1973 & $54,038.8$ \\
1956 & $36,066.1$ & 1974 & $54,683.3$ \\
1957 & $37,087.3$ & 1975 & $55,582.1$ \\
1958 & $38,098.9$ & 1976 & $56,485.6$ \\
1959 & $39,279.2$ & 1977 & $57,138.4$ \\
1960 & $40,551.9$ & 1978 & $57,803.5$ \\
1961 & $41,967.7$ & 1979 & $58,724.7$ \\
1962 & $43,223.8$ & 1980 & $60,004.5$ \\
1963 & $44,621.6$ & 1981 & $60,958.0$ \\
1964 & $45,778.8$ & 1982 & $62,237.4$ \\
1965 & $47,009.2$ & 1983 & $63,359.2$ \\
1966 & $48,346.4$ & 1984 & $64,100.3$ \\
1967 & $49,269.7$ & & \\
\hline
\end{tabular}

Appendix 6. Linear production functions with total research. All variables measured at aggregate level. Regression coefficients and their standard errors in parenthesis below coefficients, significance levels, coefficient of determination, F-ratio and Durbin-Watson test values.'

\begin{tabular}{|c|c|c|c|c|}
\hline \multirow[t]{2}{*}{ Regression } & \multirow[t]{2}{*}{ (5) } & \multirow{2}{*}{\multicolumn{2}{|c|}{ (6) }} & \multirow[b]{2}{*}{ s.l. } \\
\hline & & & & \\
\hline Constant & $\begin{array}{r}-46.232 \\
(14.949)\end{array}$ & 0.004 & $\begin{array}{r}-27.315 \\
(23.312)\end{array}$ & 0.251 \\
\hline Capital & $\begin{array}{c}1.227 \\
(0.150)\end{array}$ & 0.000 & $\begin{array}{c}1.074 \\
(0.208)\end{array}$ & 0.000 \\
\hline Labour & $\begin{array}{c}0.195 \\
(0.107)\end{array}$ & 0.070 & $\begin{array}{c}0.095 \\
(0.143)\end{array}$ & 0.511 \\
\hline External inputs & $\begin{array}{r}-0.010 \\
(0.041)\end{array}$ & 0.809 & $\begin{array}{r}-0.012 \\
(0.041)\end{array}$ & 0.767 \\
\hline $\begin{array}{l}\text { Total public \& } \\
\text { private research }\end{array}$ & $\begin{array}{c}0.025 \\
(0.013)\end{array}$ & 0.057 & $\begin{array}{c}0.022 \\
(0.013)\end{array}$ & 0.102 \\
\hline Extension & & & $\begin{array}{c}0.077 \\
(0.073)\end{array}$ & 0.300 \\
\hline $\mathbf{R}^{2}$ & 0.983 & & 0.984 & \\
\hline Stand.error of estimate & 3.263 & & 3.257 & \\
\hline F-ratio ${ }^{3}$ & $444.85^{* * * *}$ & & $357.47^{* * *}$ & \\
\hline D-W test value & 0.963 & & 0.990 & \\
\hline
\end{tabular}

1 These coeffients, the F-ratio and D-W test-value will be presented in all the regression tables.

2 Significance levels with t-test. The abbreviation applies to all regression tables.

${ }^{3 * * *}=$ Significance level for F-ratio $\leq 0.001 \%$. The abbreviation applies to all regression tables. 
Appendix 7. Linear production functions with total research. Output, capital, labour, external inputs measured at farm level, research and extension at aggregate level.

\begin{tabular}{|c|c|c|c|c|}
\hline \multirow[t]{2}{*}{ Regression } & \multirow[t]{2}{*}{ (7) } & \multicolumn{3}{|c|}{ (8) } \\
\hline & & s.l. & & s.l. \\
\hline Constant & $\begin{array}{c}-20.175 \\
(10.303)\end{array}$ & 0.059 & $\begin{array}{r}-20.087 \\
(10.401)\end{array}$ & 0.063 \\
\hline Capital & $\begin{array}{c}0.982 \\
(0.134)\end{array}$ & 0.000 & $\begin{array}{c}0.983 \\
(0.136)\end{array}$ & 0.000 \\
\hline Labour & $\begin{array}{c}0.130 \\
(0.098)\end{array}$ & 0.197 & $\begin{array}{c}0.084 \\
(0.121)\end{array}$ & 0.493 \\
\hline External inputs & $\begin{array}{r}0.0001 \\
(0.037)\end{array}$ & 0.997 & $\begin{array}{r}-0.0007 \\
(0.037)\end{array}$ & 0.985 \\
\hline Total research & $\begin{array}{c}0.054 \\
(0.022)\end{array}$ & 0.020 & $\begin{array}{c}0.047 \\
(0.025)\end{array}$ & 0.067 \\
\hline Extension & & & $\begin{array}{c}0.053 \\
(0.080)\end{array}$ & 0.512 \\
\hline $\mathbf{R}^{2}$ & 0.997 & & 0.997 & \\
\hline Stand.error of estimate & 5.158 & & 5.201 & \\
\hline F-ratio & $2479.2^{* * *}$ & & $1946.48^{* * *}$ & \\
\hline D-W test value & 1.132 & & 1.121 & \\
\hline
\end{tabular}

Appendix 8. Cobb-Douglas production functions with total research. All variables measured at aggregate level.

\begin{tabular}{|c|c|c|c|c|}
\hline \multirow[t]{2}{*}{ Regression } & \multirow[t]{2}{*}{ (14) } & \multirow[b]{2}{*}{ s.l. } & \multirow[t]{2}{*}{ (15) } & \multirow[b]{2}{*}{ s.l. } \\
\hline & & & & \\
\hline Constant & $\begin{array}{c}0.009 \\
(1.000)\end{array}$ & 0.993 & $\begin{array}{c}0.283 \\
(0.969)\end{array}$ & 0.773 \\
\hline Capital & $\begin{array}{c}0.808 \\
(0.324)\end{array}$ & 0.019 & $\begin{array}{c}0.696 \\
(0.317)\end{array}$ & 0.036 \\
\hline Labour & $\begin{array}{c}0.048 \\
(0.024)\end{array}$ & 0.060 & $\begin{array}{c}0.012 \\
(0.030)\end{array}$ & 0.685 \\
\hline External inputs & $\begin{array}{c}0.058 \\
(0.093)\end{array}$ & 0.534 & $\begin{array}{c}0.062 \\
(0.089)\end{array}$ & 0.494 \\
\hline $\begin{array}{l}\text { Total public \& } \\
\text { private research }\end{array}$ & $\begin{array}{c}0.078 \\
(0.043)\end{array}$ & 0.079 & $\begin{array}{c}0.050 \\
(0.044)\end{array}$ & 0.261 \\
\hline Extension & & & $\begin{array}{l}0.116 \\
(0.061)\end{array}$ & 0.067 \\
\hline $\mathbf{R}^{2}$ & 0.984 & & 0.986 & \\
\hline Stand.error of estimate & 0.024 & & 0.023 & \\
\hline F-ratio & $462.60^{* * *}$ & & $403.05 * * *$ & \\
\hline D-W test value & 1.048 & & 1.115 & \\
\hline
\end{tabular}


Appendix 9. Cobb-Douglas production functions with total research. Output, capital, labour, external inputs measured at farm level, research and extension at aggregate level.

\begin{tabular}{|c|c|c|c|c|}
\hline Regression & (16) & s.l. & (17) & s.l. \\
\hline Constant & $\begin{array}{r}-0.307 \\
(0.332)\end{array}$ & 0.362 & $\begin{array}{r}-0.574 \\
(0.355)\end{array}$ & 0.116 \\
\hline Capital & $\begin{array}{c}0.898 \\
(0.138)\end{array}$ & 0.000 & $\begin{array}{c}0.958 \\
(0.138)\end{array}$ & 0.000 \\
\hline Labour & $\begin{array}{c}0.048 \\
(0.026)\end{array}$ & 0.078 & $\begin{array}{c}0.012 \\
(0.033)\end{array}$ & 0.707 \\
\hline Exiernal inputs & $\begin{array}{c}0.053 \\
(0.080)\end{array}$ & 0.510 & $\begin{array}{c}0.025 \\
(0.079)\end{array}$ & 0.755 \\
\hline Total research & $\begin{array}{c}0.061 \\
(0.035)\end{array}$ & 0.089 & $\begin{array}{c}0.021 \\
(0.041)\end{array}$ & 0.602 \\
\hline Extension & & & $\begin{array}{c}0.103 \\
(0.059)\end{array}$ & 0.089 \\
\hline $\mathbf{R}^{2}$ & 0.997 & & 0.997 & \\
\hline Stand.error of estimate & 0.024 & & 0.023 & \\
\hline F-ratio & $2423.0^{* * *}$ & & $2074.5^{* * *}$ & \\
\hline D-W test value & 0.966 & & 0.976 & \\
\hline
\end{tabular}

Appendix 10. First order autoregressive Cobb-Douglas production functions with total research. All variables measured at aggregate level.

\begin{tabular}{|c|c|c|c|c|}
\hline \multirow[t]{2}{*}{ Regression } & \multirow[t]{2}{*}{ (22) } & \multirow[b]{2}{*}{ s.l. } & \multirow[t]{2}{*}{ (23) } & \multirow[b]{2}{*}{ s.l. } \\
\hline & & & & \\
\hline Constant & $\begin{array}{r}-1.798 \\
(1.199)\end{array}$ & 0.144 & $\begin{array}{r}-1.338 \\
(1.335)\end{array}$ & 0.325 \\
\hline Capital & $\begin{array}{c}1.329 \\
(0.343)\end{array}$ & 0.001 & $\begin{array}{c}1.184 \\
(0.394)\end{array}$ & 0.006 \\
\hline Labour & $\begin{array}{c}0.046 \\
(0.034)\end{array}$ & 0.184 & $\begin{array}{c}0.029 \\
(0.041)\end{array}$ & 0.489 \\
\hline External inputs & $\begin{array}{r}-0.022 \\
(0.088)\end{array}$ & 0.806 & $\begin{array}{r}-0.011 \\
(0.091)\end{array}$ & 0.905 \\
\hline Total aggregate research & $\begin{array}{c}0.025 \\
(0.036)\end{array}$ & 0.497 & $\begin{array}{c}0.022 \\
(0.037)\end{array}$ & 0.561 \\
\hline Extension & & & $\begin{array}{c}0.057 \\
(0.080)\end{array}$ & 0.481 \\
\hline$\theta_{1}$ & $\begin{array}{c}0.516 \\
(0.147)\end{array}$ & 0.001 & $\begin{array}{c}0.495 \\
(0.149)\end{array}$ & 0.002 \\
\hline $\mathbf{R}^{2}$ & 0.986 & & 0.988 & \\
\hline Stand.error of estimate & 0.020 & & 0.020 & \\
\hline F-ratio & $579.29 * * *$ & & $455.38^{* * *}$ & \\
\hline D-W test value & 1.741 & & 1.755 & \\
\hline
\end{tabular}


Appendix 11. Second order autoregressive Cobb-Douglas production functions with total research. All variables measured at aggregate level.'

\begin{tabular}{|c|c|c|c|c|}
\hline \multirow[t]{2}{*}{ Regression } & \multirow[t]{2}{*}{ (24) } & \multirow[b]{2}{*}{ s.l. } & \multirow[t]{2}{*}{ (25) } & \multirow[b]{2}{*}{ s.l. } \\
\hline & & & & \\
\hline Constant & $\begin{array}{r}-0.632 \\
(0.945)\end{array}$ & n.s. & $\begin{array}{r}-0.429 \\
(0.932)\end{array}$ & n.s. \\
\hline Capital & $\begin{array}{c}1.017 \\
(0.296)\end{array}$ & $<0.002$ & $\begin{array}{c}0.930 \\
(0.297)\end{array}$ & $<0.005$ \\
\hline Labour & $\begin{array}{c}0.037 \\
(0.030)\end{array}$ & n.s. & $\begin{array}{c}0.014 \\
(0.033)\end{array}$ & n.s. \\
\hline External inputs & $\begin{array}{c}0.047 \\
(0.086)\end{array}$ & n.s. & $\begin{array}{c}0.031 \\
(0.087)\end{array}$ & n.s. \\
\hline Total aggregate research & $\begin{array}{c}0.031 \\
(0.035)\end{array}$ & n.s. & $\begin{array}{c}0.028 \\
(0.036)\end{array}$ & n.s. \\
\hline Extension & & & $\begin{array}{c}0.088 \\
(0.061)\end{array}$ & n.s. \\
\hline$\theta_{1}$ & $\begin{array}{c}0.679 \\
(0.162)\end{array}$ & $<0.001$ & $\begin{array}{c}0.600 \\
(0.163)\end{array}$ & $<0.001$ \\
\hline$\theta_{2}$ & $\begin{array}{r}-0.287 \\
(0.162)\end{array}$ & $<0.100$ & $\begin{array}{r}-0.259 \\
(0.163)\end{array}$ & n.s. \\
\hline $\mathbf{R}^{2}$ & 0.989 & & 0.990 & \\
\hline Stand.error of estimate & 0.020 & & 0.019 & \\
\hline D-W test value & 1.931 & & 1.989 & \\
\hline
\end{tabular}

' n.s. = not significant. s.1. $>0.01$

Appendix 12. Cobb-Douglas production functions with total research for shorter periods. All variables measured at aggregate level.

\begin{tabular}{|c|c|c|c|c|c|c|c|c|}
\hline \multirow[t]{2}{*}{ Regression } & \multirow{2}{*}{$\begin{array}{c}(30) \\
1950-69\end{array}$} & \multicolumn{3}{|c|}{ (31) } & \multirow{2}{*}{$\begin{array}{c}(32) \\
1965-84\end{array}$} & \multicolumn{3}{|c|}{ (33) } \\
\hline & & s.l. & & s.l. & & s.l. & & s.l. \\
\hline Constant & $\begin{array}{c}-2.383 \\
(1.626)\end{array}$ & 0.164 & $\begin{array}{r}-2.600 \\
(1.198)\end{array}$ & 0.048 & $\begin{array}{c}3.162 \\
(2.268)\end{array}$ & 0.184 & $\begin{array}{c}4.361 \\
(2.823)\end{array}$ & 0.145 \\
\hline Capital & $\begin{array}{c}1.168 \\
(0.445)\end{array}$ & 0.019 & $\begin{array}{c}1.217 \\
(0.327)\end{array}$ & 0.002 & $\begin{array}{c}0.219 \\
(0.495)\end{array}$ & 0.664 & $\begin{array}{l}-0.120 \\
(0.683)\end{array}$ & 0.863 \\
\hline Labour & $\begin{array}{c}0.266 \\
(0.104)\end{array}$ & 0.022 & $\begin{array}{c}0.159 \\
(0.082)\end{array}$ & 0.071 & $\begin{array}{c}-0.035 \\
(0.070)\end{array}$ & 0.627 & $\begin{array}{c}-0.061 \\
(0.080)\end{array}$ & 0.453 \\
\hline $\begin{array}{l}\text { External } \\
\text { inputs }\end{array}$ & $\begin{array}{c}0.026 \\
(0.129)\end{array}$ & 0.842 & $\begin{array}{r}-0.010 \\
(0.095)\end{array}$ & 0.913 & $\begin{array}{c}0.012 \\
(0.116)\end{array}$ & 0.920 & $\begin{array}{c}0.042 \\
(0.125)\end{array}$ & 0.741 \\
\hline $\begin{array}{l}\text { Total } \\
\text { research }\end{array}$ & $\begin{array}{c}0.052 \\
(0.056 \mathrm{~b})\end{array}$ & 0.368 & $\begin{array}{r}-0.066 \\
(0.052)\end{array}$ & 0.225 & $\begin{array}{c}0.138 \\
(0.057)\end{array}$ & 0.028 & $\begin{array}{c}0.150 \\
(0.060)\end{array}$ & 0.025 \\
\hline Extension & & & $\begin{array}{c}0.243 \\
(0.066)\end{array}$ & 0.002 & & & $\begin{array}{c}0.070 \\
(0.095)\end{array}$ & 0.475 \\
\hline $\mathbf{R}^{2}$ & 0.978 & & 0.989 & & 0.925 & & 0.928 & \\
\hline $\begin{array}{l}\text { Stand.error } \\
\text { of estimate }\end{array}$ & 0.025 & & 0.018 & & 0.018 & & 0.019 & \\
\hline F-ratio & $165.26^{* * *}$ & & $247.07^{* * *}$ & & $46.46^{* * *}$ & & $36.13^{* * *}$ & \\
\hline D-W test value & 1.052 & & 1.373 & & 1.617 & & 1.784 & \\
\hline
\end{tabular}




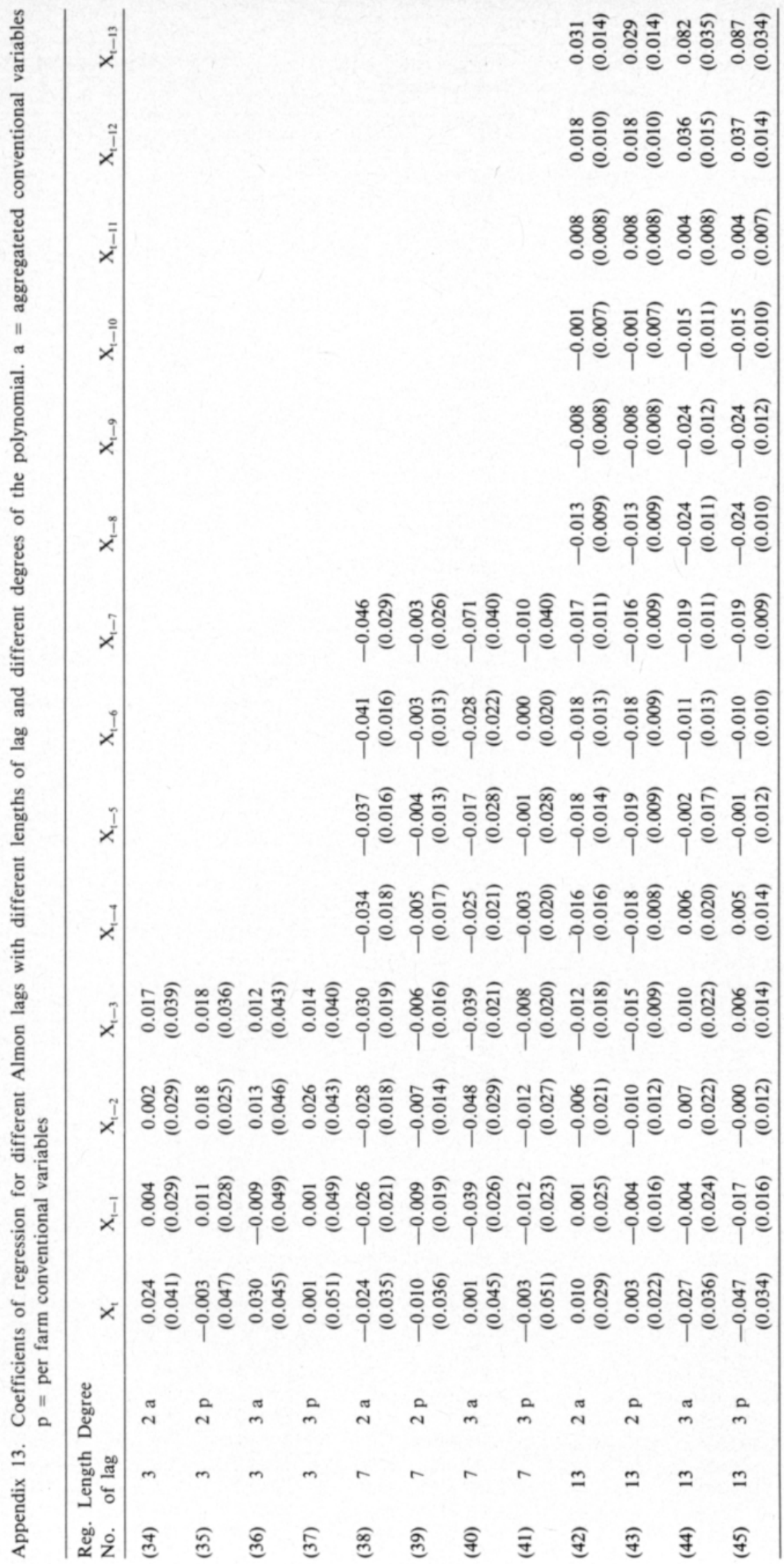


Appendix 14. Derivation of the public research capital in prices of 1984 .

\begin{tabular}{|c|c|c|c|c|c|c|c|c|}
\hline & \multirow{3}{*}{$\begin{array}{l}\text { Grants } \\
1950-84\end{array}$} & \multirow{3}{*}{$\begin{array}{c}\text { Derived } \\
\text { grants } \\
1920-50\end{array}$} & \multirow{2}{*}{\multicolumn{2}{|c|}{$\begin{array}{l}\text { Undepreciated } \\
\text { research capital }\end{array}$}} & \multicolumn{4}{|c|}{ Depreciated research capital } \\
\hline & & & & & \multicolumn{2}{|c|}{ dep.rate $=50 \%$} & \multicolumn{2}{|c|}{ dep.rate $=100 \%$} \\
\hline & & & FIM 1000 & Index & FIM 1000 & Index & FIM 1000 & Index \\
\hline 1920 & & 2,930 & 2,930 & & & & & \\
\hline 1921 & & 3,826 & 6,757 & & & & & \\
\hline 1922 & & 4,722 & 11,479 & & & & & \\
\hline 1923 & & 5,618 & 17,097 & & & & & \\
\hline 1924 & & 6,514 & 23,611 & & & & & \\
\hline 1925 & & 7,410 & 31,021 & & & & & \\
\hline 1926 & & 8,306 & 39,326 & & & & & \\
\hline 1927 & & 9,201 & 48,528 & & & & & \\
\hline 1928 & & 10,097 & 58,625 & & & & & \\
\hline 1929 & & 10,993 & 69,618 & & & & & \\
\hline 1930 & & 11,889 & 81,507 & & & & & \\
\hline 1931 & & 12,785 & 94,292 & & & & & \\
\hline 1932 & & 13,681 & 107,973 & & & & & \\
\hline 1933 & & 14,577 & 122,550 & & & & & \\
\hline 1934 & & 15,473 & 138,022 & & & & & \\
\hline 1935 & & 16,368 & 154,391 & & & & & \\
\hline 1936 & & 17,264 & 171,655 & & & & & \\
\hline 1937 & & 18,160 & 189,815 & & & & & \\
\hline 1938 & & 19,056 & 208,871 & & & & & \\
\hline 1939 & & 19,952 & 228,823 & & & & & \\
\hline 1945 & & 20,848 & 249,670 & & 248,205 & & 246,740 & \\
\hline 1946 & & 21,744 & 271,414 & & 268,036 & & 264,657 & \\
\hline 1947 & & 22,639 & 294,053 & & 288,314 & & 282,574 & \\
\hline 1948 & & 23,535 & 317,589 & & 309,040 & & 300,492 & \\
\hline 1949 & & 24,431 & 342,020 & & 330,214 & & 318,409 & \\
\hline 1950 & 25,327 & 25,327 & 367,347 & 100 & 351,836 & 100 & 336,326 & 100 \\
\hline 1951 & 34,698 & & 402,045 & 109 & 382,382 & 109 & 362,719 & 108 \\
\hline 1952 & 32,165 & & 434,210 & 118 & 409,946 & 117 & 385,682 & 115 \\
\hline 1953 & 30,139 & & 464,349 & 126 & 435,036 & 124 & 405,724 & 121 \\
\hline 1954 & 29,886 & & 494,235 & 135 & 459,426 & 131 & 424,617 & 126 \\
\hline 1955 & 35,964 & & 530,199 & 144 & 489,445 & 139 & 448,691 & 133 \\
\hline 1956 & 41,030 & & 571,229 & 156 & 524,083 & 149 & 476,937 & 142 \\
\hline 1957 & 39,004 & & 610,233 & 166 & 556,246 & 158 & 502,260 & 149 \\
\hline 1958 & 58,252 & & 668,485 & 182 & 607,210 & 173 & 545,935 & 162 \\
\hline 1959 & 57,239 & & 725,724 & 198 & 656,713 & 187 & 587,702 & 175 \\
\hline 1960 & 53,947 & & 779,671 & 212 & 702,475 & 200 & 625,280 & 186 \\
\hline 1961 & 56,226 & & 835,897 & 228 & 750,069 & 213 & 664,242 & 197 \\
\hline 1962 & 74,715 & & 910,612 & 248 & 815,704 & 232 & 720,797 & 214 \\
\hline 1963 & 76,741 & & 987,353 & 269 & 882,917 & 251 & 778,482 & 231 \\
\hline 1964 & 74,968 & & $1,062,321$ & 289 & 947,909 & 269 & 833,498 & 248 \\
\hline 1965 & 90,164 & & $1,152,485$ & 314 & $1,027,650$ & 292 & 902,814 & 268 \\
\hline 1966 & 92,697 & & $1,245,182$ & 339 & $1,109,475$ & 315 & 973,768 & 290 \\
\hline 1967 & 92,444 & & $1,337,626$ & 364 & $1,190,599$ & 338 & $1,043,572$ & 310 \\
\hline 1968 & 100,801 & & $1,438,427$ & 392 & $1,279,632$ & 364 & $1,120,838$ & 333 \\
\hline 1969 & 94,470 & & $1,532,897$ & 417 & $1,361,887$ & 387 & $1,190,877$ & 354 \\
\hline 1970 & 87,632 & & $1,620,529$ & 441 & $1,436,855$ & 408 & $1,253,182$ & 373 \\
\hline 1971 & 87,378 & & $1,707,907$ & 465 & $1,506,884$ & 428 & $1,305,862$ & 388 \\
\hline 1972 & 99,789 & & $1,807,696$ & 492 & $1,590,591$ & 452 & $1,373,486$ & 408 \\
\hline 1973 & 101,055 & & $1,908,751$ & 520 & $1,676,576$ & 477 & $1,444,402$ & 429 \\
\hline 1974 & 93,710 & & $2,002,461$ & 545 & $1,755,343$ & 499 & $1,508,226$ & 448 \\
\hline 1975 & 115,745 & & $2,118,206$ & 577 & $1,853,106$ & 527 & $1,588,007$ & 472 \\
\hline 1976 & 121,317 & & $2,239,523$ & 610 & $1,953,908$ & 555 & $1,668,294$ & 496 \\
\hline 1977 & 157,535 & & $2,397,058$ & 653 & $2,091,941$ & 595 & $1,786,825$ & 531 \\
\hline 1978 & 133,220 & & $2,530,278$ & 689 & $2,196,035$ & 624 & $1,861,793$ & 554 \\
\hline 1979 & 157,787 & & $2,688,065$ & 732 & $2,325,203$ & 661 & $1,962,341$ & 583 \\
\hline 1980 & 160,321 & & $2,848,386$ & 775 & $2,458,550$ & 699 & $2,068,715$ & 615 \\
\hline 1981 & 164,626 & & $3,013,012$ & 820 & $2,595,063$ & 738 & $2,177,115$ & 647 \\
\hline 1982 & 154,495 & & $3,167,507$ & 862 & $2,712,201$ & 771 & $2,256,895$ & 671 \\
\hline 1983 & 155,508 & & $3,323,015$ & 905 & $2,829,338$ & 804 & $2,335,662$ & 694 \\
\hline 1984 & 157,028 & & $3,480,043$ & 947 & $2,948,882$ & 838 & $2,417,722$ & 719 \\
\hline \multirow{2}{*}{\multicolumn{2}{|c|}{$\begin{array}{l}\text { SUM 1920-84 } \\
\text { SUM 1950-84 }\end{array}$}} & & $56,684,590$ & & $50,121,819$ & & $43,559,049$ & \\
\hline & & & $53,402,955$ & & $46,871,121$ & & $40,339,287$ & \\
\hline
\end{tabular}


Appendix 15. Derivation of the total research capital in prices of 1984 .

\begin{tabular}{|c|c|c|c|c|c|c|c|c|}
\hline & \multirow{3}{*}{$\begin{array}{c}\text { Grants } \\
1950-84\end{array}$} & \multirow{3}{*}{$\begin{array}{l}\text { Derived } \\
\text { grants } \\
1920-50\end{array}$} & \multirow{2}{*}{\multicolumn{2}{|c|}{$\begin{array}{l}\text { Undepreciated } \\
\text { research capital }\end{array}$}} & \multicolumn{4}{|c|}{ Depreciated research capital } \\
\hline & & & & & \multicolumn{2}{|c|}{ dep.rate $=50 \%$} & \multicolumn{2}{|c|}{ dep.rate $=100 \%$} \\
\hline & & & FIM 1000 & Index & FIM 1000 & Index & FIM 1000 & Index \\
\hline 1920 & & 1,097 & 1,097 & & & & & \\
\hline 1921 & & 2,168 & 3,265 & & & & & \\
\hline 1922 & & 3,240 & 6,505 & & & & & \\
\hline 1923 & & 4,311 & 10,816 & & & & & \\
\hline 1924 & & 5,382 & 16,197 & & & & & \\
\hline 1925 & & 6,453 & 22,650 & & & & & \\
\hline 1926 & & 7,524 & 30,174 & & & & & \\
\hline 1927 & & 8,595 & 38,770 & & & & & \\
\hline 1928 & & 9,666 & 48,436 & & & & & \\
\hline 1929 & & 10,738 & 59,174 & & & & & \\
\hline 1930 & & 11,809 & 70,982 & & & & & \\
\hline 1931 & & 12,880 & 83,862 & & & & & \\
\hline 1932 & & 13,951 & 97,813 & & & & & \\
\hline 1933 & & 15,022 & 112,835 & & & & & \\
\hline 1934 & & 16,093 & 128,928 & & & & & \\
\hline 1935 & & 17,164 & 146,093 & & & & & \\
\hline 1936 & & 18,236 & 164,328 & & & & & \\
\hline 1937 & & 19,307 & 183,635 & & & & & \\
\hline 1938 & & 20,378 & 204,013 & & & & & \\
\hline 1939 & & 21,449 & 225,462 & & & & & \\
\hline 1945 & & 22,520 & 247,982 & & 247,434 & & 246,885 & \\
\hline 1946 & & 23,591 & 271,573 & & 269,941 & & 268,308 & \\
\hline 1947 & & 25,734 & 297,307 & & 294,054 & & 290,802 & \\
\hline 1948 & & 26,805 & 324,112 & & 318,704 & & 313,296 & \\
\hline 1949 & & 27,876 & 351,987 & & 343,889 & & 335,790 & \\
\hline 1950 & 28,947 & 28,947 & 380,934 & 100 & 369,609 & 100 & 358,284 & 100 \\
\hline 1951 & 38,500 & & 419,434 & 110 & 404,347 & 109 & 389,260 & 109 \\
\hline 1952 & 37,053 & & 456,487 & 120 & 437,103 & 118 & 417,718 & 117 \\
\hline 1953 & 35,605 & & 492,092 & 129 & 467,874 & 127 & 443,656 & 124 \\
\hline 1954 & 36,184 & & 528,276 & 139 & 498,690 & 135 & 469,103 & 131 \\
\hline 1955 & 41,974 & & 570,250 & 150 & 534,759 & 145 & 499,268 & 139 \\
\hline 1956 & 48,342 & & 618,592 & 162 & 576,661 & 156 & 534,730 & 149 \\
\hline 1957 & 47,474 & & 666,066 & 175 & 617,160 & 167 & 568,253 & 159 \\
\hline 1958 & 68,026 & & 734,092 & 193 & 677,675 & 183 & 621,257 & 173 \\
\hline 1959 & 67,447 & & 801,539 & 210 & 737,075 & 199 & 672,611 & 188 \\
\hline 1960 & 65,132 & & 866,671 & 228 & 793,625 & 215 & 720,579 & 201 \\
\hline 1961 & 68,316 & & 934,987 & 245 & 852,823 & 231 & 770,659 & 215 \\
\hline 1962 & 90,026 & & $1,025,013$ & 269 & 933,196 & 252 & 841,378 & 235 \\
\hline 1963 & 95,237 & & $1,120,250$ & 294 & $1,018,244$ & 275 & 916,238 & 256 \\
\hline 1964 & 93,500 & & $1,213,750$ & 319 & $1,101,019$ & 298 & 988,289 & 276 \\
\hline 1965 & 115,500 & & $1,329,250$ & 349 & $1,205,259$ & 326 & $1,081,268$ & 302 \\
\hline 1966 & 121,290 & & $1,450,540$ & 381 & $1,314,754$ & 356 & $1,178,967$ & 329 \\
\hline 1967 & 128,237 & & $1,578,777$ & 414 & $1,430,124$ & 387 & $1,281,471$ & 358 \\
\hline 1968 & 138,658 & & $1,717,435$ & 451 & $1,555,380$ & 421 & $1,393,324$ & 389 \\
\hline 1969 & 136,053 & & $1,853,488$ & 487 & $1,677,495$ & 454 & $1,501,501$ & 419 \\
\hline 1970 & 131,421 & & $1,984,909$ & 521 & $1,794,442$ & 485 & $1,603,975$ & 448 \\
\hline 1971 & 135,184 & & $2,120,093$ & 557 & $1,910,376$ & 517 & $1,700,659$ & 475 \\
\hline 1972 & 167,606 & & $2,287,699$ & 601 & $2,059,456$ & 557 & $1,831,212$ & 511 \\
\hline 1973 & 162,395 & & $2,450,094$ & 643 & $2,204,048$ & 596 & $1,958,002$ & 546 \\
\hline 1974 & 142,132 & & $2,592,226$ & 680 & $2,328,088$ & 630 & $2,063,950$ & 576 \\
\hline 1975 & 162,685 & & $2,754,911$ & 723 & $2,469,786$ & 668 & $2,184,661$ & 610 \\
\hline 1976 & 183,527 & & $2,938,438$ & 771 & $2,629,142$ & 711 & $2,319,846$ & 647 \\
\hline 1977 & 218,264 & & $3,156,702$ & 829 & $2,823,669$ & 764 & $2,490,636$ & 695 \\
\hline 1978 & 192,500 & & $3,349,202$ & 879 & $2,982,156$ & 807 & $2,615,110$ & 730 \\
\hline 1979 & 219,421 & & $3,568,623$ & 937 & $3,167,854$ & 857 & $2,767,084$ & 772 \\
\hline 1980 & 219,421 & & $3,788,044$ & 994 & $3,354,709$ & 908 & $2,921,373$ & 815 \\
\hline 1981 & 217,106 & & $4,005,150$ & 1051 & $3,537,657$ & 957 & $3,070,163$ & 857 \\
\hline 1982 & 218,264 & & $4,223,414$ & 1109 & $3,710,908$ & 1004 & $3,198,401$ & 893 \\
\hline 1983 & 234,764 & & $4,458,178$ & 1170 & $3,898,053$ & 1055 & $3,337,928$ & 932 \\
\hline 1984 & 230,132 & & $4,688,310$ & 1231 & $4,081,435$ & 1104 & $3,474,560$ & 970 \\
\hline \multirow{2}{*}{\multicolumn{2}{|c|}{$\begin{array}{l}\text { SUM 1920-84 } \\
\text { SUM 1950-84 }\end{array}$}} & & $70,271,929$ & & $63,283,710$ & & $56,295,492$ & \\
\hline & & & $67,123,932$ & & $60,154,653$ & & $53,185,374$ & \\
\hline
\end{tabular}


Appendix 16. Cobb-Douglas production functions with total research measured as an undepreciated stock.

\begin{tabular}{|c|c|c|c|c|}
\hline \multirow[t]{2}{*}{ Regression } & \multirow[t]{2}{*}{ (48) } & \multirow[b]{2}{*}{ s.l. } & \multirow[t]{2}{*}{ (49) } & \multirow[b]{2}{*}{ s.l. } \\
\hline & & & & \\
\hline Constant & $\begin{array}{c}1.023 \\
(1.136)\end{array}$ & 0.375 & $\begin{array}{c}1.237 \\
(1.095)\end{array}$ & 0.268 \\
\hline Capital & $\begin{array}{c}0.299 \\
(0.424)\end{array}$ & 0.486 & $\begin{array}{c}0.247 \\
(0.408)\end{array}$ & 0.550 \\
\hline Labour & $\begin{array}{c}0.207 \\
(0.072)\end{array}$ & 0.007 & $\begin{array}{c}0.143 \\
(0.077)\end{array}$ & 0.072 \\
\hline External inputs & $\begin{array}{r}-0.008 \\
(0.091)\end{array}$ & 0.930 & $\begin{array}{c}0.010 \\
(0.087)\end{array}$ & 0.052 \\
\hline Research stock & $\begin{array}{c}0.278 \\
(0.110)\end{array}$ & 0.017 & $\begin{array}{c}0.222 \\
(0.110)\end{array}$ & 0.052 \\
\hline Extension & & & $\begin{array}{c}0.109 \\
(0.057)\end{array}$ & 0.066 \\
\hline $\mathbf{R}^{2}$ & 0.985 & & 0.987 & \\
\hline Stand.error of estimate & 0.023 & & 0.022 & \\
\hline F-ratio & $505.25 * * *$ & & $440.57^{* * *}$ & \\
\hline D-W test value & 1.095 & & 1.164 & \\
\hline
\end{tabular}

Appendix 17. Cobb-Douglas production functions with total research measured as a stock with $50 \%$ depreciation after 20 years.

\begin{tabular}{lcccc}
\hline Regression & $(54)$ & & $(55)$ & s.l. \\
& & s.l. & 0.868 & 0.388 \\
Constant & 0.586 & 0.570 & $(0.991)$ & \\
& $(1.021)$ & & 0.362 & 0.341 \\
Capital & 0.433 & 0.273 & $(0.374)$ & \\
& $(0.387)$ & & 0.129 & 0.085 \\
Labour & 0.191 & 0.008 & $(0.072)$ & \\
& $(0.067)$ & & 0.013 & 0.879 \\
External inputs & -0.005 & 0.958 & $(0.088)$ & 0.061 \\
Research stock & $(0.091)$ & & 0.199 & $(0.102)$ \\
& 0.252 & 0.020 & 0.109 & 0.069 \\
Extension & $(0.102)$ & & $(0.058)$ & \\
& & & 0.987 & \\
$\mathrm{R}^{2}$ & & & 0.022 & \\
Stand.error of estimate & 0.985 & & $436.47^{* * *}$ & \\
F-ratio & 0.023 & & 1.141 & \\
D-W test value & $501.59^{* * *}$ & & & \\
\hline
\end{tabular}


Appendix 18. Cobb-Douglas production functions with total research measured as a stock with $100 \%$ depreciation after 20 years.

\begin{tabular}{lcccc}
\hline Regression & $(56)$ & s.l. & $(57)$ & s.l. \\
\hline Constant & & 0.896 & 0.474 & 0.600 \\
& $(0.908)$ & & $(0.894)$ & \\
Capital & 0.585 & 0.102 & 0.493 & 0.154 \\
& $(0.347)$ & & $(0.337)$ & \\
Labour & 0.170 & 0.009 & 0.110 & 0.108 \\
& $(0.060)$ & & $(0.066)$ & \\
External inputs & -0.001 & 0.990 & 0.017 & 0.848 \\
& $(0.091)$ & & $(0.088)$ & \\
Research stock & 0.219 & 0.022 & 0.169 & 0.074 \\
& $(0.091)$ & & $(0.091)$ & \\
Extension & & & 0.108 & 0.073 \\
& & & $(0.058)$ & \\
R & & & 0.987 & \\
Stand.error of estimate & 0.985 & 0.022 & \\
F-ratio & 0.023 & $431.49 * * *$ & \\
D-W test value & $497.80^{* * *}$ & & 1.117 & \\
\hline
\end{tabular}




\section{SELOSTUS}

\section{Maataloustutkimuksen tuotto Suomessa 1950-1984}

\section{John Sumelius}

\section{Maatalouden taloudellinen tutkimuslaitos}

Tämän tutkimuksen tarkoituksena on estimoida yhteiskunnan tuotto maataloustutkimuksesta vuosina 1950-1984. Arvioimalla maataloustutkimuksen yhteiskuntataloudellista korkoa voidaan luoda eräs mittapuu tutkimusvarojen allokoinnille. Tarkemmin mäăriteltynă estimoidaan maataloustutkimuksen rajakorko sekă sisăinen rajakorko ajanjaksolle 1950 - 1984. Maataloustutkimuksen tuottoa arvioitaessa on käytetty pääasiassa kahta paaämenetelmaaă: tuotantofunktioanalyysia ja hyvinvointiteoriaa. Menetelmien păăperiaatteet sekă aikaisemmat tutkimukset on selostettu toisessa luvussa. Tuotantofunktioanalyysiin perustuen tăssă tutkimuksessa spesifioidaan Cobb-Douglas ja lineaarisia malleja, joihin sisăllytetään tutkimusmuuttuja kolmen perinteisen ja yhden neuvontamuuttujan lisäksi. Tutkimusmuuttuja on määritelty kahdella eri tavalla; toisaalta julkisten tutki- mus- ja korkeakoulumäărärahojen rahavirran perusteella, toisaalta karttuvan tutkimuspảaman perusteella. Tutkimuspanos on samoin mäăritelty toisaalta pelkän julkisen tutkimuspanoksen ja korkeakouluopetuksen perusteella, toisaalta julkisen ja yksityisen sektorin tutkimuspanoksen perusteella. Tutkimusjoustoestimaattien avulla lasketaan rajakorko. Valtiontuki neuvontajärjestöille huomioidaan lopullisessa laskelmassa.

Tutkimuspääomaestimaatteihin nojautuen julkisen maataloustutkimuksen rajakoroksi on saatu $183-191 \%$. Tămă on tulkittava niin, ettă maataloustutkimuksen yhden markan lisăys kyseessă olevina vuosina olisi palautunut lăhes kaksinkertaisena vuotuisena reaalikorkona tuottajille ja kuluttajille. Tutkimusmäărärahojen rahavirran perusteella estimoitu sisäinen rajakorko on ollut $20-62 \%$ riippuen viiveen pituudesta (4-10 vuotta). 